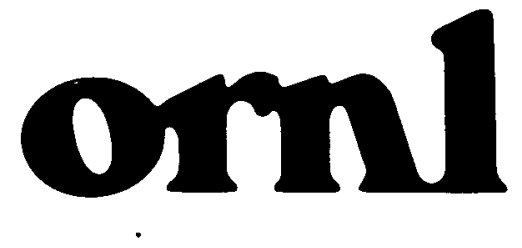

JUN 302000

OSTI

\section{OAK RIDGE NATIONAL LABORATORY}

\section{Fabrication of Control Rods for the High Flux Isotope Reactor}

J. D. Sease

MANAGED AND OPERATED BY LOCKHEED MARTN ENERGY RESEARCH CORPORATION FOA THE UNTED STATES

DEPARTMENT OF ENERGY

ORNL-27 (3-96) 


\section{DISCLAIMER}

This report was prepared as an account of work sponsored by an agency of the United States Government. Neither the United States Government nor any agency thereof, nor any of their employees, make any warranty, express or implied, or assumes any legal liability or responsibility for the accuracy, completeness, or usefuiness of any information, apparatus, product, or process disclosed, or represents that its use would not infringe privately owned rights. Reference herein to any specific commercial product, process, or service by trade name, trademark, manufacturer, or otherwise does not necessarily constitute or imply its endorsement, recommendation, or favoring by the United States Government or any agency thereof. The views and opinions of authors expressed herein do not necessarily state or reflect those of the United States Government or any agency thereof. 


\section{DISCLAIMER}

Portions of this document may be illegible in electronic image products. Images are produced from the best available original document. 
ORNL/TM-9365/R1

\title{
FABRICATION OF CONTROL RODS FOR THE \\ HIGH FLUX ISOTOPE REACTOR
}

\author{
J. D. Sease
}

March 1998

Prepared by the

OAK RIDGE NATIONAL LABORATORY

Oak Ridge, Tennessee 37831-6398 managed by

LOCKHEED MARTIN ENERGY RESEARCH CORP.

for the

U.S. DEPARTMENT OF ENERGY

under Contract No. DE-AC05-96OR22464 


\section{CONTENTS}

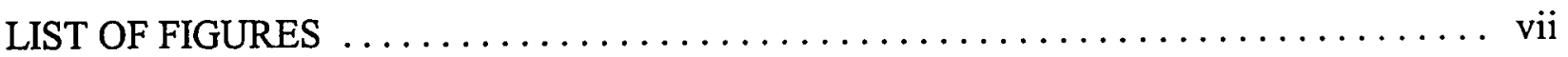

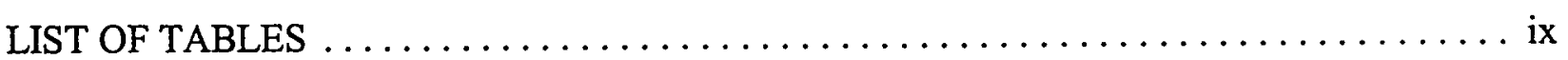

ACKNOWLEDGMENTS $\ldots \ldots \ldots \ldots \ldots \ldots \ldots \ldots \ldots \ldots \ldots \ldots \ldots \ldots \ldots \ldots \ldots \ldots$

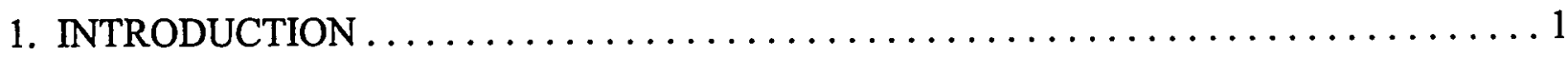

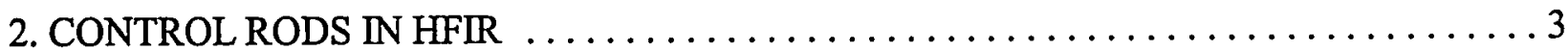

2.1 CONFIGURATION OF HFIR CONTROL RODS $\ldots \ldots \ldots \ldots \ldots \ldots \ldots \ldots 4$

2.2 PERFORMANCE OF HFIR CONTROL RODS $\ldots \ldots \ldots \ldots \ldots \ldots \ldots \ldots \ldots$

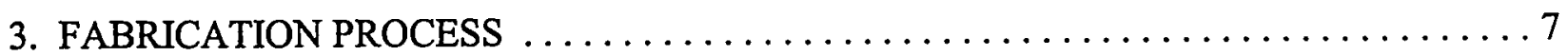

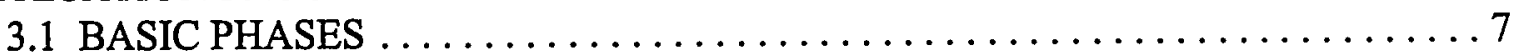

3.2 DEVELOPMENT OF FABRICATION PROCESS $\ldots \ldots \ldots \ldots \ldots \ldots \ldots \ldots 7$

3.3 PREPARATION OF FLAT PLATES $\ldots \ldots \ldots \ldots \ldots \ldots \ldots \ldots \ldots \ldots \ldots \ldots \ldots \ldots \ldots \ldots$

3.3.1 Neutron Absorber Loading Requirements $\ldots \ldots \ldots \ldots \ldots \ldots \ldots \ldots \ldots$

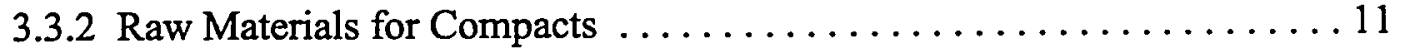

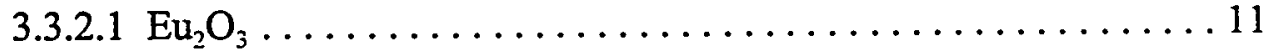

3.3.2.2 Tantalum ................................ 14

3.3.2.3 Aluminum powder $\ldots \ldots \ldots \ldots \ldots \ldots \ldots \ldots \ldots \ldots \ldots$

3.3.2.4 Prepare powder compacts .................... 17

3.4 BILLET COMPONENT PREPARATION AND ASSEMBLY $\ldots \ldots \ldots \ldots \ldots 25$

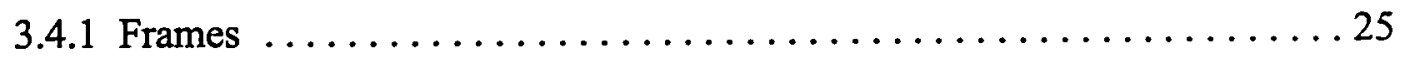

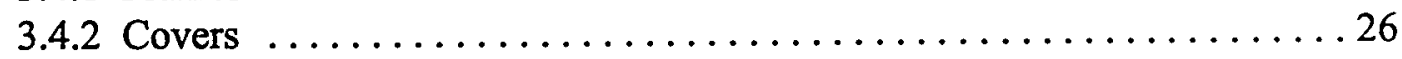

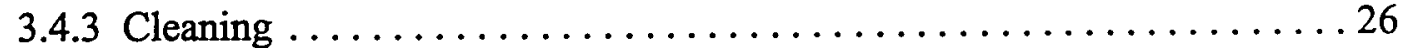

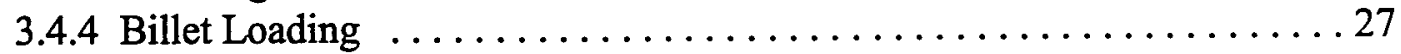

3.4.5 Billet Welding ................................... 27

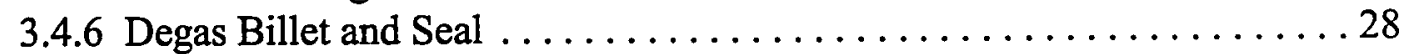

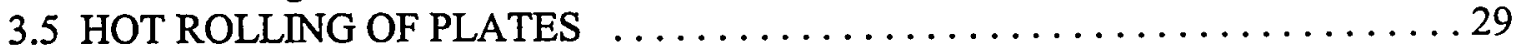

3.5.1 Description of Hot-Rolling Process . . . . . . . . . . . . . . . 29

3.5.1.1 Qualification of rolling mill ..................... 29

3.5.1.2 Furnace used for hot rolling $\ldots \ldots \ldots \ldots \ldots \ldots \ldots \ldots \ldots \ldots$

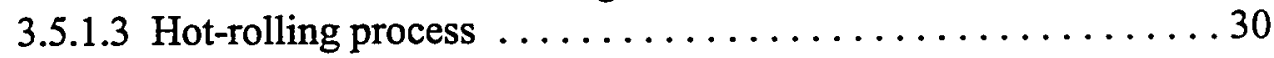

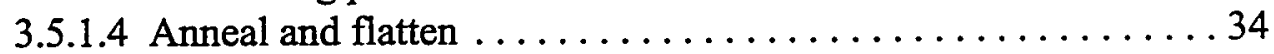

3.5.1.5 Shear to size .............................. 35

3.5.1.6 Weld repair of blisters . . . . . . . . . . . . . . . . 35

3.5.2 Nondestructive Inspection of Finished Rolled Plate ............ 35

3.5.2.1 Visual inspection ............................ 35

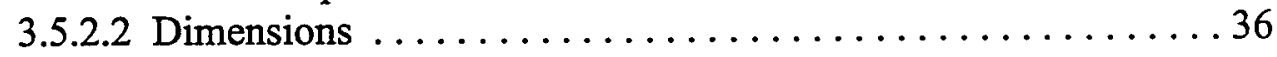

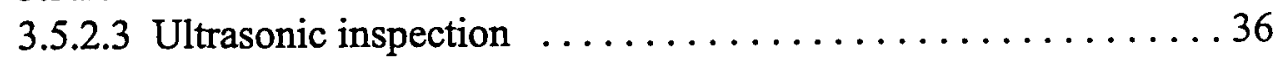


3.5.2.4 Radiography .............................. 36

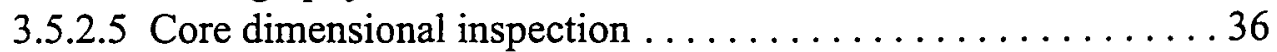

3.5.3 Destructive Evaluations . . . . . . . . . . . . . . . . . . . 38

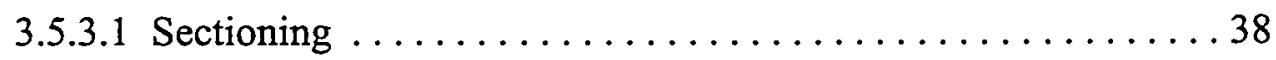

3.5.3.2 Clad thickness measurements ................... 38

3.5.3.3 Aluminum bonding at interfaces . . . . . . . . . . . . . 39

3.5.3.4 Tantalum/aluminum distribution $\ldots \ldots \ldots \ldots \ldots \ldots . \ldots . \ldots . \ldots 39$

3.5.3.5 Microstructural features $\ldots \ldots \ldots \ldots \ldots \ldots \ldots \ldots \ldots . \ldots \ldots$

3.6 FABRICATION OF CURVED PLATES $\ldots \ldots \ldots \ldots \ldots \ldots \ldots \ldots \ldots \ldots . \ldots \ldots$

3.6.1 Flatten and Anneal ................................ 41

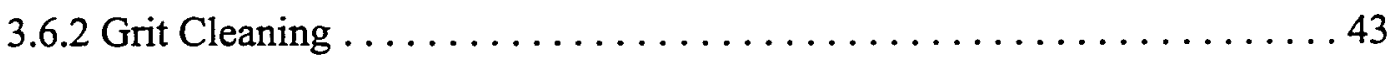

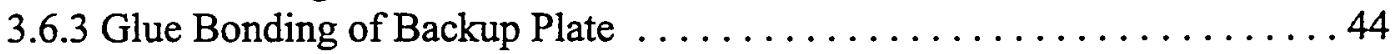

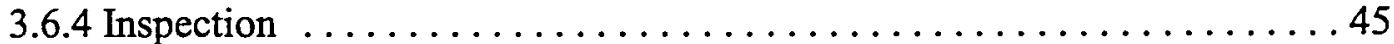

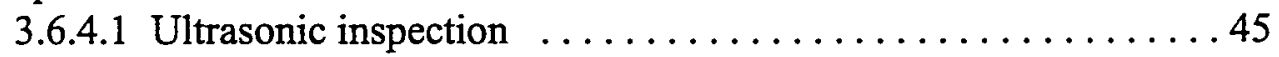

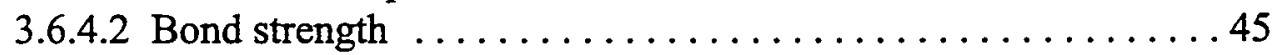

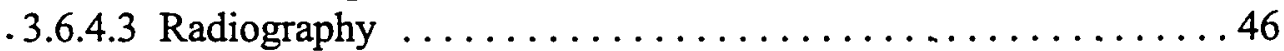

3.6.5 Drill Reference Holes . . . . . . . . . . . . . . . . . . . . . 46

3.6 .6 Lay Out Centerline . . . . . . . . . . . . . . . . . 47

3.6.7 Press-Brake Forming . . . . . . . . . . . . . . . . . 48

3.6 .8 Remove Backup Plate . . . . . . . . . . . . . . . 50

3.6 .9 Remove Epoxy and Clean . . . . . . . . . . . . . . . . . 51

3.6 .10 Stress Anneal . . . . . . . . . . . . . . . . . . . 52

3.6 .11 Positioning Holes . . . . . . . . . . . . . . . . . . . . . .

3.6 .12 Inspection . . . . . . . . . . . . . . . . 52

3.6.13 Prepare Explosive-Forming Die . . . . . . . . . . . . 53

3.6 .14 Package and Ship . . . . . . . . . . . . . . . . 53

3.6.15 Assemble Plate in Forming Die . . . . . . . . . . . . 54

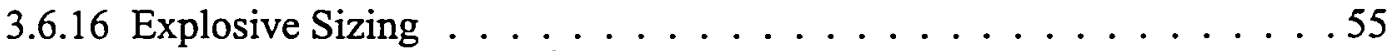

3.6 .17 Inspection . . . . . . . . . . . . . . . . 57

3.6 .17 .1 Visual inspection . . . . . . . . . . . . 57

3.6 .17 .2 Radiography . . . . . . . . . . . . . . 58

3.6.17.3 Contour inspection . . . . . . . . . . . . 58

3.6.17.4 Centerline Comparison . . . . . . . . . . . . . 59

3.7 FABRICATION OF OUTER CONTROL ROD $\ldots \ldots \ldots \ldots$. . . . . . 61

3.7.1 Lay Out Centerline and Machine Edges . . . . . . . . . . . 61

3.7 .2 Drill $1 / 4$-in. Holes . . . . . . . . . . . . . . . . . . 63

3.7 .3 Radiograph . . . . . . . . . . . . . . . . . . . . 64 64

3.7.4 Radius $1 / 4$-in. Holes . . . . . . . . . . . . . . . . . . . . 65

3.7.5 Dimensional Inspection of Plate . . . . . . . . . . . 65

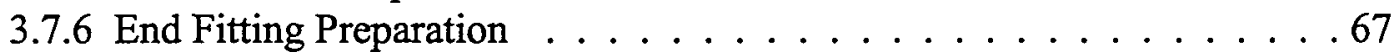

3.7 .7 Attachment of End Fittings $\ldots \ldots \ldots \ldots . \ldots \ldots 6$

3.7.8 Final Dimensional Inspection $\ldots \ldots \ldots 69$ 
3.7.9 Final Cleaning of Outer Control Plate . . . . . . . . . . 70

3.7 .10 Bearing Installation . . . . . . . . . . . . . . 70

3.8 FABRICATION OF INNER CONTROL ROD CYLINDER . . . . . . . . . . 72

3.8.1 Lay Out Centerline and Machine Edges . . . . . . . . . . 72

3.8 .2 Welding . . . . . . . . . . . . . . . 74

3.8 .3 Scrape and Planish Weld Surface . . . . . . . . . . . . 77

3.8.4 Inspection of Welded Half and Full Cylinder $\ldots \ldots \ldots \ldots . .78$

3.8 .5 Face Cylinder Ends . . . . . . . . . . . . . . . . . . . 79

3.8.6 Explosive Size . . . . . . . . . . . . . . . . . . 79

3.8.7 Inspection of Sized Cylinder and Machine Ends . . . . . . . . . 83

3.8.8 Drilling and Radiusing of Holes . . . . . . . . . . . . . 84

3.8.9 Final Machining of Cylinder . . . . . . . . . . . . . 84

3.8 .10 Final Inspection . . . . . . . . . . . . . 85

4. SUMMARY OF OBSERVATIONS AND RECOMMENDATIONS $\ldots \ldots \ldots \ldots$. . . 87

4.1 GENERAL . . . . . . . . . . . . . . . . . . 87

4.2 PREPARATION OF FLAT PLATES $\ldots \ldots \ldots \ldots$. . . . . . . . . . . . . . .

4.3 FORMING OF CURVED PLATES . . . . . . . . . . . . 91

4.4 FABRICATION OF OUTER PLATES . . . . . . . . . . . . 91

4.5 FABRICATION OF INNER CYLINDER . . . . . . . . . . . . . 93

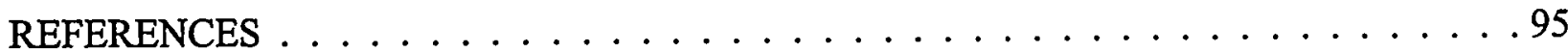

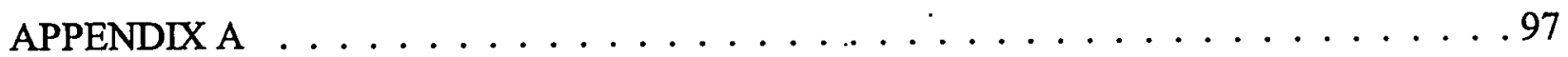




\section{LIST OF FIGURES}

Figure

1. Schematic of HFIR core and control rods basic arrangement . . . . . . . . 3

2. Schematic of HFIR control rods without attachment brackets . . . . . . . . . . 5

3. Example of failure of control rod plate in tantalum region . . . . . . . . . . . 6

4. Swelling on a plate at the black/gray interface . . . . . . . . . . . 6

5. Outline flowsheet for fabricating HFIR control plates . . . . . . . . . . . 8

6. Flowsheet for formation of flat plates . . . . . . . . . . . . . 10

7. Schematic of arc melting furnace used to consolidate europium powder into a highdensity form . . . . . . . . . . . . . . . . . 12

8. Description of components required for billet assembly . . . . . . . . 18

9. Schematic of billet components . . . . . . . . . . . . . . 25

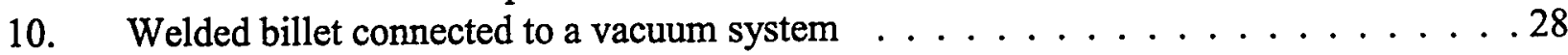

11. Sealed billet ready for hot rolling . . . . . . . . . . . . . . . 32

12. A plate near its final size being fed into the rolling mill . . . . . . . . . . 32

13. Outline of core section with dimensional requirements (in inches) for outer plates . . . 37

14. Typical microstructure of tantalum (top) and $\mathrm{Eu}_{2} \mathrm{O}_{3}$ (bottom) in the aluminum matrix. Magnification $\sim 50 \times \ldots \ldots \ldots \ldots . \ldots . \ldots . \ldots 40$

15. Microstructural features of the tantalum-to-aluminum interface (left) and the tantalum-to- $\mathrm{Eu}_{2} \mathrm{O}_{3}$ interface (right). Magnification $\sim 6 \times \ldots \ldots \ldots \ldots$

16. Flowsheet for formation of curved plates . . . . . . . . . . . . . .42

17. A movable-hearth electrical-resistance-heated furnace with monorail crane . . . . . 43

18. Fixture used to prepare samples for comparison testing and for performing quality control check on bond strength . . . . . . . . . . . . . . .44

19. Plate setup for drilling reference holes on a horizontal milling machine . . . . . .46

20. Layout of required machined-hole pattern . . . . . . . . . . . . . 47

21. Plate setup for marking centerline and for scribing inflection points for press-brake operation . . . . . . . . . . . . . . . . . 48

22. Punch and die arrangement used to form control plates . . . . . . . . . . . . 49

23. Control plate during preforming operation . . . . . . . . . . . . . . . . 49

24. Completed preformed control plate . . . . . . . . . . . . . . 50

25. Heating unit for removal of backup plate from control plate . . . . . . . . . . 51

26. Plate positioned on heating unit ................. . . . . . .

27. Fixture used to support preformed control plate for stress-relieve annealing step . . . . 52

28. Explosive-forming die with sealing fixtures . . . . . . . . . . . . . . 53

29. Die with Primacord explosive and detonators in place ready to fire . . . . . . . . . 56

30. Fixture for positioning curved control plate for radiography . . . . . . . . . . . 58

31. Inspection mandrel with master gauge attached . . . . . . . . . . . . . . . . 59

32. Clamping arrangement of outer plate for machining longitudinal edges . . . . . . 61

33. Clamping arrangement for cutting end clad on outer control plates . . . . . . . 63

34. Tool used for radiusing $1 / 4$-in.-diam holes on outer control plate . . . . . . . . 65 
35. Outer control plate setup for inspection on machine tool bed. The master gauge is shown on the left side . . . . . . . . . . . . . . . . .665

36. Outer control plate mounted for dimensional inspection on the Mauser CMM . . . . 66

37. Rough-cut bottom end flange for outer control plates . . . . . . . . . . . . . . 67

38. Finished machined top and bottom flanges before attachment to outer control plate . .67

39. Plate positioned on the mandrel for attachment of the end fitting . . . . . . . . 68

40. Fixture used for flaring the aluminum screws . . . . . . . . . . . . . . 69

41. Setup for final machining of bearing surfaces and holes . . . . . . . . . . 70

42. Flowsheet for fabrication of inner cylinder . . . . . . . . . . . . . . . 73

43. Machine setup for scribing weld shrinkage monitor on inner control plate . . . . . 74

44. Overall view of seam welder set up to weld plates in a half cylinder . . . . . . . 75

45. Top view of weld setup showing plates aligned in chill clamps for welding . . . . . 75

46. Cross section of a typical two-pass TIG weld in a HFIR inner control rod cylinder . . . 77

47. Scraping operation for inner and outer surfaces . . . . . . . . . . . . . 77

48. Special inspection fixture used for measuring arc length of a plate . . . . . . . 78

49. End view of inspection fixture showing the machined reference lands . . . . . . . 79

50. Inner cylinder forming die showing outside tapered surfaces and retaining rings . . . : 80

51. Closing of the assembled explosive-forming die by positioning the retaining rings . . . 80

52. Lifting fixture used to lift cylinders . . . . . . . . . . . . . . 81

53. Inner part of bottom-positioning fixture in front of assembled die . . . . . . . . 82

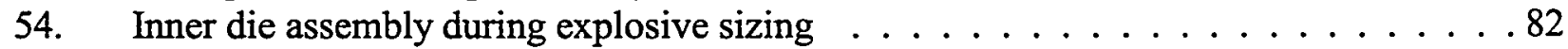

55. Closeup view of end bracket attached to an inner cylinder . . . . . . . . . . . 84

56. Setup for final machining of control cylinder . . . . . . . . . . . . . . 85

57. Position of inner control cylinder for final inspection . . . . . . . . . . . 85

58. Completed inner control cylinder . . . . . . . . . . . . . . . 86

59. Critical path for fabrication of HFIR control plates $\ldots \ldots \ldots \ldots \ldots$ 


\section{LIST OF TABLES}

Table

1. Calculations for preparing compacts for HFIR control rods . . . . . . . . . . 19

2. Dimensions and weights of typical absorber compacts . . . . . . . . . 23

3. Hot-rolling schedule and typical resulting plate dimensions . . . . . . . . . 33

4. Plate thickness and key core dimensions in plates made for O-93 campaign, in inches . . . . . . . . . . . . . . . . . . . . . 37

5. Edge clad margin measured on $0-93$ series outer control plates (side edges minimum is $0.125 \mathrm{in}$; top and bottom are 2 in. nominal) . . . . . . . . . . . . . 64 


\section{Acknowledgments}

Many people have been involved in the development of the HFIR control rod processes and past campaigns, and I would like to recognize their contributions to the technology in this report. Rodney Knight coordinated all prior control rod campaigns and was the principal author of the previous technical report on control rod fabrication. Rodney also served in an advisory role during the last campaign. The processes for fabricating HFIR control rods were developed in the early 1960s in the Metals and Ceramics Division (M\&C), and people such as Jesse Erwin, Mel Martin, Gene Hicks, Carl Leitten, and Joe Tackkett along with Rodney Knight developed the basic forming and fabrication processes. The Y-12 Plant forming, welding, and machining procedures and many special fixtures were developed by the $Y-12$ Development Division in the 1960s. Some of the people involved included A. A. Allston, W. T. Carey, W. C. Collins, Wimpy Helton, Ed Hutto, N. A. O'Neal, Jim Thompson, Bill Steinkamp, P. W. Turner, and Jim Turley. Dick Cheverton, the principal reactor designer, selected the control materials and played a role in selecting the fabrication processes.

Several people made major contributions in the successful completion of the last campaign. I would particularly like to recognize Ted Huxford, the M\&C Division project manager, for his contribution in the hot rolling of the plates. After assuming the leadership role late in the campaign, he spent many hours sorting out the fabrication details. Other contributors in M\&C included Paul Jones, Charlie Dunn, Ken Blakely, and Ed Hatfield. At the Y-12 Plant, the fabrication effort was led by Carl Linginfelter and Gale Helton. Jim Turley, who developed the explosive-forming process and has been the explosive-forming expert for all campaigns along with Charlie Hatcher, was most helpful in the explosive-forming effort at NTI.

I would especially like to thank Mike Aaron for his support in editing this report and Carolyn Campbell for preparing the manuscript. 


\section{INTRODUCTION}

The High Flux Isotope Reactor (HFIR) is a research-type nuclear reactor that was designed and built in the early 1960s and has been in continuous operation since its initial criticality in 1965 . Under current plans, the HFIR is expected to continue in operation until 2035.

The HFIR is a compact (51-L core) flux-trap type reactor that is light-water moderated and designed to operate at $100 \mathrm{MW}(\mathrm{t})$. The very high-power-density core uses two nested, cylindrical aluminum (Al) plate-type fuel elements and a beryllium $(\mathrm{Be})$ reflector that surrounds the core. The high-neutron-leakage core is controlled by a reflector control system that has two concentric cylindrical control rods, operated between the core and the beryllium reflector, which control the reflection of the thermal and the epithermal neutrons back into the core. A detailed description of the various elements of the HFIR control systems is contained in the report that describes the reactor for operational purposes.'

The two concentric cylindrical control rods, $\sim 20$ in. in diameter, contain europium (Eu) and tantalum (Ta) as the neutron-absorbing (poison) materials in aluminum plates. The outer rod, which serves as both a shim and scram rod, is segmented into four quadrant plates that operate independently for redundancy in scramming the reactor. Any one outer plate is capable of scramming the reactor. The control rods have a design lifetime in the reactor of $100,000 \mathrm{MWd}$ and are replaced after about 4 years of reactor operation.

The control rods are fabricated to stringent material and dimensional tolerances to meet the functional requirements of the HFIR. Both inner and outer rods are fabricated from plates that are formed by a hot-rolling process in almost an identical manner. The neutron-absorbing components are incorporated by a powder metallurgical technique in which pressed powder compacts containing the absorbers are placed into a billet prior to the hot-rolling operation. Quadrants of cylinders are formed by press-brake operation followed by an explosive-sizing operation. The cylinders are fabricated by welding four formed plates together and are sized by a second explosive-forming operation.

Fabrication of control rods has been performed periodically in campaigns to meet HFIR requirements. Since the beginning of HFIR operations, 13 inner and 17 outer control rods (sets of 4 quadrant plates) have been fabricated in five fabrication campaigns spaced about every 7 to 9 years. To date, a total of $\sim 150$ control plates have been fabricated, including dummies and spares. The development of the control rod fabrication process was done in the Metals and Ceramics (M\&C) Division at Oak Ridge National Laboratory (ORNL) in the early 1960s. Because of the unique equipment and fixturing requirements and the relatively small number of control rods required, fabrication of the control rods has been done in the M\&C Division and at the Oak Ridge Y-12 Plant. The fabrication campaigns for control rods is a lengthy process, typically taking from 2 to 3 years to be completed. 
The fabrication of outer rod sets 16 and 17 (4 quadrant plates in each set) was completed in the first quarter of 1998. Because of the length of time since the last campaign and changes in personnel resulting from retirements, the fabrication of these control rods required a considerable effort in relearning the processes. More stringent environmental regulations also required changes in the processes to eliminate the use of some hazardous chemicals. A stand-down at the Y-12 Plant, which began in the fall of 1994, delayed the fabrication process by about 1 year because of the unavailability of some $\mathrm{Y}-12$ Plant facilities used in past campaigns. The development of a number of work-around processes for the facilities not available was required, and an outside vendor was used for the explosive-sizing operation. The fabrication of outer rods 16 and 17 took about 4 years to complete because of the Y-12 Plant stand-down and process problems in the hot rolling of the plates.

This report updates ORNL/TM-9365, Fabrication Procedure for HFIR Control Plates, which was mainly prepared in the early 1970 s but was not issued until $1984,{ }^{2}$ and reflects process changes, lessons learned in the latest control rod fabrication campaign, and suggested process improvements to be considered in future campaigns. Most of the personnel involved with the initial development of the processes and in past campaigns have retired or will retire soon. Because of their unlikely availability in future campaigns, emphasis has been placed on providing some explanation of why the processes were selected and some discussions about the importance of controlling critical process parameters. Contained in this report is a description of the function of the control rods in the reactor, the brief history of the development of control rod fabrication processes, and a description of procedures used in the fabrication of control rods. A listing of the controlled documents and procedures used in the last fabrication campaigns is referenced in Appendix A. 


\section{CONTROL RODS IN HFIR}

A schematic of the basic arrangement of the HFIR core and the control rods is shown in Fig. 1. The control rods slide vertically in a 0.9 -in.-thick annulus region between the outer fuel element and the beryllium reflector. The control rods consist of two $1 / 4$-in.-thick concentric cylinders separated by a nominal 0.129 -in.-wide coolant channel. Coolant channels are provided between the inner control rod and the outer fuel element $(0.101 \mathrm{in}$.) and between the outer control rod and the beryllium reflector $(0.136 \mathrm{in}$.). The coolant flow through the channels is $\sim 16 \mathrm{ft} / \mathrm{s}$ during operation.

ORMR-LR-DWG-6S776

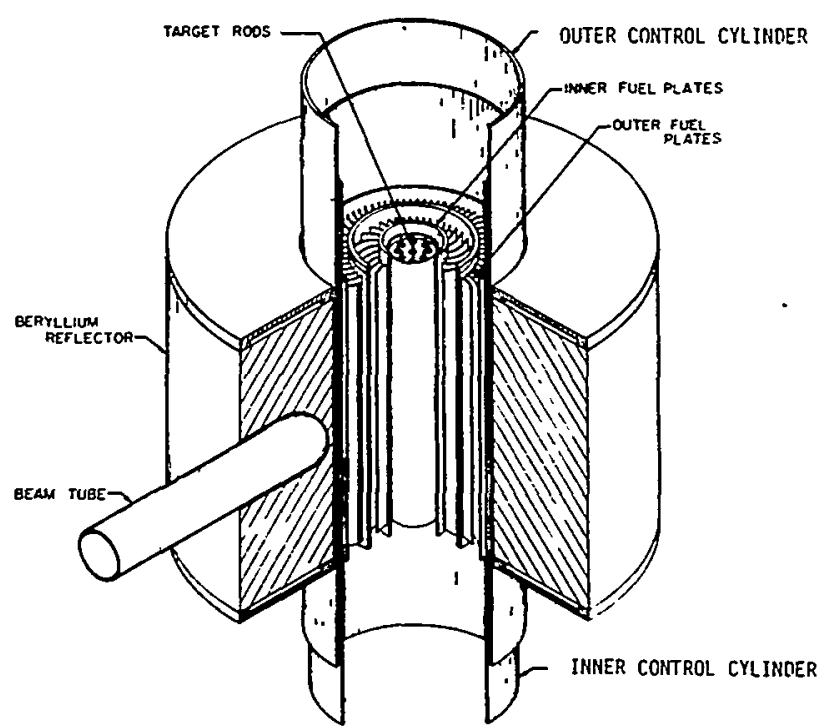

Fig. 1. Schematic of HFIR core and control rods basic arrangement.

A reflector control system is used to control the power level, for shutdown, and for scramming the reactor in the high-leakage-type core used in the HFIR. The movement of the control rods adjusts the efficiency of the beryllium reflector. Each control rod has three sections that absorb neutrons differently. The highest absorption section is termed the black section; the intermediate section is the gray section; and the section with the least absorption is the white section. In the shutdown mode, the black sections of the control rods are positioned between the core and the beryllium reflector. Criticality and the control of the power level during normal operation are achieved by removing the control rods vertically from the reactor core area. The inner rod is 
moved downward while the outer rod is moved upward out of the core area until criticality and the desired power level are achieved. To accommodate fuel burnup and loss of reactivity, the control rods are gradually withdrawn to maintain a symmetrical power density in the axial direction. The inner cylinder is driven by a servo mechanism to maintain a constant power level. At the end of core life, the black and gray sections in the control rods are completely withdrawn

from the core area. The outer control rod, which is divided into four independent quadrants, also serves as the safety scram rod for off-normal conditions. The outer rod quadrants each have separate shim drive and scram mechanisms. Any one outer plate is capable of scramming the reactor.

Reducing the power peaking in the fuel was a primary consideration in the design of the HFIR control system, and initially some consideration was given to a neutron absorber or poison added to the coolant. The solid control rods were designed with the black, gray, and white sections to minimize power peaking in the fuel. In the design of the HFIR control system, several neutron absorbers were considered for the black sections. Hafnium was not available when the reactor was designed, and thus, was not considered. Boron and cadmium were also considered but rejected for various performance reasons. The initial neutron absorbers chosen were silver and nickel, but these were later rejected because of difficulties fabricating silver into aluminum plates. Europium was chosen as the primary neutron absorber because europium and its activation products have high cross sections. Tantalum, which is used in the gray region, has an intermediate cross section and is compatible with aluminum. A section of the aluminum plate is the white section.

\subsection{CONFIGURATION OF HFIR CONTROL RODS}

The details of the HFIR control rods without the attachment brackets are shown schematically in Fig. 2. The 1/4-in.-thick inner cylinder is $683 / 8 \mathrm{in}$. long with a nominal outer diameter of 17.842 in. The 1/4-in.-thick outer quadrant plates, which are formed to a nominal 18.600-in. diameter, are $663 / 16$ in. long with an arc length of $139 / 16$ in. The structural material and the clad for the neutron absorbers in both the inner and outer control rods is the 6061 alloy of aluminum.

The black section, which is nominally 22 in. long, contains $\sim 33$ vol \% europium oxide as particles $(<0.008$ in. in diameter) dispersed in an aluminum matrix and with a $1 / 32$-in.-thick cladding. The gray section, which is nominally $5 \mathrm{in}$. long, is composed of $40 \mathrm{vol} \%$ tantalum metal particles ( $<0.008$ in. in diameter) dispersed in an aluminum matrix and with a 1/32-in.thick cladding. Numerous 1/4-in.-diam holes are drilled through the gray and white sections of the control rods to balance the hydraulic forces that result from the flow of the cooling water over the surfaces of the control rods during operation in the reactor. No holes are drilled in the black section because europium oxide reacts readily with water and hydrogen. Maintaining the integrity of the cladding surrounding the black section is a major consideration in fabrication and operation of the control rods. Holes also are drilled though the inner cylinder and outer plates to attached brackets. 
In the reactor, the tracking guidance for the inner control cylinder is provided by eight bearings that extend through the gaps between the outer control plate quadrants and ride on the cylinder. The bearing contact on the cylinder is in the welded spaces between plates; these bearings do not ride on the areas that contain absorbing materials. A welded bracket assembly attached to the bottom end of the cylinder by 1/4-in.-diam screws is used to connect the inner control cylinder to the reactor inner control rod drive mechanism. The quadrant plates are positioned radially and circumferentially in the reactor by four journal bearings mounted on lugs at the corners of each plate that ride in tracks contained in the reactor support structure. Bracket assemblies for the bearing lugs and reactor drive coupling seat are attached to the outer control plates by 1/4-in.-diam screws.

\subsection{PERFORMANCE OF HFIR CONTROL RODS}

Bearing problems and the cracking in the bearing brackets on the first five sets of outer control rods have been the only problems affecting the mechanical performance of the control rods in the HFIR. Because of the way the outer plates are supported, a cyclic-type loading is placed on the bearings and brackets from the coolant water flow. The bearing brackets were redesigned in the mid1960 s to increase the thickness of the bearing support and have performed satisfactorily since the initial five sets were made. ${ }^{3}$ The bearing problems persisted through the 1960 s and were partially solved in the early 1970 s by changing from ball bearings to journal bearings made from Hastalloy C. Under the current operating schemes, bearings on the outer plates must be replaced after seven cycles. Replacement of the bearings is a difficult task that must be performed remotely at a depth of $\sim 20 \mathrm{ft}$ in the 
reactor pool. The plates also need to cool from 6 to 12 months after operating in the reactor to allow the activation products in the control plates to decay before the bearings are changed. Two sets of outer control plates are used in tandem; this arrangement allows for bearing replacement on one set while the other set is operating in the reactor. In addition, bearing wear from the abrasion of activated cobalt- 60 from the Hastalloy used in the bearings contributes significantly to the radiation content of the radioactive waste generated during operation of the HFIR. Efforts to improve bearing performance are ongoing within ORNL's Research Reactors Division.(RRD).

The performance of the control rods in HFIR has been generally good. Through reactor cycle 339 , the accumulated exposure in the inner rods before being taken out of service averaged about $74,000 \mathrm{MWd}$, with one rod being taken out of service at 12,000 MWd. The blisters that required the inner rods to be taken out of service were over the tantalum sections in all cases. An example of this type of failure is shown in Fig. 3. The accumulated exposure on the outer plates before being taken out of service averaged $\sim 63,000 \mathrm{MWd}$, with one plate removed at $3800 \mathrm{MWd}$. The lower accumulated exposure on the outer plates is mainly a result of the bracket design problem on the first five sets of rods and the handling problems involved with changing bearings.

Outer rod sets 13,14 , and 15 were scrapped just prior to their use in the reactor when swelling was noticed on several plates at the black/gray interface (Fig. 4). This swelling problem subsequently was traced to the use of improperly specified tantalum powder in the fabrication of these rods. ${ }^{4}$ The tantalum powder specification used inadvertently allowed a vendor to supply an agglomerated direct sodium-reduced powder having very poor mechanical fracture strength rather than the stronger arc-melted powder that had been used in the fabrication of previous control plates. Normally the tantalum in the core section is present as discrete particles surrounded by an aluminum matrix similar to the way the fuel particles are microencapsulated in HFIR fuel elements. In the plates that were scrapped, the low-strength tantalum powder particles fractured during the hot-rolling step and, because of the high volume loading of the tantalum in the plates, became a continuous phase in the matrix. This allowed hydrogen to diffuse through the tantalum and reach the europium oxide particles located along the interface with the tantalum powder. The europium oxide particles along the interface reacted with hydrogen and expanded, which caused the swelling noted in the plates.
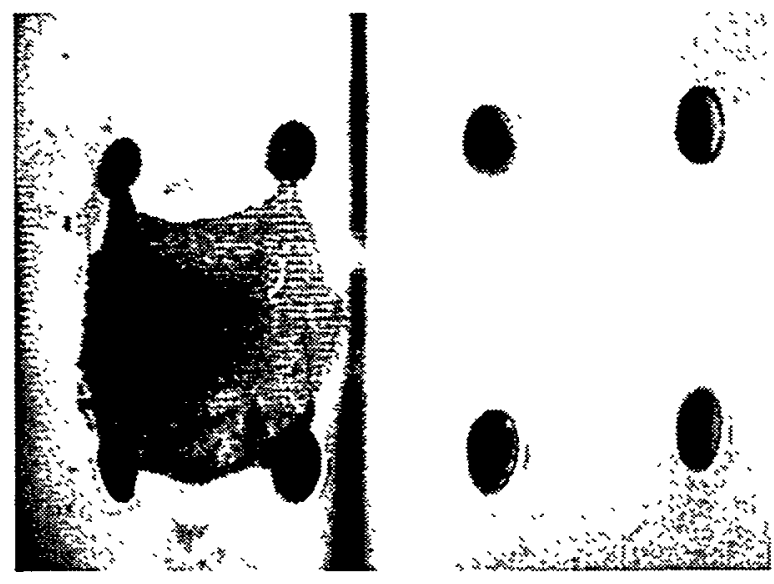

Fig. 3. Example of failure of control rod plate in tantalum region.

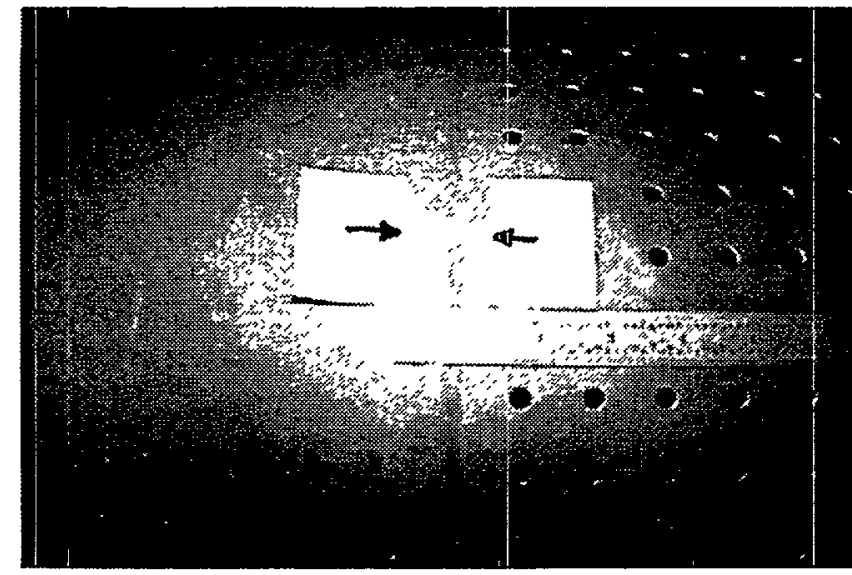

Fig. 4. Swelling on a plate at the black/gray interface. 


\section{FABRICATION PROCESS}

\subsection{BASIC PHASES}

The process used to fabricate HFIR control rods is outlined in Fig. 5. As indicated, the process can be separated into four phases: preparation of flat plates, formation of curved plates, fabrication of the outer control plates, and fabrication of the inner cylinder. In the preparation of the flat plates, the process begins with blended powders of the absorber materials and aluminum; this mixture is pressed into rectangular compacts. The powder metallurgy compacts are then placed in a 6061 aluminum frame, and covers are added and welded to the frame to form a billet for hot rolling. The evacuated billet is then hot rolled at $500^{\circ} \mathrm{C}$ through an $8: 1$ reduction ratio to form a flat plate approximately 74 in. long $\times 19$ in. wide $\times 1 / 4$ in. thick. Because of the small edge margins allowed around the core section, the longitudinal centerline of the core section is very carefully determined for forming using radiography. In the formation of curved plates, the flat plate is glued to a backup plate and the press brake operation is used to form a quadrant of a cylinder. The quadrants are then sized by explosive forming. For the outer plates, this is the last metal-forming step. For the inner control rod cylinders, the quadrant plates are welded first into a half cylinder shape and two half cylinders are welded to form the final cylindrical shape. The cylinder is then explosive sized a second time to obtain its final dimensions.

The layout and machining of the quadrant plates and cylinder are primarily done on a large numerically controlled vertical milling machine using specially designed fixtures. The longitudinal centerline of the core section is checked and verified again before beginning the final machining operations. The end fitting for the inner cylinder is a machined stainless steel weldment, and the brackets for the outer plates are machined from aluminum plate stock. The end fittings are attached to the plates and cylinders using special 1/4-in.-diam recessed-head aluminum screws.

\subsection{DEVELOPMENT OF FABRICATION PROCESS}

The fabrication process for HFIR control rods was developed in the early 1960 s by ORNL's M\&C Division and by the Y-12 Plant. Because of the relatively small number of control plates required and the expense of further process and tooling development, the process has remained essentially unchanged. The process of fabricating the flat plates was based largely on the powder metallurgy-hot-rolled bonding processes developed for making plate-type research reactor fuel.

Forming the cylindrical shapes with the relatively brittle neutron-absorbing core sections to the very tight dimensional tolerances required a significant development effort. Initial attempts to form the quadrant plates were not successful because the cores in the plates fractured from tensional stresses introduced in the cores on the convex side during the press brake forming operation. The core cracking problem was solved by attaching a 3/8-in.-thick backup plate using an adhesive to the flat control plate to maintain the core in compression during the press brake forming. The backup plate effectively shifted the neutral axis into the backup plate during forming and allowed the core to remain in compression. 
PREPARATION OF FLAT PLATES

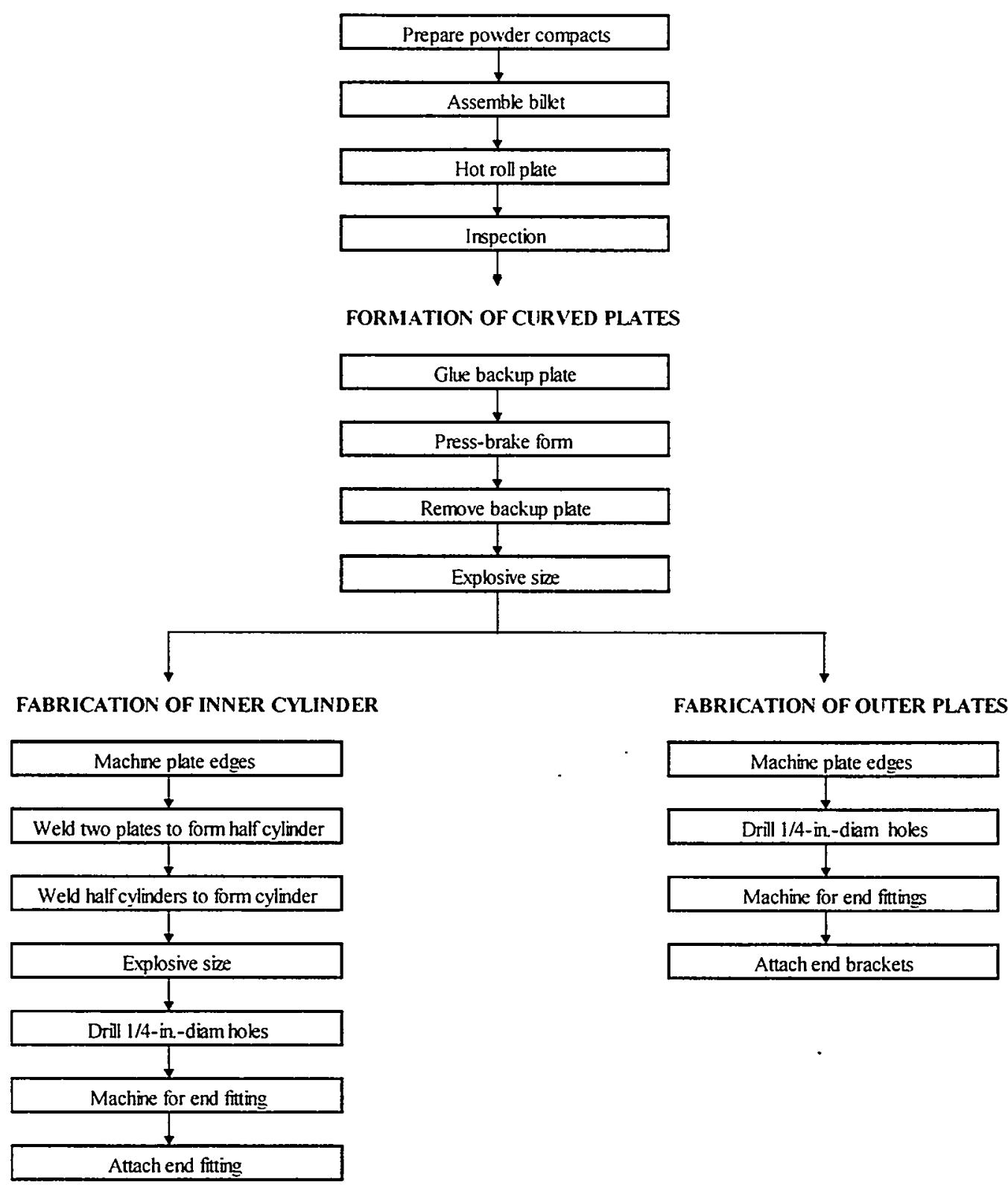

Fig. 5. Outline flowsheet for fabricating HFIR control plates. 
Press-brake forming alone could not consistently meet the dimensional tolerance requirements for the HFIR control plates. Explosive forming, which was being used in the early 1960s for forming unique aluminum aircraft components, was proposed for the final sizing of the quadrants and cylindrical inner control rod. The Y-12 Plant had an explosive-forming facility in operation and developed the explosive-sizing tooling and specified the explosives required. Explosive sizing provided very favorable results in obtaining the desired dimensional tolerances essentially in the first trials.

The welding processes for welding the inner cylinder were developed by ORNL and the Y-12 Plant in the early 1960s. An excellent article on this development by W. C. Collins, D. G. Scott, J. W. Tackett, and P. W. Turner, "Welding of the Control Plates of the High Flux Reactor," is presented in Welding Journal, October 1967, pp. 833-941.

In the fabrication of outer sets 16 and 17 , some process development was required to better define some of the details, primarily in the hot-rolling process, and to work around the Y-12 Plant facilities that were unavailable because of the stand-down. The billet design for hot rolling was modified to provide for a slightly more narrow core section. In the hot rolling of plates for. sets 16 and 17 , considerable difficulties were encountered with excessive curvature in some billets during the initial rolling passes and with maintaining the core dimensions within the specified tolerances because of the introduction of skewness in the cores in later passes through the rolling mill. Some of the problems in the rolling process were traced to the initial setup of the rolling mill and limitations of the old rolling mill manufactured in 1908. More detailed rolling mill procedures were developed to safeguard against mill setup problems and to account for some of the limitations of the outdated rolling mill. The work-around procedures developed at the Y-12 Plant included use of a flattening annealing process employing a different furnace, use of a grit cleaning process that replaced the old acid cleaning process, use of an outside vendor for the explosive forming operation, and use of a lower power X-ray source for the radiography operations. In addition, improvements in the process control of the gluing step and the fabrication of the outer control plate upper and lower brackets by a single-piece construction were implemented.

\subsection{PREPARATION OF FLAT PLATES}

A detailed flowsheet of the processes for preparation of flat plates is presented in Fig. 6. This entire operation has always been done in the M\&C Division, using laboratory facilities in Building 4508, and in the Building 3718 rolling mill. Detailed operating procedures for the M\&C operation were extensively revised after completion of the flat plates for sets 16 and 17 in February 1995. A list of these procedures along with the materials specifications used is given in Appendix A. 


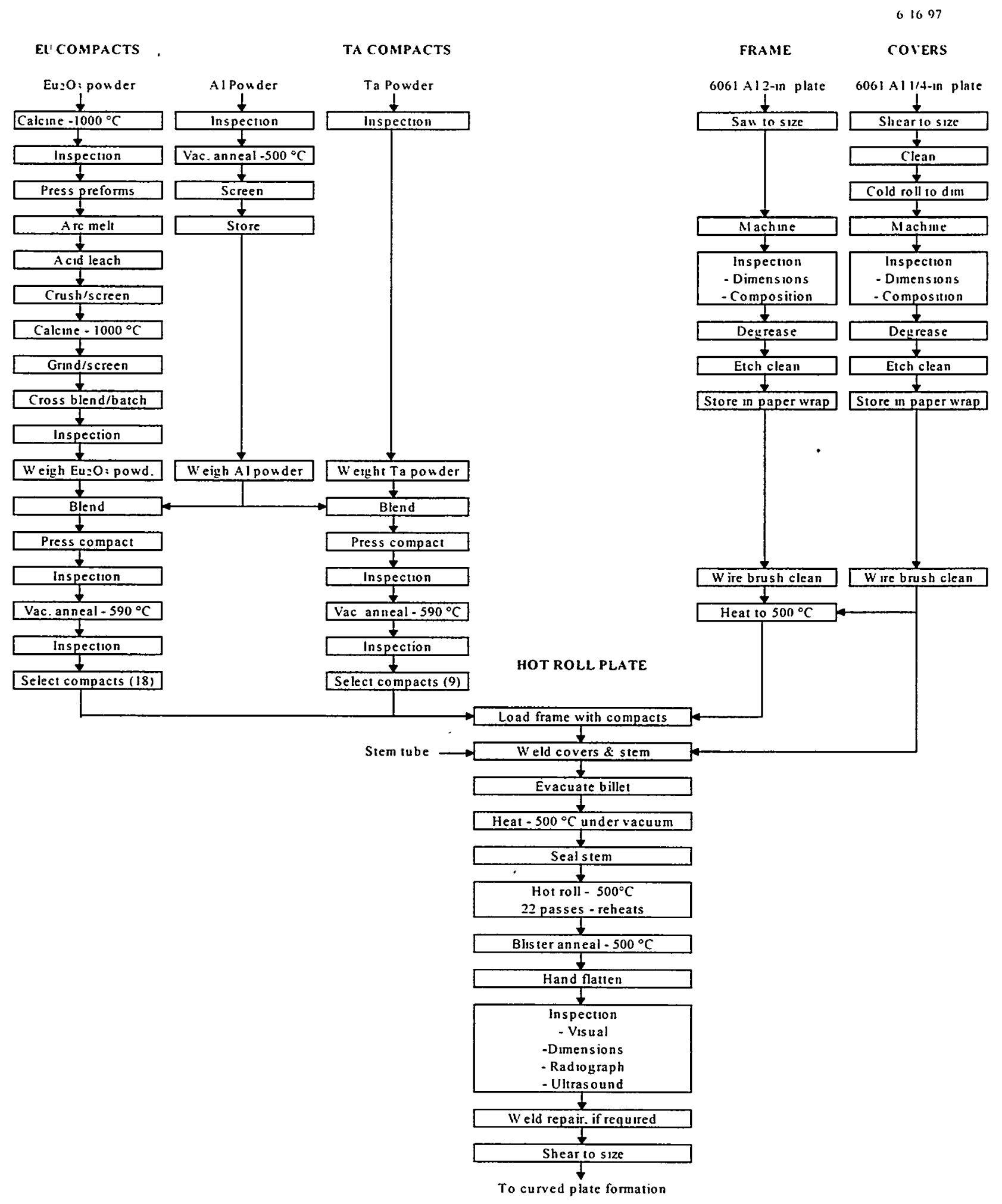

Fig. 6. Flowsheet for formation of flat plates. 


\subsubsection{Neutron Absorber Loading Requirements}

The loading for the neutron absorbers in the core sections in flat plates for both the inner cylinder and the outer plates is $33 \mathrm{vol} \% \mathrm{Eu}_{2} \mathrm{O}_{3}$ and $40 \mathrm{vol} \%$ tantalum, as defined in the functional description of HFIR.' The calculated quantities of absorbing materials in grams derived from this requirement are as follows:

\begin{tabular}{ccc}
\hline Type flat plate & $\begin{array}{c}\mathrm{Eu}_{2} \mathrm{O}_{3} \\
(\mathrm{~g})\end{array}$ & $\begin{array}{c}\text { Tantalum } \\
(\mathrm{g})\end{array}$ \\
\hline Inner & 1922 & 1297 \\
Outer & 1912 & 1292 \\
\hline
\end{tabular}

The quantities of absorbing materials in the powder compacts are derived from these values.

\subsubsection{Raw Materials for Compacts}

The raw materials for the compacts are specified in RRD-MS-101, tantalum powder; RRD-MS102 , aluminum powder; and RRD-MS-103, europium powder. The general requirements of the specifications and a description of the preparation of powders for use in the control plates are provided in the following subsections.

\subsubsection{1 $\mathrm{Eu}_{2} \mathrm{O}_{3}$}

The $\mathrm{Eu}_{2} \mathrm{O}_{3}$ is commercially available as an electronic-grade oxide powder of $99.99 \%$ purity and having an ultrafine powder size on the order of 1 to 7 microns in diameter. As received, this fine particle material is unsuitable for inclusion in a roll-bonded plate because, after processing, it would be present as an undesirable continuous phase rather than as discrete particles surrounded by the aluminum matrix. The as-received oxide is consolidated by arc melting followed by crushing and grinding to obtain the particle size distribution of $<100$ microns in diameter.

The specification for ordering $\mathrm{Eu}_{2} \mathrm{O}_{3}$ is tailored around a commercial product (grade 5000) manufactured by Molycorp, Inc. The principal attribute specified is the purity content at $99.99 \%$ europium oxide. Because of a concern for the generation of long-life radionuclides during operation in the reactor, the thorium content is limited to $<5$ alpha counts per milligram above background or $<10 \mathrm{ppm}$, as determined spectrographically. Trace element analysis for other cations and a Fisher subsieve particle-size analysis, which are normally determined by the vendor, are specified. The Fisher value specified is 1 to 4 microns but is of little practical value for further processing other than providing a comparative value between lots of materials ordered. A gross screen size of less than U.S. Standard 100 mesh is specified to ensure against the presence of large agglomerates in the material. The loss on ignition is specified at $<1 \%$ at $1000^{\circ} \mathrm{C}$ to ensure that the ordered quantity of europium has been shipped. The commercial oxide is normally a shelf-stock item of the vendor, packaged in 25 -lb quantities in 5-gal plastic pail containers. 
The processing of the $\mathrm{Eu}_{2} \mathrm{O}_{3}$ to produce a powder suitable for incorporation into control plates involves a number of steps shown in Fig. 6. Because of the water-reactive nature of europium oxide, the material is stored under argon between processing steps. A brief description of each of these steps follows.

Calcine at $1000^{\circ} \mathrm{C}$ - In preparing the as-received europium oxide for arc melting and characterization, the powder is removed from the receiving container, placed in high-alumina ceramic crucibles, and calcined in air at $1000^{\circ} \mathrm{C}$ for $3 \mathrm{~h}$. This step removes absorbed moisture from the ultrafine europium oxide powder because some materials may have been stored for a considerable length of time before use. The presence of even small quantities of water will create an unstable arc during the melting step. The calcine material is placed in 1- to 2-L plastic or glass bottles and stored under argon until ready for pressing into preforms.

Inspection-A composite sample representative of the calcination runs of the as-received powder is taken and submitted for trace-element analysis of anionic impurities and for verification that the major constituent is europium. The thorium content is determined either by alpha counting or from the analytical analysis.

Press preforms - To make a product suitable for arc melting, the very low-density europium oxide powder $\left(0.5-0.7 \mathrm{~g} / \mathrm{cm}^{3}\right.$ pore density) must be pressed in powder compacts. This is accomplished by volumetrically loading $\sim 100 \mathrm{~g}$ of the powder into a 3-in.diam double-action steel die and pressing at $\sim 2500-3000$ psi to form a compact $\sim 1$ in. high having a green density of $\sim 1.5 \mathrm{~g} / \mathrm{cm}^{3}$. The pressing pressure is established as the maximum pressure that can be applied to the powder without causing significant delaminations in the compacts. No organic binder is used, and stearic acid in a solvent is used sparingly as the die lubricant. After several kilograms of powder is pressed, the green compacts are placed in plastic trays and stored in argon until they are ready for arc melting.

Arc melting-An electric arc fusion process is used to consolidate the ultrafine europium powder into a high-density form. The small arc melting furnace used is shown in Fig. 7.

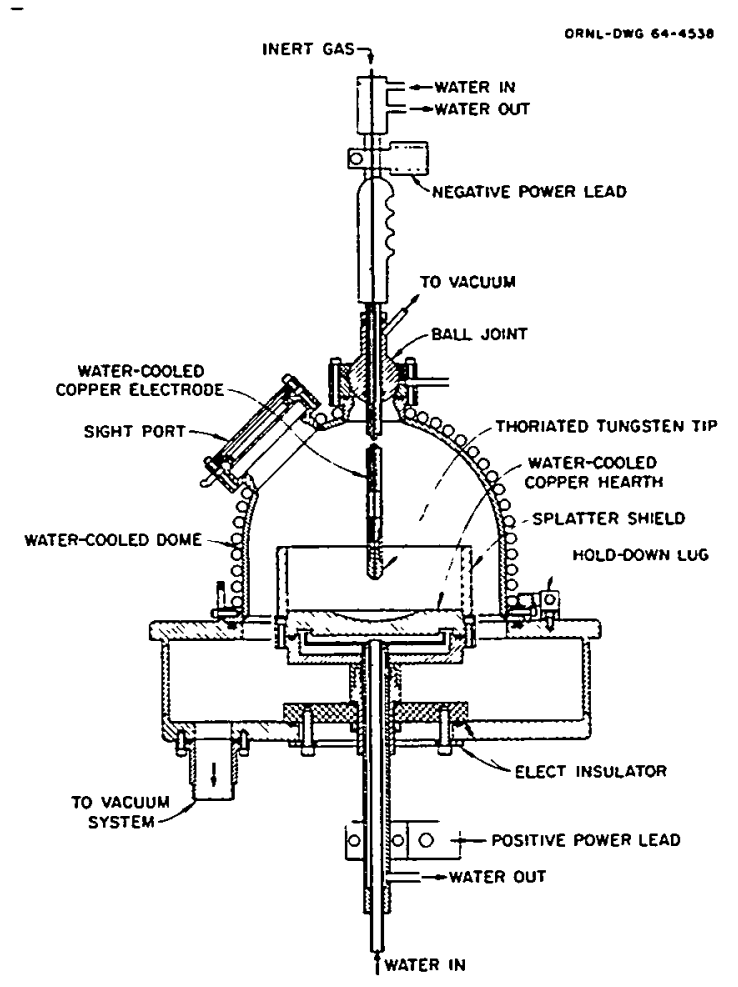

Fig. 7. Schematic of arc melting furnace used to consolidate europium powder into a highdensity form. 
The furnace consists of a water-cooled copper hearth and a hollow, thoriated tungsten electrode tip. The hearth contains a deep hemispherical cavity to help contain the arc splatter during melting. A single preform compact is placed on the hearth for melting. During operation, the chamber is pressurized to 5 psi using argon, and a mixture of equal parts of argon and helium is introduced through the melting electrode to reduce arc instability. In melting a compact after the arc has been struck, the power is increased (from $300 \mathrm{~A}$ at $30 \mathrm{~V}$ to 600 to $800 \mathrm{~A}$ at $40 \mathrm{~V}$ ) and the entire preform pellet is fused. The resulting button is $\sim 3$ in. in diameter and is essentially $100 \%$ dense. If a button is found not to be completely fused, the button is turned over and completely re-fused. The arc melting operation requires $\sim 5 \mathrm{~min}$ to process a single preform compact, and several kilograms of europium can be processed in a single shift.

Acid leach-After arc melting, the buttons normally have a reddish-brown hue caused by the deposition of copper from the copper hearth during the arc melting process. This copper coating is removed by acid leaching the buttons in a $30-35 \%$ nitric acid solution until the reddish hue disappears or up to a maximum of 1 hour. The europium oxide buttons will also dissolve in the acid bath, and care must be exercised to remove the buttons as soon as the hue disappears. The maximum specified time should not be exceeded. After leaching, the buttons are rinsed in warm water and dried with warm air.

Crush/screen-The dense vitreous-appearing arc-melted buttons next are broken into small chunks with a hammer and passed through a small-jaw crusher to produce a coarse granular product that will pass through a screen with 1/4-in. openings. At this stage in the process, tramp materials such as pieces of the copper hearth and the tungsten electrode may be encountered. The europium oxide particles are carefully examined during this crushing and screening operation, and any tramp materials present are carefully removed by hand.

Calcine at $1000^{\circ} \mathrm{C}$ - The second calcination operation is to adjust the oxygen content of the europium oxide to stoichiometric. Because the arc melting of the europium oxide powder is performed in an inert atmosphere, the resulting fused europium oxide is oxygen deficient or substoichiometric. This oxygen deficiency is evident from the darker color of the arc-fused oxide in contrast to the gray hue of air-fused oxide. Calcination is performed by heating the granular europium oxide product in alumina boats in a ceramic muffle furnace in air to $1000^{\circ} \mathrm{C}$ for $4 \mathrm{~h}$. The calcined product is removed from the furnace boats while still warm $\left(-40\right.$ to $\left.50^{\circ} \mathrm{C}\right)$ to minimize moisture absorption and packed in bottles for storage.

Grind/screen - The required particle distribution for the europium oxide in the control plates is $<3 \%+100$ mesh, $>70 \%-100+325$ mesh, and $<30 \%-325$. No +100 mesh material is purposely added, but the limit was set to allow some difference between the screening of the bulk material and the particle size analysis. To produce the desired particle size distribution, the granular product is ground using a direct-drive disk pulverizer (Bico Model UA) equipped with adjustable 8-in.-diam high-purity alumina grinding disks. The disk pulverizer grinds particles when they are passed between a stationary and a rotating disk, with the amount of size reduction roughly dependent on the amount of separation between the grinding disks. 
The primary concern in grinding the arc-melted europium oxide product is to obtain $\mathrm{a}-100$-mesh powder without generating an excess quantity of -325 -mesh fines. To achieve the desired -100 mesh product, after each pass through the pulverizer the -100 -mesh fraction is removed while the +100 -mesh fraction is repeatedly recycled through the pulverizer with the disks set at progressively narrower gaps. Initially the gap is set at 1/8 in. and all the product is fed through the grinder. The resulting material is then screened using a laboratory vibratory sieve shaker and separated into three fractions: +100 mesh; $-100+325$ mesh; and -325 mesh. The +100 mesh fraction is then fed back through the pulverizer. The acceptable product fractions are collected in $\sim 2$-L plastic bottles. The grinding and screening sequence is then repeated as the pulverizer gap settings are changed from 0.032 , to 0.015 , to $<0.005$ in. until all the material is -100 mesh. Excess fine material can be recycled through the arc melting process, but the impurities added in this step are significant.

Cross blend/batch-The amount of material in each product collection bottle is first determined by weight and then homogenized using either an oblique or a " $\mathrm{V}$ " blender and returned to the original bottles. To verify particle size, analysis of particle size is performed on the contents of each bottle in accordance with American Society for Testing and Materials (ASTM)-B214, "Sieve Analysis of Granular Metal Powders." Depending on the quantity of -325 -mesh fines generated, the amount of the -325 fractions that can be added to the $-100+325$ fraction to obtain the specified particle size distribution of the europium powder is calculated. The calculated quantities of each fraction are then dispensed by weight, blended, and placed into several $\sim 2-\mathrm{L}$ collection bottles. The contents of each collection jar is a batch.

Inspection - The particle size distribution in each batch is determined by performing a particle size analysis in accordance with ASTM-B214. To verify composition, samples are analyzed for europium and trace-element content. The europium content shall be $>86 \mathrm{wt} \%$; the maximum thorium content shall be $<20 \mathrm{ppm}$; with other anionic impurities $<1200 \mathrm{ppm}$. The density of the europium particles, which is determined on a representative sample by a toluene displacement technique, must be $>90 \%$ of the theoretical X-ray crystal density of $\mathrm{Eu}_{2} \mathrm{O}_{3}\left(7.99 \mathrm{~g} / \mathrm{cm}^{3}\right)$. The crystal structure of the $\mathrm{Eu}_{2} \mathrm{O}_{3}$, determined by $\mathrm{X}$-ray diffraction, must be crystalline with a predominant monoclinic structure.

\subsubsection{Tantalum}

The specification for the tantalum powder to be used in control plates is contained in RRD-MS101. This specification reflects lessons learned from deficiencies in the physical properties of the tantalum powder used in outer sets 13,14 , and 15 , which had to be scrapped. H. C. Stark Inc. is the vendor that supplied the tantalum powder used in the last campaign. They are the only domestic vendor still producing an electronic-grade (Q30) melt-refined tantalum powder for use in the control plates. 
Physical requirements-The tantalum powder required for roll bonding must have dense discrete particles that can withstand the rigors of the roll-bonding process without significant fragmentation. The specification requires that the powder be a high-purity electronic-grade material produced by a melt refining and hydrating/dehydrating process or equivalent process to produce dense nonagglomerated particles that are $<74 \mu \mathrm{m}$ ( -200 U.S. standard mesh size). The specified particle size distribution as measured by ASTM-B214 is as follows:

\begin{tabular}{cc}
\hline U.S. standard mesh size & Fraction (\%) \\
\hline+200 & $<3$ \\
$-200+325$ & $>70$ \\
-325 & $<27$ \\
\hline
\end{tabular}

In the melt refining process, tantalum powder is made by grinding the tantalum in the hydride form and is commercially produced for limited electronic applications. Most commercial electronic-grade tantalum powder is produced by direct sodium reduction. The size distribution specified is not a standard commercial product, and the supplier for sets 16 and 17 had a difficult time producing the required size distribution. To ensure that the powder lot ordered meets the required physical attributes, an advance sample is examined under a light microscope at $\sim 10 \mathrm{X}$ and compared to "good" powder used in previous control plates before accepting the powder for use in control plates.

Chemical requirements-The tantalum powder is specified at a chemical purity of $99.8 \%$ tantalum minimum. The tantalum content is determined by subtracting all trace-level impurities from $100 \%$. Maximum trace-element concentrations are specified for carbon (200 ppm), oxygen $(1200 \mathrm{ppm})$, and nitrogen $(300 \mathrm{ppm})$. These concentrations are somewhat higher than specified previously but better reflect the process capabilities of a melt-refined powder process. Low concentrations of these elements are normal in a direct sodium-reduced powder and were noted as one of the differences in the "bad" tantalum used in sets 13,14 , and 15. Other trace elements to be analyzed include: $\mathrm{Al}, \mathrm{Ca}, \mathrm{Co}, \mathrm{Cr}, \mathrm{Cu}, \mathrm{Fe}, \mathrm{Ni}, \mathrm{K}, \mathrm{Si}, \mathrm{Mo}, \mathrm{Mg}, \mathrm{Mn}, \mathrm{Na}, \mathrm{Nb}, \mathrm{W}$, Ti, and $\mathrm{Si}$.

Inspection-The inspection of the tantalum powder upon receipt is performed mainly to verify the supplier's certified analysis. A random grab sample is analyzed to ensure that the material is tantalum and to inspect for all the specified trace elements. The particle density is determined by toluene displacement, and the total gas content is determined by measuring the gas release to fusion. The material in each batch received is then homogenized by blending in an oblique or twin-cone blender, and a sieve analysis is performed on at least two randomly selected batches in accordance with ASTM-B214. If the sieve analysis on any one batch is not as specified, the entire lot will be analyzed and rescreened, if necessary, before use. 


\subsubsection{Aluminum powder}

The specification for the aluminum powder to be used in control plates is contained in RRD-MS102. The general requirement for the aluminum powder is that it be atomized spherical powder manufactured in accordance with military procurement specification MIL-A-81335. Alcan grade 101 is the general type of powder required. The specification for aluminum powder is based on the powder purchased by the ORNL HFIR fuel element contractor for fabricating HFIR fuel elements. Large lots of the specified aluminum powder are purchased and production qualified for this purpose. This powder is the normal source of the aluminum powder used in control plate fabrication and is accepted on the basis of the HFIR fuel element contractor's qualification. The powder is vacuum annealed prior to use.

Chemical requirements - The aluminum powder should be dry and free from oil and grease and should meet all the other chemical requirements except for having more stringent requirements for some trace impurities. The aluminum shall be $>99.3 \%$ metallic aluminum. The limits of the trace impurities allowed in weight percent are as follows: $\mathrm{Cd}(0.002 \%), \mathrm{Li}(0.008 \%)$, $\mathrm{B}(<0.001 \%), \mathrm{Si}$ and $\mathrm{Fe}(0.250 \%), \mathrm{Zn}(0.001 \%), \mathrm{Cu}(0.200 \%), \mathrm{Al}_{2} \mathrm{O}_{3}(0.007 \%)$, and other singleanion impurities $(0.050 \%)$. Increased boron levels could be a problem in the future because of some recent changes in the manufacture of aluminum.

Physical requirements - The aluminum powder shall be spheroidal particles of aluminum with generally smooth surfaces and free from foreign materials. Acceptance is based on a microscopic examination (at least 20X) of several samples within the lot and all samples meeting these requirements. One hundred percent of the powder must pass a 100-mesh screen, as determined by a sieve analysis performed in accordance ASTM-B214 on a number of samples within the lot.

The flow properties of the aluminum powder are very important in the function of the powder in a roll-bonded plate. Attributes such as particle shape and surface effects, which cannot be quantitatively measured readily, affect how the powder blends with the disperse phase and then flows into a die cavity. These flow properties have a pronounced effect on the homogeneity of the dispersed phase in finished plates, particularly in the manufacture of HFIR fuel. Therefore, final acceptance of a lot of aluminum powder is based on the ability of a representative sample of the lot to function in a manner similar to previous lots of like aluminum powder.

Vacuum annealing-Typically aluminum powder is received in 5-gal metal cans. For a control plate campaign, two to three cans of aluminum powder in current use in HFIR fuel manufacture are obtained from the fuel element fabrication contractor. This material is divided into $1500 \mathrm{~g}$ batches, loaded into stainless steel furnace boats, and annealed in a multipurpose vacuum tube furnace at $500^{\circ} \mathrm{C}$ for $60 \mathrm{~min}$. An oil-diffusion vacuum pump system is used to evacuate the furnace tube and is maintained at $<10^{-3}$ torr when the powder is heated above $350^{\circ} \mathrm{C}$. To avoid excessive oxidation of the aluminum powder, the specified vacuum must be maintained during the run. If any process problems are encountered during a run, then that batch of powder is discarded. To minimize moisture absorption, the powder is removed from the furnace while still 
warm $\left(<50^{\circ} \mathrm{C}\right)$ and sealed in glass bottles. Multiple furnace runs are required to process the required powder.

Screen-After annealing, each annealed batch of powder is screened through a 100-mesh screen. The +100 mesh fraction is weighed, recorded, and discarded from the batch. The -100 -mesh fraction is weighed, recorded, returned to a glass bottle, and sealed. If the +100 -mesh fraction is significant compared to other batches, that entire batch should be discarded.

Inspection-The inspection of the annealed aluminum powder consists of a screen analysis of three randomly selected batches and the analysis of a representative sample from all batches to verify the metallic aluminum and trace-element content. The screen analysis is performed in accordance with ASTM-B214 and requires that the powder have $<0.5 \%+100$ mesh and $>70 \%$ -325 mesh. If these requirements are not met on any one of the batches sampled, all the batches in the lot must be sampled and analyzed for particle size. In either case, the samples for particle size analysis are discarded after analysis. Because of the relatively low cost of aluminum powder, any batch of aluminum powder should be discarded if any questionable process conditions are encountered or if the screen analysis results are not consistent with other batches. The metallic and trace element content must be consistent with the requirements of the procurement specification to be accepted.

\subsubsection{Prepare powder compacts}

The dimensions and arrangement of the compacts required for billet assembly are shown in Fig. 8. The dimensions for the compacts were derived from the required dimensions of the core section in the rolled plate. The length and width dimensions of the compacts allow for the stacking of layers of compacts in an overlapping building-block fashion. Overlapping minimizes the aluminum-rich edge effects of the pressed compacts and improves the integrity of the core in finished plates. This required geometric arrangement of the compacts also establishes the billet cavity dimensions and is the reason that cross rolling is necessary to obtain the required core dimensions in the finished control plates. As indicated in Fig. 8, 18 europium and 9 tantalum compacts are required for each control plate.

Loading calculations - The total weight of absorber materials present in the core sections of the finished plates is the primary nuclear consideration. The specified weights of the europium oxide and tantalum, which were derived from a volume loading in the core section of $\sim 33 \%$ for the europium oxide and $40 \%$ for the tantalum in the core are presented in the following table.'

\begin{tabular}{ccc}
\hline Type & Tantalum $(\mathbf{g})$ & $\mathrm{Eu}_{2} \mathbf{O}_{3}(\mathbf{g})$ \\
\hline & 1297 & 1922 \\
Inner plate & 1292 & 1912 \\
\hline
\end{tabular}



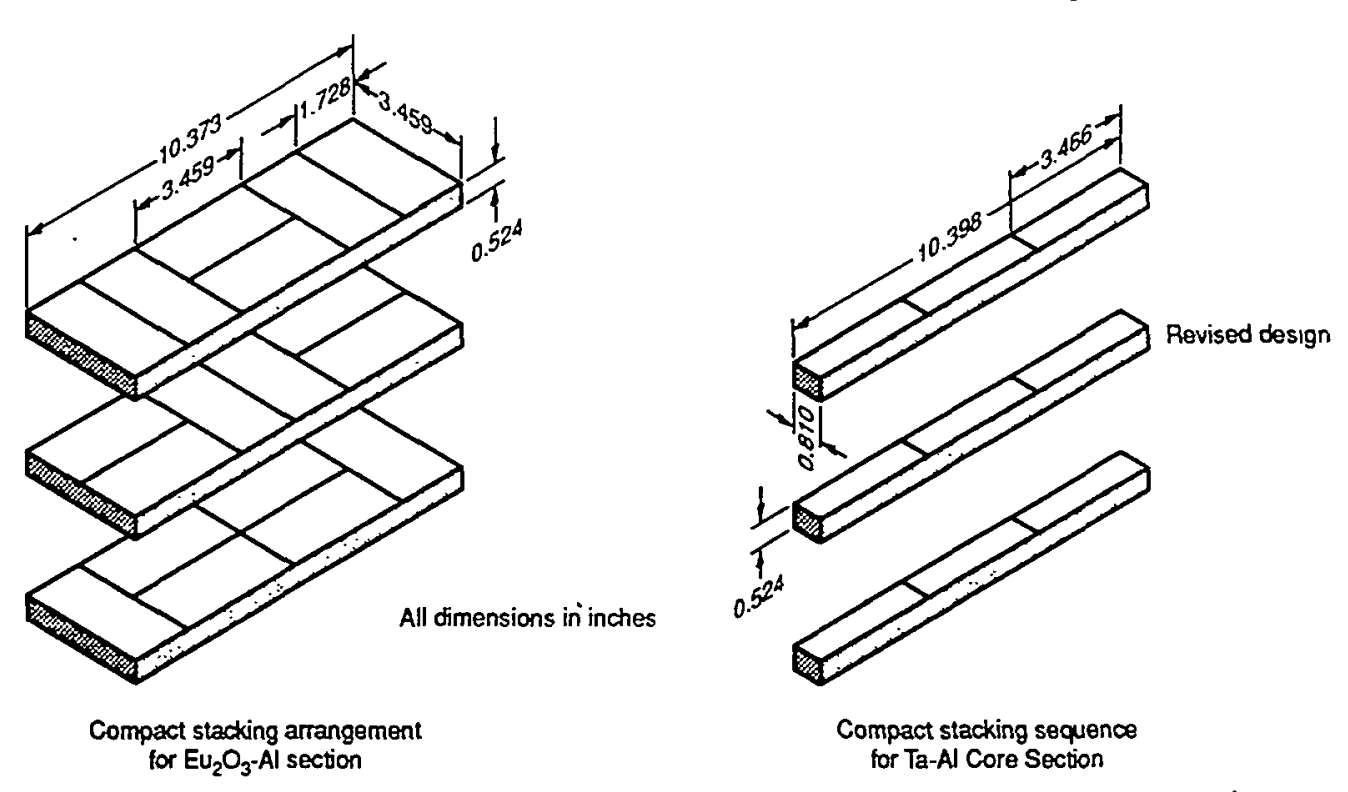

Fig. 8. Description of components required for billet assembly.

The specified values were derived during development of the control plate roll-bonding process and represent volume loading of the absorbers that could be readily achieved in a dispersion-type plate. The use of the different loading for inner and outer plates is probably unnecessary, and single loading for the absorbers should be specified for future control plates to simplify fabrication. (The current loading tolerance for the europium oxide is $\pm 19 \mathrm{~g}$ and, for the tantalum, $\pm 13 \mathrm{~g}$ in both finished plate types.)

- The design of the compacts for outer sets 16 and 17 was derived from the design of compacts made for inner control plates during the past campaign in an effort to produce a slightly narrower core section still within the existing tolerances. The dimensions for the core sections in the inner and outer plates overlap and are within the process capabilities. A slightly narrower core to increase the edge margins around the core was desirable.

The assumptions and calculations for the weights of the absorber materials and aluminum powder for the individual compacts in outer control plates sets 16 and 17 are presented in Table 1. 
Table 1. Calculations for pre paring compacts for HFIR control rods

\begin{tabular}{|c|c|c|c|}
\hline \multirow[b]{2}{*}{ Absorber in compact } & & Tantalum & $\mathrm{Eu}_{2} \mathrm{O}_{3}$ \\
\hline & Specified quantity absorber (g) & 1297 & 1922 \\
\hline \multirow{4}{*}{ 、 } & Content of absorber in powder & $99.9 \%$ & $86 \%$ \\
\hline & Quantity powder required $(\mathrm{g})$ & 1298.3 & 2227.1 \\
\hline & Compacts per billet core & 9 & 18 \\
\hline & Powder per compact $(g)$ & 144.26 & 123.73 \\
\hline
\end{tabular}

\begin{tabular}{|l|l|r|r|}
\cline { 2 - 4 } Volume of compact & Width (in.) $+/-0.002$ & 0.810 & 1.731 \\
\hline & Length (in.) $+/-0.002$ & 3.465 & 3.459 \\
\hline Thickness (in.) $+1-0.003$ & 0.5255 & 0.523 \\
\cline { 2 - 4 } & Total volume $\left(\mathrm{cm}^{3}\right)$ & 24.17 & 51.32 \\
\hline
\end{tabular}

\begin{tabular}{|l|l|r|r|}
\cline { 2 - 4 } Vol. of absorber in compact & Density $\left(\mathrm{g} / \mathrm{cm}^{3}\right)$ (toluene) & 16.460 & 7.933 \\
\hline & Volume absorber /compact $\left(\mathrm{cm}^{3}\right.$ & 8.76 & 15.60 \\
\hline
\end{tabular}

\begin{tabular}{|l|l|r|r|}
\cline { 2 - 4 } Void volume in compact & Density of press compact - \% T & $89 \%$ & $91.5 \%$ \\
\hline & Void volume/compact $\left(\mathrm{cm}^{3}\right)$ & 2.66 & 4.34 \\
\hline
\end{tabular}

\begin{tabular}{|l|l|r|r|}
\cline { 2 - 4 } Volume of aluminum & Density of $\mathrm{Al}\left(\mathrm{g} / \mathrm{cm}^{3}\right)$ & 2.70 & 2.70 \\
\hline \multirow{2}{*}{} & Vol. A $/ / \operatorname{core}\left(\mathrm{cm}^{3}\right)$ & 12.75 & 31.38 \\
\hline
\end{tabular}

\begin{tabular}{|l|l|r|r|}
\cline { 2 - 3 } W t. of compact components & W t. of absorber per compact $(\mathrm{g}$ & 144.26 & 123.73 \\
\hline & weight of Al per compact $(\mathrm{g})$ & 34.42 & 84.72 \\
\cline { 2 - 4 } & Total compact weight $(\mathrm{g})$ & 178.67 & 208.45 \\
\hline
\end{tabular}

\begin{tabular}{|c|c|c|c|}
\hline Loading in core section & Volume of core $\left(\mathrm{cm}^{3}\right)$ & 206 & 909 \\
\hline & Volume of Al and absorber $\left(\mathrm{cm}^{3}\right.$ & 194 & 846 \\
\hline & $\%$ TD of core section & $94 \%$ & $93 \%$ \\
\hline & Volume \% absorber in core sect & $38 \%$ & $31 \%$ \\
\hline & W eight $\%$ of absorber in core & $81 \%$ & $59 \%$ \\
\hline
\end{tabular}


The dimensions and weights of compacts made for the previous inner plate campaign were used to establish the volume of aluminum and void volumes in the pressed compacts. The quantity of aluminum is the primary variable affecting the finished core dimensions because the void volume is dependent on densification during the roll-bonding process. The void volumes were calculated from the densification values expressed as a percentage of theoretical density (\% TD) given in the following table:

\begin{tabular}{ccc}
\hline Process stage & $\mathrm{Eu}_{3} \mathrm{O}_{3}$ section (\% TD) & Tantalum section (\% TD) \\
\hline & & 89 \\
Pressed compact & 91.5 & 89 \\
Annealed/degassed & 91.2 & \\
compact & & 94 \\
Rolled plate & 93 & \\
\hline
\end{tabular}

The densification during processing is somewhat dependent on the characteristics of the powder lots used but appears to have been relatively consistent between campaigns, judging from an analysis of finished core dimensions of a number of plates from different campaigns. The rolled plate densification values determined by using the nominal design dimensions of the core sections and the volume of the absorbers are consistent with the assumed values.

Weigh components-Each component for a compact is dispensed by weight to within $0.01 \mathrm{~g}$ and poured into individual glass bottles. Material control is maintained on a daily basis for each powder component. The quantity of component materials plus $10 \mathrm{~g}$ that is expected to be used during an 8-h shift are withdrawn and dispensed by weight into interim storage containers. The additional $10 \mathrm{~g}$ is provided to allow for some spillage. After dispensing the components for the individual compacts, the materials remaining should balance with no more than $15 \mathrm{~g}$ or no less than $5 \mathrm{~g}$ remaining.

Blend-The blending of the component powders is performed in individual glass bottles. The blending bottles are of clear glass, wide-mouth design, and have screw tops fitted with aluminum liners. A 4-oz. bottle is used for the tantalum compacts, and an 8-oz. bottle is used for the europium compacts. These size bottles were required to allow a mixing space of $60 \mathrm{vol} \%$ over the powder. This blending space is necessary for the proper end-for-end tumbling action when blending the components using an oblique-type blending action. The aluminum top liners are used to minimize the introduction of foreign materials into the powders. Blending is accomplished by placing multiple blending bottles into a container attached at a $30^{\circ}$ angle from vertical to the end of a horizontal shaft (oblique blender). The rotational speed is controlled at 20 to $25 \mathrm{rpm}$ and is operated for $2 \mathrm{~h}$ to blend the compact powders. The bottle size, container angle, and rotational speed are important to achieve the required end-to-end tumbling action for correctly blending the powders. Because of the large difference in densities of the aluminum and the absorbers, extreme care must be exercised in handling the blended powders to minimize segregation. Vibrations from machinery or jarring the blended powders must be avoided. Because of these segregation concerns, the blended powder must be compacted within $4 \mathrm{~h}$ of blending. 
Press compact - Immediately after blending, the powders are compacted by a standard powder metallurgy cold-pressing operation. The dimensions of the required rectangular-shaped compacts are shown in Fig. 8. As discussed previously, the dimensions of the europium compacts were designed to allow them to be stacked in an overlapping arrangement. In the initial design of the tantalum compacts, two different-size compacts were used to allow overlapping. In the current design, a single-size tantalum compact is used without overlapping.

Compacting is accomplished using relatively large-capacity hydraulic presses. About 20 tons per square inch (tsi) is required to press both compacts. Because of the difference in pressing area, a press load of $\sim 120$ tons is required to press the europium compacts and a press load of 60 tons is required for the tantalum compacts. For convenience during the last campaign, two presses were used: a 100 - and a 500-ton press.

The dies used were standard hardened tool steel, rectangular cavity, powder metallurgy dies and punches. The die cavities in the dies used have tapers to allow expansion of the compacts after pressing to aid in the ejection of compacts. The dies are operated on the presses in springsupported die set assemblies. This support assembly allows the bottom punch to be raised for loading the powder and then lowered for pressing. When lowered, the bottom punch is free or floating during the application of the pressing load to simulate a double-action press.

The general sequence for a pressing operation is (1) apply a die lubricant, (2) raise the bottom punch to loading position, (3) load powder and level, (4) lower the bottom punch, (5) insert the top punch into the die and lower slowly, (6) press the compact to length, (7) eject the pressed compact, (8) measure and mark the compact, and (9) clean the die and punches. Stearic acid, at a concentration of $\sim 5 \%$ dissolved in methylene chloride or similar organic solvent, is used to lubricate the die and punches. The light coating of lubricant is applied to the die cavity with a cotton swab. The punches are not lubricated. Raising the bottom punch to the loading position is required to minimize the free fall of the powder when pouring the blended powder mixture into the die and to level the powder charge for pressing. The proper pouring of the powder charge into the die cavity is very important to make a compact with a homogeneous dispersion of the absorbers. The powder should be poured rapidly to maintain it in a slug, rather than poured slowly from the blending jar. The powder leveling is done with a metal straight edge while adjusting the position of the bottom punch. The powder must be leveled so that it completely fills the die cavity without any depressions. The lowering of the top punch needs to be done slowly to allow the trapped air to escape without disrupting the powder bed. An experienced operator is desirable for performing the die loading and pressing operations.

The die sets used to press the compacts are relatively expensive, and the same dies have been used for pressing compacts for all control plates made to date. Some rework of the dies was required before the last campaign to remove rust and to square the punch faces.

The pressing is done by applying the load slowly, using a dial indicator and pressure gauge to control both the final pressure and the pressed length of the compact. The required pressing pressure is relatively constant, but the use of the dial indicator allowed better control of the 
compact thicknesses than by pressing to a constant pressure. The ejection of the compact is done by pressing the compact up to the top of the die. The measurement of the thickness of the pressed compact at six locations along the edges of the compact is to ensure that the die set is producing a compact with a uniform thickness. If thickness measurements are not consistent within $0.001 \mathrm{in}$., shimming of the punches is required. Shimming of the punches in the last campaign was not required. Marking of the compact is done with a metal scribe. The cleaning of the die between compacts is very important, but the amount of cleaning may vary depending on the condition and tolerances of the die and punch set being used. Removal and cleaning of the bottom punch after each compact is pressed may be necessary to ensure uniformity in pressing.

Vacuum anneal-Vacuum annealing of all compacts is performed in a vacuum furnace at $590^{\circ} \mathrm{C}$. This step is required to remove the die lubricant remaining from the pressing operation and moisture absorbed during the handling of the powders. In the vacuum annealing operation, compacts are placed on stainless steel mesh screening and stacked in layers in a furnace. The screen is necessary to separate the layers and to allow a path for vapors to escape. The vacuum is maintained at a pressure of $<0.05$ torr during the heating cycle. The temperature required in this operation is very close to the melting point of aluminum (which is $660^{\circ} \mathrm{C}$ ), and care must be taken to avoid melting the aluminum in the compacts. In the last campaign, the vacuum annealing was performed in a relatively large, cold-wall, resistant, heated vacuum furnace. To control the temperature and guard against an overtemperature condition, a thermocouple was placed directly in the stack of compacts.

Inspection of compacts-Each compact is visually inspected for defects such as cracks, blisters, chipped corners, inclusion of foreign materials, or unusual discoloration after pressing and again after vacuum annealing. After pressing and vacuum annealing, the width, length, and thickness of compacts are measured with micrometers and recorded. The width and length are measured along each edge, and the average is recorded. The thickness is the average of six measurements, two on each end and two in the middle. The thickness is the only dimension that should show any variation because the width and length dimensions are a direct function of the die cavities being used to press the compacts. The same dies have been used for pressing compacts for all control plates made to date. The measurement of the relatively soft compacts with micrometers requires some experience in obtaining consistent readings while not damaging the compacts. Dimensions and weights of typical compacts made in the last campaign are presented in Table 2.

In the tantalum compacts, the dimensions and weights did not vary significantly between the aspressed and annealed conditions and are presented as a single tabulation. The extremely good control of the thicknesses of the europium compacts during the last campaign is demonstrated in Table 2. Almost no variation in the thickness was noted in the randomly chosen group of $\sim 25$ europium compacts. During annealing, the europium compacts expanded in thickness uniformly while shrinking slightly in width and length. The amount of expansion in the europium compacts is consistent with previous campaigns. As shown, the average weight loss for a tantalum compact from the dispensed weight was $\sim 0.040 \mathrm{~g}$. For nine compacts loaded in a plate, this weight loss would amount to $<0.4 \mathrm{~g}$ of tantalum if all the weight lost was assumed to be tantalum. This is a relatively insignificant quantity considering the allowed tantalum weight variation in a plate of 
Table 2. Dimensions and weights of typical absorber compacts

Ta compacts-pressed and annealed

\begin{tabular}{lccccc}
\hline & Specified & Tolerance & Average & Maximum & Minimum \\
\hline & & & & & \\
Width (in.) & 0.810 & $+1-0.002$ & 0.810 & 0.810 & 0.0 .810 \\
Length (in.) & 3.464 & $+/-0.002$ & 3.465 & 3.465 & 3.465 \\
Thickness (in.) & 0.5255 & $+/-0.002$ & 0.525 & 0.526 & 0.523 \\
Weight (g) & 178.67 & $+0.0 /-0.18$ & 178.63 & 178.65 & 178.61 \\
& & & & & \\
\hline
\end{tabular}

$\mathrm{Eu}_{2} \mathrm{O}_{3}$ compacts-pressed

\begin{tabular}{lccccc}
\hline & Specified & Tolerance & Average & Maximum & Minimum \\
\hline Width (in.) & 1.728 & $+/-0.002$ & 1.729 & 1.729 & 1.729 \\
Length (in.) & 3.459 & $+/-0.002$ & 3.460 & 3.460 & 3.460 \\
Thickness (in.) & 0.523 & $+/-0.002$ & 0.523 & 0.523 & 0.523 \\
Weight (g) & 208.45 & $+0.0 /-0.21$ & 208.44 & 208.45 & 208.42 \\
& & & & & \\
\hline
\end{tabular}

$\mathrm{Eu}_{2} \mathrm{O}_{3}$ compacts-annealed

\begin{tabular}{lccccc}
\hline & Specified & Tolerance & Average & Maximum & Minimum \\
\hline Width (in.) & 1.730 & $+/-0.002$ & 1.728 & 1.728 & 1.728 \\
Length (in.) & 3.460 & $+/-0.002$ & 3.459 & 3.459 & 3.459 \\
Thickness (in.) & 0.5255 & $+/-0.002$ & 0.525 & 0.525 & 0.525 \\
Weight (g) & 208.45 & $+0.0 /-0.21$ & 208.39 & 208.41 & 208.38 \\
\hline
\end{tabular}

$\mathrm{Eu}_{2} \mathrm{O}_{3}$ compacts - difference annealed from pressed

\begin{tabular}{lc}
\hline & Average \\
\hline Width (in.) & -0.001 \\
Length (in.) & -0.001 \\
Thickness (in.) & 0.002 \\
Weight (g) & -0.05 \\
\hline
\end{tabular}


$\pm 9 \mathrm{~g}$. In europium compacts, the average weight loss from the dispensed weight was $0.060 \mathrm{~g}$, and for the 18 compacts used in the europium section the average weight loss was equal to $\sim 1.1 \mathrm{~g}$. In the tantalum compacts, the dimensions and weights did not vary significantly between the aspressed and annealed conditions and are presented as a single tabulation. This quantity is also insignificant when considering the allowed weight variation of $\pm 18 \mathrm{~g}$ in the europium section in a plate. Because of the small weight losses experienced, there was no need to compensate for these losses in the dispensed weights of the components for the compacts.

After inspection, all acceptable compacts are placed in plastic bags and stored in a vacuum chamber or desiccator. During the last campaign, the yield of usable compacts within specification was essentially $100 \%$. 


\subsection{BILLET COMPONENT PREPARATION AND ASSEMBLY}

In addition to the compacts, the billet components consist of a machined aluminum frame approximately $15 \times 15 \times 1.6 \mathrm{in}$. and having two $1 / 4$-in.-thick aluminum cover plates. A $5 / 8$-in.diam aluminum tube is welded to the frame to allow the evacuation of the cavity containing the compacts after assembly of the billet. The billet components, shown graphically in Fig. 9, are detailed on Engineering Drawing E-49433. The frame and cover materials are purchased as "milled marked" 6061-T6 aluminum alloy plates stock in conformance with ASTM-B209, "Aluminum and Aluminum-Alloy Sheet and Plate." Because these materials will be used in a HFIR safety-related application, documentation is required from the vendor to certify the composition and to identify the traceability as to heat number to conform with the requirements of RRD-MS-52, Sect. 5. To verify the alloy composition, a sample from each plate to be used is analyzed for chemical composition for conformance to the alloy composition requirements of ASTM-B209 for the 6061 alloy. An archive sample is also cut for each plate used and retained for future analysis if required.

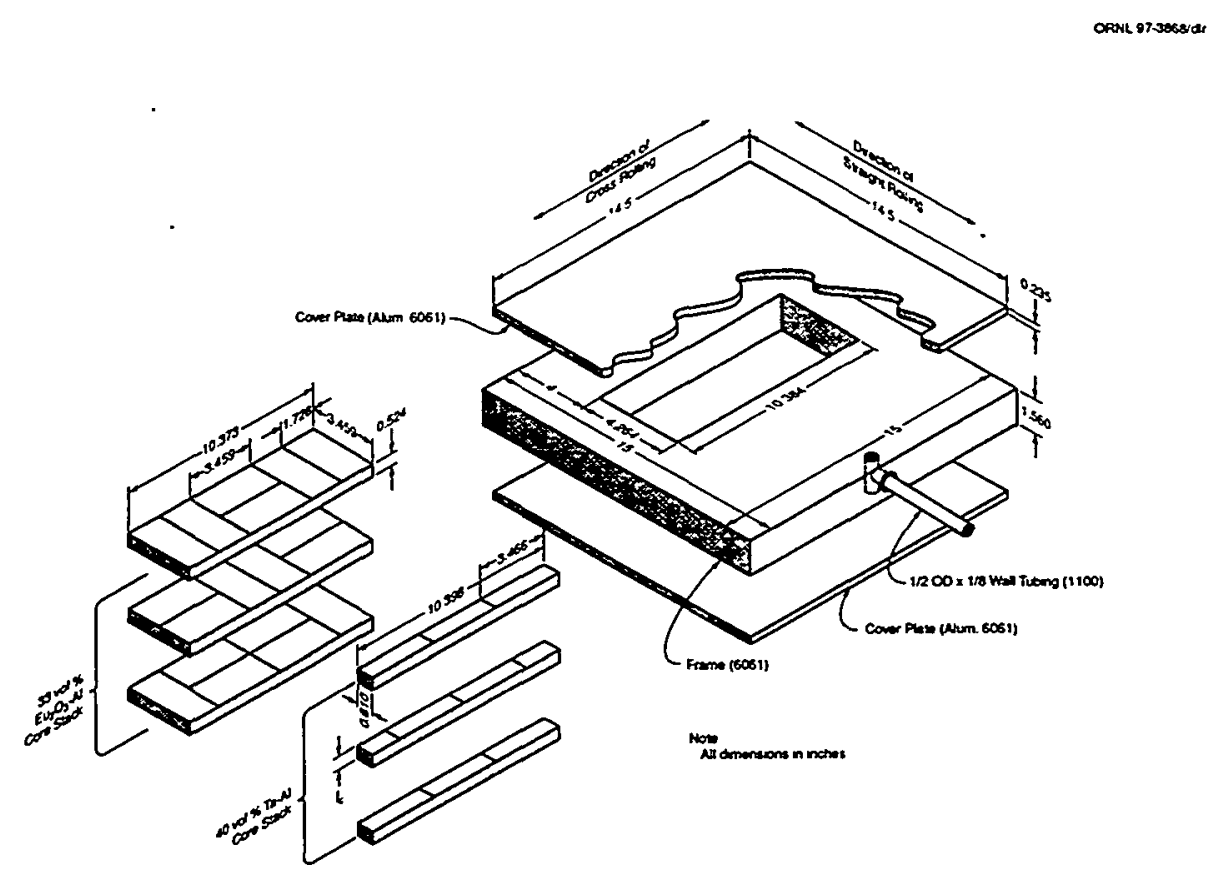

Fig. 9. Schematic of billet components.

\subsubsection{Frames}

The frames are rough saw cut from 2-in.-thick plate stock that is normally received in 4- by 12 -ft plates and then machined to meet the requirements of Engineering Drawing E-49433, Rev. D. Each frame is marked on a saw cut face in a machined, recessed spot that will be below the final machined edge having the heat number and a serial number before machining to maintain 
material traceability. The thickness of the billet frame for both the inner and outer control plates is $1.560 \mathrm{in}$. Prior to the 1993 campaign, the frame for the outer plate was 0.009 in. thicker but was changed to the thickness of the inner plate to reduce the width of the as-rolled core section. The reduced frame thickness changed the cavity volume slightly and, along with changes in the volume of the compacts to the inner billet design, resulted in a calculated reduction of $\sim 0.080 \mathrm{in}$. in the core width. The machining tolerances for the frames are relatively restrictive, particularly the alignment of the cavity with the outside edge of the frame. Because of the 8:1 reduction ratio in hot rolling, a small variation in this alignment will be magnified approximately 8 times and could affect the ability to obtain a parallelogram-shaped end to the rolled cores. The frame thickness and cavity dimensions will affect the cavity volume and also will need to be controlled to the tolerances specified. The cavity dimensions are sized to shrink-fit the compacts into the cavity. In the future, electric-discharge machining (EDM) should be considered for cutting the cavity. This process was very successful in machining brackets from thick aluminum plate. The shrink fit of compacts is not necessary, and redimensioning the cavity in future campaigns should be considered. After machining, the frames are degreased, annealed at $500^{\circ} \mathrm{C}$ for $2 \mathrm{~h}$, and then visually inspected for unusual discoloration, blisters, or embedded materials. Any frame that exhibits any significant defect should be rejected at this stage.

\subsubsection{Covers}

The covers are made from 1/4-in.-thick plate stock that has been visually inspected for surface defects. Rough blank covers $\sim 16$ in. ${ }^{2}$ are sheared from the plate stock and then cold rolled to the specified nominal thickness of 0.235 in. Each sheared blank cover is marked with an identification number. Before rolling, each blank is solvent cleaned and wire brushed, if necessary, to remove surface inclusions and is reinspected. Any blank having surface inclusions or flaws is rejected. The cold rolling is done on the large (19.5-in.-diam rolls) rolling mill, and the parts are rotated after each pass to obtain a uniform thickness. A thickness uniformity of \pm 0.0005 in. can be readily obtained by cold rolling. After cold rolling, each blank is roughly resized by shearing to 16 -in. squares before being sent to the machine shop for machining. After machining, the covers are degreased, annealed at $500^{\circ} \mathrm{C}$ for $2 \mathrm{~h}$ in stacks of five, and then visually inspected for unusual discoloration, blisters, or embedded materials. Any cover that exhibits any significant defect should be rejected at this stage.

\subsubsection{Cleaning}

The cleaning of the frames and covers before assembly is extremely important to minimize blisters in the rolled plates. Just prior to the hot-rolling campaign using a standard etch-cleaning procedure, the frames and covers are etch cleaned in a hot $\left(165-175^{\circ} \mathrm{F}\right)$ Oakite 160 solution (10 oz./gal), followed by a hot water rinse and neutralized in cold $60 \%$ nitric acid to remove the black soot-like deposits. The etched components are then rinsed in alcohol, air dried, and wrapped in clean brown kraft paper for storage in a dry atmosphere. The etching process removes about 0.001 in. from each of the surfaces of the components and must be closely controlled to 
avoid removing excess metal. It is highly desirable to minimize the time the frames and covers must be stored before use, but in the last campaign some of the frames and covers were stored longer than desired because of problems in the hot-rolling process.

Immediately prior to assembly of an individual billet for rolling, the selected frames and covers are wire brushed with a rotating stainless steel brush. The wire brush and device must be cleaned before each use, with particular care in removing buildup on the guard. The wire brushing is a relatively difficult step to perform uniformly and has been eliminated in the fabrication of fuel plates. Elimination of the wire brushing step should be considered in future campaigns if the etch-cleaning step can be closely timed to billet assembly.

\subsubsection{Billet Loading}

The frame and one cover are loaded into a furnace operating at $500^{\circ} \mathrm{C}$ and held for $1 \mathrm{~h}$ to expand the cavity to accommodate the compacts. The 27 selected compacts are laid out in the loading arrangement shown schematically in Fig. 9 on a table close to the furnace used to heat the frame. Using metal tongs, the compacts are loaded as quickly as practical into the hot frame assembly in layers starting with the first three tantalum compacts on the side of the cavity containing the evacuation stem. The heating of the frame is important to ensure that the entire billet has reached $500^{\circ} \mathrm{C}$ to provide the required expansion. The loading of the compacts in the array with a shrink fit is a tedious step, and if problems are encountered, the compacts likely cannot be removed intact if the compacts have been heated by the hot frame. In fabricating fuel plates, the shrink fitting of compacts has been found to be unnecessary and likely could be eliminated in future control plate campaigns. After the compacts are loaded, the top cover is placed on the assembly and the assembly is clamped together using at least eight " $C$ " clamps positioned 2 in. from the corners and around the edges of the assembly. The still-warm assembly is then transferred for welding.

\subsubsection{Billet Welding}

The covers are welded to the frame using a qualified gas tungsten arc welding process. In this weld, the groove made between the frame and the smaller cover plate is filled with $1 / 8$-in.-diam 4043 weld wire. The evacuation stem is also welded to the recess in the frame in a similar manner. Because the welds are required only to seal the billet for the initial passes in the hot rolling process and will be trimmed from the plates in a subsequent fabrication step, the welds must only meet visual and leak-test inspection requirements. The leak checking of the billet is accomplished by evacuation of the assembly to $<0.025$ torr and by spraying all joints with acetone. Any rise in pressure is an indication of a leak, which must be repaired. Making leaktight billets using the prescribed process is relatively easy. During the last campaign, almost no leaks were detected. A welded billet connected to a vacuum system is shown in Fig. 10. 


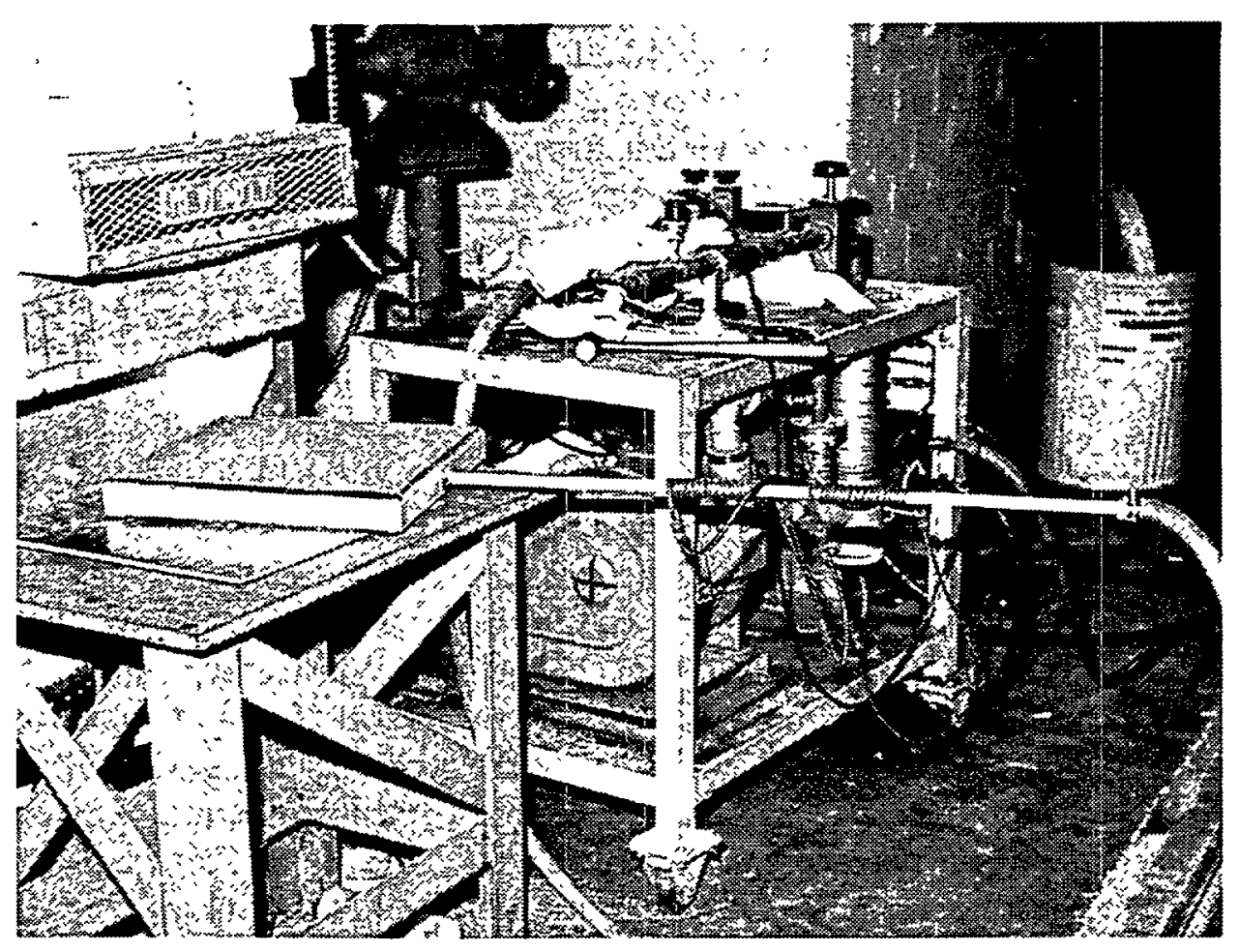

Fig. 10. Welded billet connected to a vacuum system.

\subsubsection{Degas Billet and Seal}

To ensure that the billet internal components are free of volatiles and gases, the billet is evacuated to a pressure of $<0.025$ torr and then heated to $500^{\circ} \mathrm{C}$ while under vacuum and held for a minimum of $16 \mathrm{~h}$ at that temperature. With the vacuum system still attached, the hot billet is removed from the furnace and the evacuation stem is closed by flattening the stem with an anvil and hammer (forge welding) at a point $\sim 2$ in. from the billet. Because the aluminum stem and weld joint at $500^{\circ} \mathrm{C}$ is relatively weak, care must be exercised not to stress the welded stem joint during the sealing step. In one instance during the last campaign, the welded stem was pulled out from the billet during the stem sealing step and had to be rewelded. After sealing, the billet is ready for hot rolling, which must begin immediately. 


\subsection{HOT ROLLING OF PLATES}

All control plates manufactured to date have been rolled on the two-high Mesta mill equipped with 19.5-in.-diam by 30 -in.-wide rolls and located in the rolling mill at ORNL. The Mesta mill, manufactured in 1908 , and its motor controls, drive suspension springs, and $120^{\circ}$ bearing supports are antiquated compared to modern rolling mills. During the last campaign, the mill was initially set up improperly with unmatched rolls. These unmatched rolls likely caused some of the problems experienced in maintaining the flatness of the plates when the first 10 plates were rolled. Maintaining parallel separation of rolls during rolling was also a significant problem that required the mill to be "leveled" before and during rolling and changes to be made in rotational sequence of the plate during rolling. A mill with level rolls is extremely important in rolling core sections with parallel ends. Because of the need for cross rolling, available mills of the required size are rare, and another suitable mill could not be located. The hot rolling of the control plates requires a technician experienced in the operation of rolling mills.

\subsubsection{Description of Hot-Rolling Process}

\subsubsection{Qualification of rolling mill}

A mill setup and qualifications-for-use procedure (MET-MatP-SOP 4) was developed during the last campaign that requires documentation of the mill setup and qualification to be prepared before rolling control plates. The setup procedure requires that the rolls and journal surfaces be match ground to the same diameter (rolls: $\sim 19.5$ in. in diameter \pm 0.001 in. maximum; journal surfaces: $15.0 \mathrm{in}$. in diameter \pm 0.010 ) with a surface finish of 11 to $22 \mathrm{rms}$. A 0.0002 -in.-thick hard chrome surface was specified to protect the roll surfaces from rusting. Neo Industries, located in Maryville, Tennessee, was employed during the last campaign to refinish the rolls. They picked up the rolls, ground them, and returned the finished rolls in less than 2 weeks. Neo Industries recommended a $22-\mathrm{rms}$ surface finish on rolls for rolling aluminum to minimize the rolls' slipping on the plate during rolling passes. In the initial setup of the mill and in previous campaigns, the roll surfaces have had a polished finish of $\sim 4 \mathrm{rms}$. This polished finish allowed the plates to slip during rolling and probably minimized the effects of the mismatched rolls during the last campaign.

In the installation of the rolls in the mill, the babbit journal bearing surfaces are first checked and replaced if necessary. The rolls are then lubricated and placed into the mill and adjusted to a 2-in. opening between the rolls. The total indicated runout (TIR) of the rolls is checked and should be $<0.001 \mathrm{in}$. The initial level (parallel rolls) adjustment is made at a mill opening of $0.010 \mathrm{in}$. and is adjusted to within \pm 0.002 in. Final level adjustment is made by rolling annealed aluminum test strips (initially $\sim 1 \times 12 \times 1 / 4$ in.) rolled on each side of the roll opening and measuring the strips after rolling them through a reduction of about $30 \%$. Adjustments are then made to the adjustment screws until the rolled test strips are within $1 / 16$ in. of each other. 
After leveling, the mill is then run-in and the rolls are conditioned by rolling at least one aluminum billet comparable to a control plate billet and rolling schedule to seat the journal bearings and condition the rolls with an aluminum oxide film. The aluminum oxide film is important in establishing the proper lubrication level on the rolls for maintaining a flat contour on the plate during rolling. The level of the mill is monitored during each pass with dial indicators, and in later passes, with scribe marks scratched on the test plate that is being rolled. If any shift in level is noted, test strips are run and adjustments are made as required.

The qualification of the mill for rolling control plates consists of rolling at least one dummy plate with dimensions similar to the product to be rolled. A dummy plate qualification will be deemed acceptable if the dummy meets the expected dimensions and the levelness of the mill does not shift more than $0.001 \mathrm{in}$.

\subsubsection{Furnace used for hot rolling}

The furnace used to heat the billets and plates during hot rolling is a resistance-heated furnace with a heated cavity of $\sim 24 \times 24 \times 78$ in. During the entire hot-rolling process, the furnace is maintained at $500^{\circ} \mathrm{C}$. Before using the furnace, the control thermocouples must be calibrated and the furnace profiled with thermocouples to determine if the thermal gradients present are within acceptable limits of $\pm 10^{\circ} \mathrm{C}$. The furnace used in the last campaign was equipped with a proportional controller rather than with the on/off-type controller used in past campaigns. The use of this type of controller may have resulted in a slightly slower temperature recovery in the plates after each rolling pass. An evaluation of the recovery rate, however, indicated that the type of controller used was not a major factor, but those involved in future campaigns should be aware of the influence of the furnace recovery rate, and adjustments should be made to the rolling schedule if necessary. A stainless sheet, which is bent to protect the back wall of the furnace, is used as the hearth. Maintaining the hearth cleanliness is important to avoid scratching the soft plate while placing and removing the hot plates from the furnace. After a plate has reached a length of $\sim 48 \mathrm{in}$. during the rolling process, the plate is placed and removed from the furnace on its edges to minimize surface scratches.

\subsubsection{Hot-rolling process}

The hot-rolling schedule and process for control plates was developed in the 1960s and has remained essentially unchanged. Changes in personnel over the years have resulted in some loss of company expertise relating to this process and probably resulted in some of the difficulties encountered in the hot rolling of plates during the last campaign.

Before rolling a plate, the rotational speed of the mill is set at $65 \mathrm{lin} \mathrm{ft} / \mathrm{min}$ and a lubrication of $10 \%$ SAE 90 -wt pinnacle cylinder oil (supplied by Texaco) in kerosene is applied continuously to both rolls with felt wipers. Improvements in the felt wipers should be considered in future campaigns. The mill speed used in previous campaigns was not clearly specified in procedures used in the past, and the 65-lin- $\mathrm{ft} / \mathrm{min}$ speed was established based on the experience of the 
technicians. Establishing and maintaining the correct amount of lubrication on the rolls is difficult and almost impossible to control to a point where there is little curvature in the rolled plate. The general guideline for the correct amount of lubrication to be used is a thin film that will barely wet the end of one's finger when it is held in contact with a roll during one complete revolution. During rolling, the plates are rotated end-to-end and top-to-bottom to minimize directional effects of the mill. During the last campaign, the rotational sequence was modified to perform top-to-bottom passes before rotating the plate end-to-end to compensate for any shift in the levelness of the mill during rolling. This rotational sequence, which was implemented after plate 0-93-7, was very successful in obtaining plate core sections with parallel ends.

The billet/plates are fed to the mill manually using Norfab gloves. A sealed billet ready for hot rolling is shown in Fig. 11. A hot billet/plate weighs $\sim 50 \mathrm{lb}$ and requires significant strength to handle manually. Use of the specified gloves is important because difficulties were experienced in previous campaigns when foreign materials from the asbestos gloves got embedded in the plates. Roller-type tables are used for both the feed and take-off tables. The feed table height is adjusted between passes to introduce the billet/plate at the center of the opening between the rolls. The take-off table is set at the top of the bottom roll, and the plates are "caught" manually. The take-off table should be positioned very close to the bottom roll to help release and guide the plate and to minimize the chance of a plate getting caught between the take-off table and the bottom roll. In the later passes, the release of the plate from the rolls likely will not be consistent and some scratching of the plate may result when the plate releases from the rolls and contacts the take-off table. Maintaining cleanliness of the lubricating wipers, rolls, feed, and take-off tables is extremely important in minimizing embedding of foreign materials in the surfaces of the plates during rolling. The rolls should be inspected for aluminum flakes after each pass and should be cleaned, if necessary. A plate being fed into the rolling mill near its final size is shown in Fig. 12.

Because the billet size of both the inner and outer plates is the same, a single rolling schedule can be employed for both types of plates. Previously, separate rolling schedules were used, but their differences were very minor. The rolling schedule is about a $10 \%$ reduction per pass in the initial stages and about a $13.5 \%$ reduction per pass in the later passes. The hot-rolling schedule and the typical resulting plate dimensions from the last campaign are shown in Table 3. 


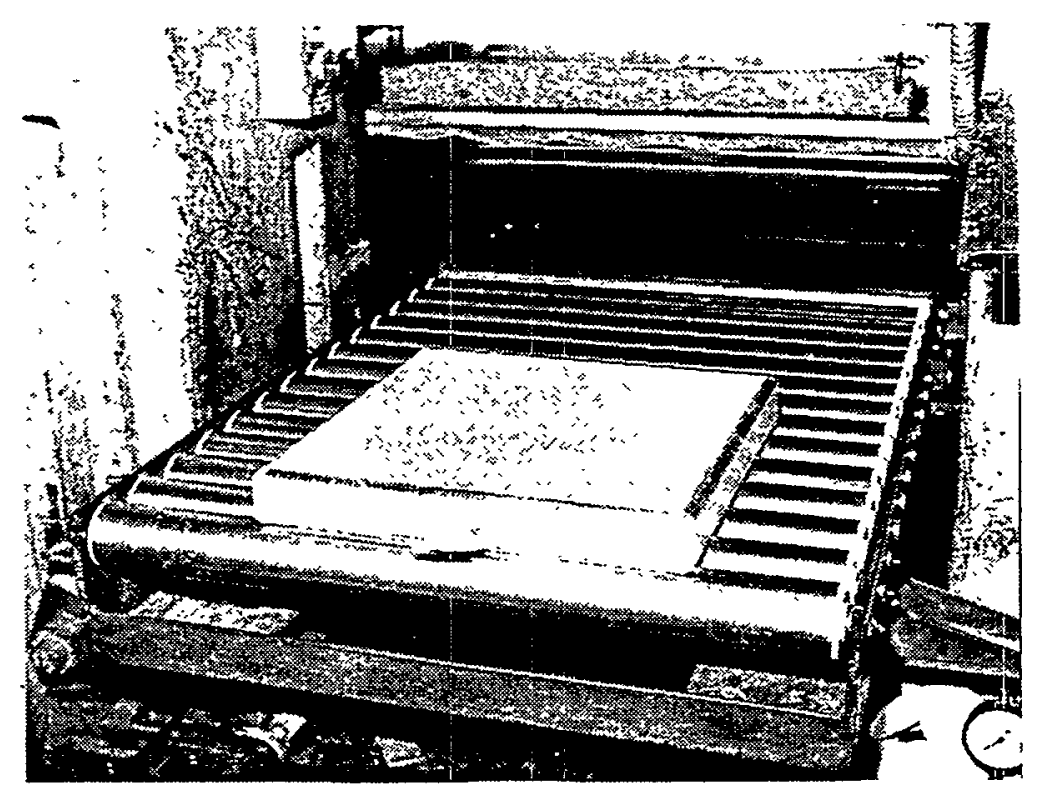

Fig. 11. Sealed billet ready for hot rolling.

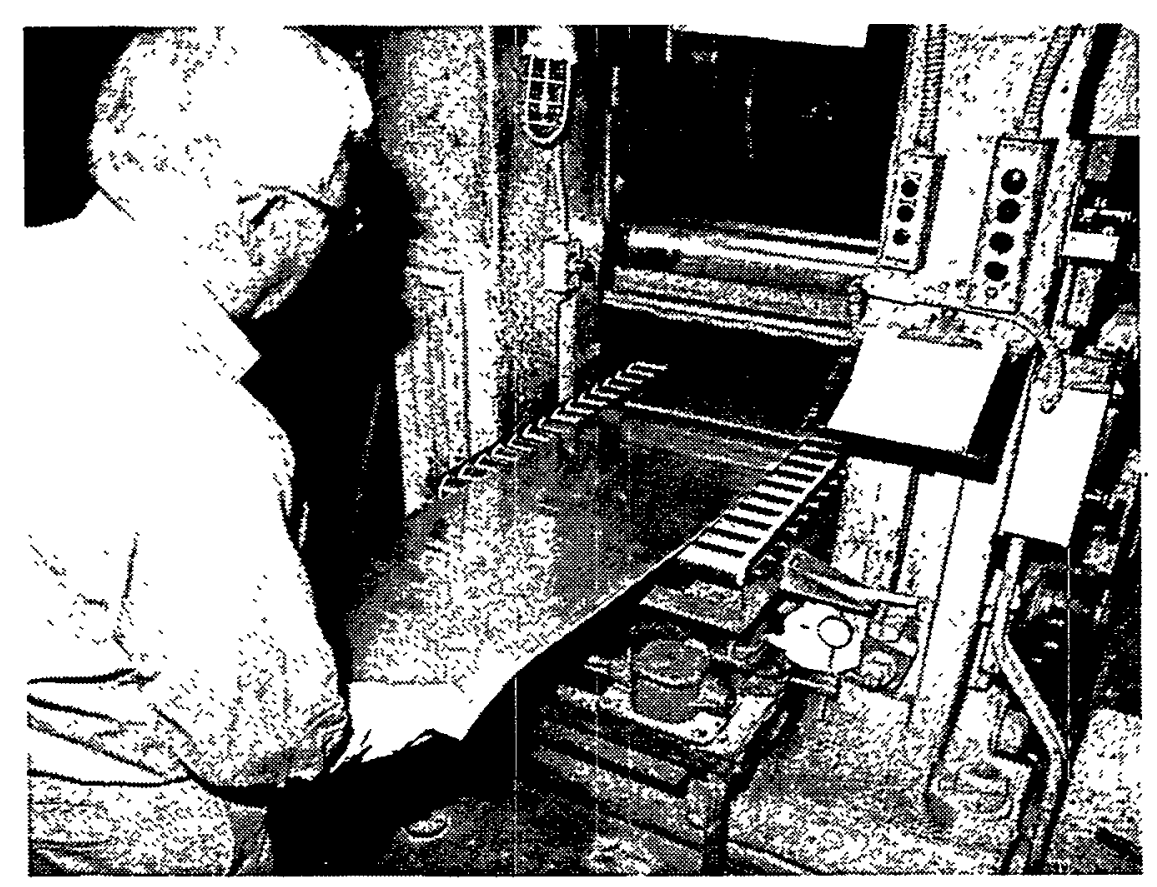

Fig. 12. A plate near its final size being fed into the rolling mill. 
Table 3. Hot-rolling schedule and typical resulting plate dimensions

Rolling Schedule

\begin{tabular}{|r|r|r|r|r|r|r|}
\hline Pass No. & $\begin{array}{r}\text { Preheat } \\
\text { (min) }\end{array}$ & $\begin{array}{c}\text { Mill } \\
\text { opening } \\
\text { (in.) }\end{array}$ & $\begin{array}{c}\text { Reduction } \\
\text { (mill \%) }\end{array}$ & $\begin{array}{c}\text { Thickness } \\
\text { (in.) }\end{array}$ & \multicolumn{1}{c|}{$\begin{array}{c}\text { Length } \\
\text { (in.) }\end{array}$} & \multicolumn{1}{c|}{$\begin{array}{c}\text { Width } \\
\text { (in.) }\end{array}$} \\
\hline 0 & & & & 2.031 & 15.000 & 15.000 \\
\hline 1 & 120 & 1.833 & 9.75 & 1.845 & 16.750 & 15.125 \\
\hline 2 & 12 & 1.650 & 9.98 & 1.660 & 18.625 & 15.125 \\
\hline 3 & 12 & 1.485 & 10.00 & 1.495 & 20.625 & 15.125 \\
\hline 4 & 12 & 1.336 & 10.03 & 1.346 & 22.948 & 15.125 \\
\hline 5 & 0 & 1.336 & 0.00 & 1.337 & 23.000 & 15.125 \\
\hline
\end{tabular}

Flatten passes $-2 ; 12-\mathrm{min}$ preheat between passes.

\begin{tabular}{|l|r|r|r|r|r|r|}
\hline $6-$ Cross & 20 & 1.201 & 10.10 & 1.216 & 23.062 & 16.562 \\
\hline $7-$ Cross & 12 & 1.080 & 10.07 & 1.096 & 23.062 & 18.312 \\
\hline $8-$ Cross & 12 & 1.080 & 0.00 & 1.086 & 23.062 & 18.500 \\
\hline 9 -Cross & 0 & 1.080 & 0.00 & 1.084 & 23.062 & 18.562 \\
\hline
\end{tabular}

Flatten passes: 2 ; 12-min preheat between passes.

\begin{tabular}{|r|r|r|r|r|r|r|}
\hline 10 & 25 & 0.934 & 13.52 & 0.940 & 26.562 & 18.562 \\
\hline 11 & 15 & 0.808 & 13.49 & 0.819 & 30.562 & 18.625 \\
\hline 12 & 15 & 0.699 & 13.49 & 0.710 & 35.312 & 18.620 \\
\hline 13 & 15 & 0.604 & 13.59 & 0.615 & 40.687 & 18.687 \\
\hline 14 & 15 & 0.522 & 13.58 & 0.532 & 47.000 & 18.750 \\
\hline 15 & 10 & 0.452 & 13.41 & 0.462 & 53.187 & 18.750 \\
\hline 16 & 10 & 0.391 & 13.50 & 0.403 & 67.875 & 18.750 \\
\hline 17 & 10 & 0.338 & 13.55 & 0.348 & 71.250 & 18.750 \\
\hline
\end{tabular}

Shear 11 in. from plate.

\begin{tabular}{|r|r|r|r|r|r|r|}
\hline 18 & 20 & 0.292 & 13.61 & 0.302 & 66.125 & 18.812 \\
\hline 19 & 10 & 0.272 & 6.85 & 0.278 & 71.062 & 18.875 \\
\hline 20 & 10 & 0.259 & 4.78 & 0.262 & 76.000 & 18.875 \\
\hline 21 & 10 & 0.254 & 1.93 & 0.254 & 78.500 & 18.875 \\
\hline $22 *$ & 10 & 0.254 & 0.00 & & & \\
\hline
\end{tabular}

Note: $*$ indicates passes that may be omitted. 
During the rolling process, in the initial passes the plate is sealed and a significant volume of aluminum is moved into the voids in the core cavity. The voids in the core cavity are from the compacts that are not fully dense and from the fit tolerances between the compacts and core cavity. In moving aluminum from the covers into the voids, the outline of the core cavity is obvious and stretch areas $\sim 1 / 8 \mathrm{in}$. wide around the cavity are apparent in the covers during the first five or six passes. Having some curvature in the plate during the initial passes cannot be completely avoided. This curvature is a particular problem in the rolling of control plates because of the requirement for cross rolling. In the initial cross roll pass and the first reduction pass after the last cross pass, the rolling mill with a feed table will not "bite" a plate that has a curvature greater than $\sim 1 / 8$ in. In addition, a plate with excessive curvature cannot be fed to the mill in the prescribed rotational sequence. If the rotational sequence cannot be followed, the resulting pass usually results in additional curvature. During the last campaign, the cladding on two plates fractured because of excessive plate curvature after flattening passes along the interface of the core cavity on the tantalum side. Considerable efforts were spent in working out a flattening process to minimize the effect of this curvature on the plates.

The flattening passes, indicated on the rolling schedule after passes 5 and 9 , were necessary in all the plates rolled during the last campaign even after changing the rolls and improving the lubrication technique. The flattening step depends on the amount of curvature and will vary significantly between plates. In flattening, the mill must be opened to a point where there is no chance of reducing the billet thickness (opening the mill $1 / 2$ in. over the last pass setting may be required) and the plates are passed through the mill diagonally. Several passes at different mill openings may be necessary to flatten a plate. The plate should be reheated between flattening passes. Because of the experience in the last campaign with excessive plate curvature that resulted in tears in the cladding at the cavity interface, additional flattening passes are recommended after any of the initial five passes if the plate cannot be fed using the prescribed rotational sequence or exhibits a curvature greater than $\sim 1$ in.

The dimensions of the plate during rolling were consistent and agreed with calculated values for the volume of the billet. The width of the plate during the cross rolling must be monitored very closely, and it may be necessary to eliminate one of the cross passes if the plate's width exceeds $\sim 18.5 \mathrm{in}$. during cross rolling. In the later passes, the thickness of the plate must also be monitored carefully and the rolling schedule must be adjusted to achieve a plate within the top range of the specified final thickness. Monitoring of the dimensions of the plate during rolling provides a process control check on the overall rolling process. During rolling, the outline of the core area is apparent and the interfaces of the core area should also be monitored. A carpenter's framing square can be used to measure the skewness of the core section.

\subsubsection{Anneal and flatten}

After completion of the rolling process, the plate is returned to the furnace that was used for rolling and annealed for $1 \mathrm{~h}$ at $500^{\circ} \mathrm{C}$, primarily to enhance the visibility of any blisters that may be present. After $1 \mathrm{~h}$ the plate is removed and placed on a table covered with an aluminum 
surface, and while still hot, the plate is flattened by pressing on the high areas manually. When a plate is at an elevated temperature, it is relatively ductile and can be flattened relatively easily. In previous campaigns, a roller fulcrum-type device was used after the plate had cooled to straighten the plate, but we found the use of the hand-flattening technique made it much easier to obtain the 3/4-in. flatness required for X-ray inspection. Some type of clamping fixture for flattening should be considered in the future.

\subsubsection{Shear to size}

After inspection, the plate is cut to $74 \pm 1 / 8$ in. long by shearing the ends. To provide equal margins on both ends, the amount to be sheared is established for each plate from radiographs. Measurements should also be made from the core outline that is visible on the plate surfaces as a secondary check. Cutting the plate to 74 in. is required for subsequent sizing operations.

\subsubsection{Weld repair of blisters}

During the last campaign, it was necessary to repair some blisters outside the core area to salvage three plates. Repairing of blisters had not been required in past campaigns, so this work required the development of a special weld repair procedure. This procedure requires that the blister and the immediate area around the blister at least $1 / 8$ in. greater than the blister be removed and replaced with 4043 aluminum weld filler metal. For weld preparation, a milling device was used to prepare a flat-bottom cavity about 0.030 in. deep with tapered sides. After welding, the milling device was also used to remove excess weld metal to reestablish the plate contour. A standard aluminum welding gas tungsten arc procedure (ORNL Welding Procedure Specification WPS1000-ASME-1) using a filler metal was employed. ${ }^{5}$ Metallographic samples prepared of test welds showed that a sound weld could be made on the control plates without evidence of cracks or debonding of clad. Some slight bulging of the plate on the side opposite the weld repair was present that required the removal of some metal to reestablish the thickness requirement. After repairing, all welds were checked by dye-penetrant inspection for cracks.

\subsubsection{Nondestructive Inspection of Finished Rolled Plate}

Nondestructive inspection of a finished rolled plate consists of a visual inspection to determine if there are any surface defects; measurements of thickness and overall length; ultrasonic inspection of the core area for cladding bond integrity; and radiography to determine the core dimensions, location, and the internal features of the core section.

\subsubsection{Visual inspection}

After cooling, the plate is visually inspected for blisters, inclusions, scratches, and dents. Any blisters on the plate and other surface defects over 0.003 in. deep are noted. The area over the core section containing the europium oxide is the most sensitive area because of the reactivity of the europium oxide with water, and any significant surface defect in this area will likely result in 
rejection of the plate. Blisters along the billet weld zones are relatively common and, because this area will be cut from the plate during fabrication, are of little concern. Blisters on the plate outside the core area that will not be cut off during subsequent fabrication are a concern and likely are indicative of cleaning problems during billet preparation. During the last campaign, several blisters outside the core area were present. and were repaired by welding.

\subsubsection{Dimensions}

The thickness over and around the core section is measured in 20 places with micrometers to within 0.001 in. Typically the thickness over the tantalum core section is several mils thicker than in other areas of the plate. A thickness range of 0.003 to $0.005 \mathrm{in}$. is normal. During the last campaign, the length of the as-rolled plates was in the range of 76 to 78 in.

\subsubsection{Ultrasonic inspection}

All control plates are subject to ultrasonic inspection of the area around the core sections (core section plus 6-in. margins) using 3/4-in.-diam water-coupled transducers collimated to $1 / 8$-in. diameter. The test is calibrated using a europium core portion of a control plate (HC-79-12) that has been drilled with 1/8-in.- and 1/16 in.-diam flat-bottom holes as defects. A plate is acceptable if the signal loss is less than the loss obtained from the 1/8-in.-diam calibration holes. Some signal losses are present in all plates at the core-to-frame and europium-to-tantalum core interfaces. These signal losses are considered normal and are not a reason for rejection.

\subsubsection{Radiography}

Radiography is performed a number of times during the course of fabricating a control plate. The initial radiography is set up to maximize the visibility of the core outline to determine the dimensions and the location of the core in the plate. Tungsten or tantalum wires are attached to the approximate centerline of a plate and a europium core section before $\mathrm{x}$-raying to provide orientation references. The core dimensions are measured either directly from the X-ray film or by transferring the X-ray image to a transparent sheet, if multiple X-ray film sheets are required. In the radiographs, the outline of the compact stacks is readily apparent as straight, low-density lines because the edges in the compacts are aluminum rich. At the prescribed X-ray film density for determining the core outline, the internal features of the europium section and the amount of overlap between the tantalum and europium and the core sections with the frame are also apparent. To examine the internal features of the tantalum section, additional radiographs are required because of the high X-ray density of the tantalum core.

\subsubsection{Core dimensional inspection}

Fig. 13 is an outline of a core section with the required dimensional tolerances for the outer plates. Table 4 shows the thickness and key core section dimensions from the last campaign. 


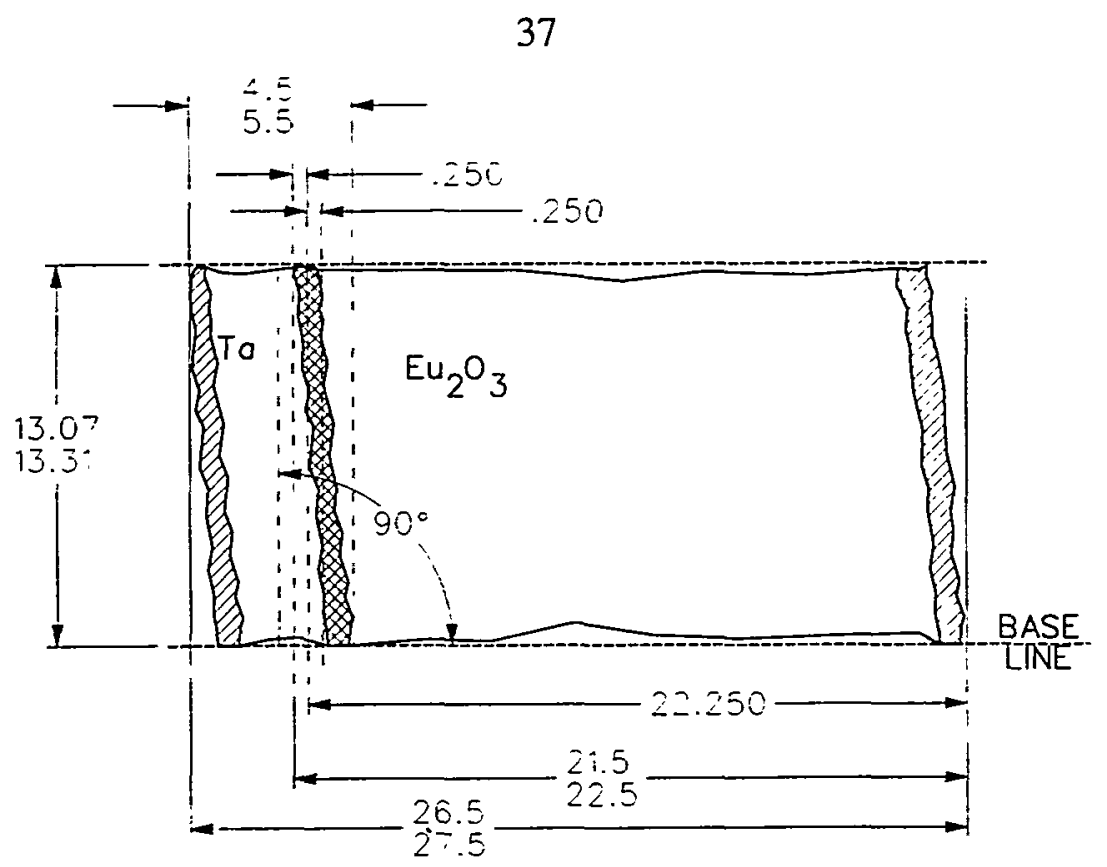

Fig. 13. Outline of core section with dimensional requirements (in inches) for outer plates.

Table 4. Plate thickness and key core dimensions in plates made for 0-93 campaign, in inches

\begin{tabular}{lccccc}
\hline & Specification & Average & Maximum & Minimum & Past extremes \\
\hline Thickness & & & & & \\
Maximum & 0.254 & 0.255 & 0.256 & & 0.256 \\
Minimum & 0.248 & 0.250 & & 0.249 & 0.247 \\
& & & & & \\
Core skewness & & & & & \\
Eu into Ta (max) & 0.250 & 0.182 & 0.475 & 0.050 & 0.595 \\
Eu into Ta (min) & 0.250 & 0.214 & 0.500 & 0.050 & 0.440 \\
& & & & & \\
Core width & $13.07-13.31$ & 13.139 & 13.250 & 13.063 & 13.260 \\
& & & & & \\
Core length & & & & & \\
Overall & $26.5-27.5$ & 27.044 & 27.625 & 26.310 & 27.840 \\
Eu length (ref) & 22.25 max & 22.098 & 23.125 & 21.375 & \\
Eu length (max) & $21.5-22.5$ & 22.312 & 23.523 & 21.475 & \\
Ta length (max) & $4.5-5.5$ & 5.507 & 6.050 & 4.950 & 6.030 \\
Ta length (avg) & $4.5-5.5$ & 5.108 & 5.569 & 4.680 & \\
\hline
\end{tabular}


Table 4 illustrates the variations in thickness and core dimensions that are likely to be encountered in as-rolled plates. The plates were purposely rolled to the high side of the thickness tolerance because metal will be removed from the surfaces during subsequent cleaning steps. The extreme skewness in two plates is the principal reason that several of the core dimensions are outside the specified ranges and illustrates the importance of reducing the skew during rolling. The core dimensions achieved in the last campaign were typical of dimensions achieved in past campaigns. The extremes of some dimensions measured in some past campaigns are provided for a comparison.

\subsubsection{Destructive Evaluations}

During the last campaign, one plate was destructively examined to evaluate the bonding of the cladding aluminum to the frame aluminum, the dispersion of the poison materials in the core section, the low-density regions from radiography, and the cladding thickness variations over the core section. Destructive evaluations were not routinely performed during past control plate campaigns, and few historical data were available for comparative purposes. A plate (HC-66) made during a past campaign with companion plates that have performed satisfactorily in HFIR was used as the primary reference for comparison. In addition, strips for each plate sheared during the final sizing of the flat plates were evaluated for the bonding of the cladding by a bendfracture test.

\subsubsection{Sectioning}

The core was sectioned longitudinally in the middle of the plate, and one side was polished for clad thickness measurements. From the other side of the plate, 0.75 - by 0.75 -in. metallographic samples were taken that represent the following: (1) the tantalum core, (2) the tantalum-europium interface, (3) the europium core, (4) the tantalum frame longitudinal and transverse interfaces, (5) the europium frame longitudinal and transverse interfaces, (6) the radiographic line indication in the europium core $1.5 \mathrm{in}$. from the frame, and (7) the radiographic line indications in the europium core at the midpoint where compact stacking interfaces were observed. The samples were mounted so that both sides of the cladding and the core could be observed.

\subsubsection{Clad thickness measurements}

The clad thickness was measured on each side of the polished longitudinal section using a 10X optical comparator eyepiece in 1-in. intervals and at each interface, and the minimum reading was recorded to $0.001 \mathrm{in}$. The results of this analysis showed the minimum clad thickness of $0.023 \mathrm{in}$. compared to a nominal clad thickness of 0.0285 in. The spot minimum clad thickness was also determined by examining the various metallographic sections. Using this technique, the minimum spot or micro clad thickness was determined to be 0.020 in., which was identical to similar measurements for samples from the HC-66 comparative plate. The minimum clad thickness occurred at the frame-europium core section interface and at the tantalum-europium core section interfaces. Typically, in the rolling of plates some clad thinning or "dog boning" is expected at the interfaces when the core is harder than the frame and the cover materials. 


\subsubsection{Aluminum bonding at interfaces}

The assessment of the aluminum bonding was made by a microstructural evaluation of electrolytically etched surfaces under polarized light in each of the frame-to-core interface samples. Grain growth across the interfaces is indicative of "metallurgical bonding" and is very important to the performance of a roll-bonded plate. In this evaluation, the amount of grain growth observed was difficult to quantify because, in some areas, the grain structure across the interfaces could not be readily observed. If these uncertain areas were considered as not having any grain growth across the interface, then the grain growth across the interface would be $30-40 \%$. If the questionable areas were considered as grain growth areas, then the amount of growth across the interface would be $50-80 \%$. There was no significant difference in the amount of grain growth across the interfaces observed in the plate from the current campaign and from the comparative plate. The specified criteria for grain growth in HFIR fuel plates is $>50 \%$ but is based on plates that have received $20 \%$ cold work and a longer annealing time. The cold work tends to disrupt both the interfaces and the oxide film present to promote grain growth. Because no cold work is specified in the control plate process, the difference between the values observed compared to the HFIR fuel plate grain growth specification is likely the absence of cold work in the control plates.

As an additional evaluation of aluminum bonding, a bend-fracture test was performed on longitudinal and transverse sheared strips from the aluminum portion of the sample plate and strips were cut from the ends of each plate during sizing to length. In this test, a 1 1/2-in.-wide strip specimen is placed in a vise and bent back and forth until the specimen fractures and the fracture surfaces are examined. Several back-and-forth actions are usually required to fracture the strip. The bend test has been found to be a good method of assessing bonding and has been used for a number of years in fuel plate fabrication. If poor bonding is present, defoliation will be evident in the fracture surface. The evaluation of all strips was positive for good bonding.

\subsubsection{Tantalum/aluminum distribution}

The purpose of this evaluation was to ensure that tantalum is not present in a continuous phase, and the evaluation was based on a direct comparison of metallographic sections and the fracture surfaces of the HC-66 plate with the current campaign plate. The metallographic comparison of the tantalum in the 0-93-1 plate with the tantalum in the HC-66 showed that the tantalum in both plates was very similar, and there was no evidence of stringering or breakup of the tantalum particles in the aluminum matrix. The fracture test consisted of cutting a 1-in.-wide strip from the tantalum section in each plate, breaking the strip, and comparing fracture surfaces. This test was based on the distinct difference observed in the fracture surfaces of the "good" plate, which was bright and shiny, and the "bad" plate, which was dull in the evaluation of the failed 1976 plates. The fracture surface of plate 0-93-1 appeared bright and shiny and had a similar appearance to the fracture observed in the $\mathrm{HC}-66$ plate. 


\subsubsection{Microstructural features}

A typical microstructure of tantalum and $\mathrm{Eu}_{2} \mathrm{O}_{3}$ particles in the aluminum matrix in HFIR control plates is shown in Fig. 14. The microstructure at the tantalum-to-europium interfaces and the tantalum-to-frame interfaces is shown in Fig. 15. The overlapping of the materials at the interfaces and some clad thinning over the tantalum section are shown in Fig. 15. Judging from radiographs, the amount of overlapping varies between plates, and the sections shown in the figure are toward the high side of the amount of overlap in a typical control plate. In other cross-section samples examined, the core components at the frame edges were almost at a right angle with little or no overlap. The examination of sections through low X-ray density areas showed no discernable cracks. One sample from an area where the radiograph indicated a crack in the europium core showed a slight clad thickening in the area of the defect, but the core dispersion was typical of other sections examined. Apparently the crack healed during the rolling process because no cracks or other defects were noted in the section.

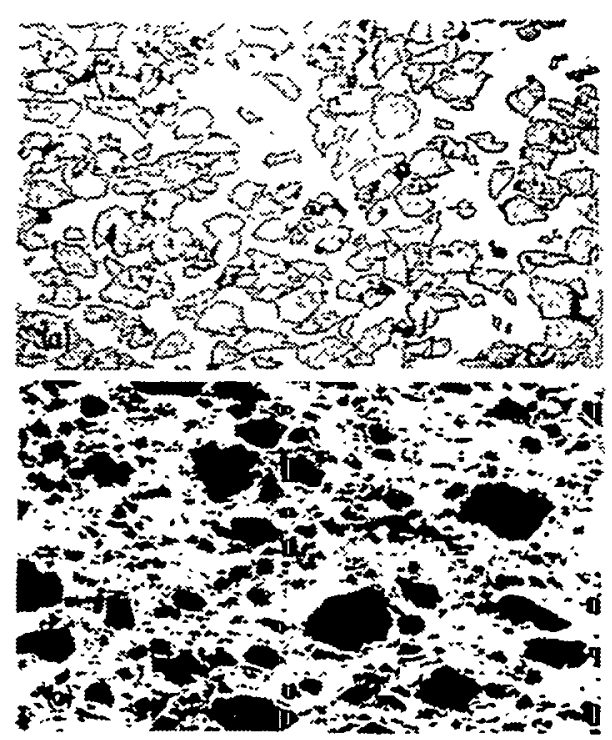

Fig. 14. Typical microstructure of tantalum (top) and $\mathrm{Eu}_{2} \mathrm{O}_{3}$ (bottom) in the aluminum matrix. Magnification $\sim \mathbf{5 0 x}$.

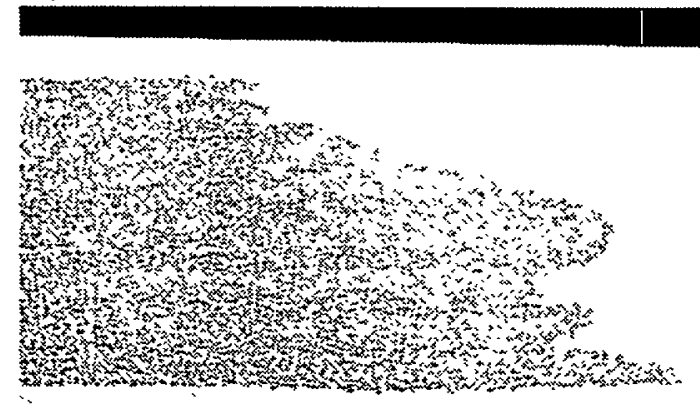

Fig. 15. Microstructural features of the tantalum-to-aluminum interface (left) and the tantalum-to-Eu $\mathrm{E}_{2} \mathrm{O}_{3}$ interface (right). Magnification $\sim 6 \times$. 


\subsection{FABRICATION OF CURVED PLATES}

The detailed flowsheet for the fabrication of curved plates for the HFIR control rods is presented in Fig. 16. This operation has been done in the past at the $\mathrm{Y}-12$ Plant using various processing and inspection facilities and the large machine shop located in Building 9201-1 (Alpha 1). The 9201-1 machine shop and inspection facilities were available during the last campaign, but facilities used previously for cleaning, annealing, radiography, and explosive forming were unavailable because of the Y-12 Plant stand-down. Alternate processes and facilities were developed and qualified to work around these unavailable facilities. The annealing and cleaning operations were accomplished by changing the procedures and using other existing facilities at the Y-12 Plant. The radiography was done at ORNL. The explosive-sizing operation was contracted to an outside vendor. A list of the detailed operating procedures used in the last campaign is given in Appendix A. Several of these procedures were extensively modified to accommodate the process changes and to provide a better definition of the process requirements.

\subsubsection{Flatten and Anneal}

The flattening and programmed " 0 " temper anneal operation was accomplished in a single furnace run for each plate. The purpose of the flattening and annealing step is to provide a flat plate in as soft a state as possible for press-brake forming. The flattening is accomplished by high-temperature creep from weights placed on the plate and by heating the plate to $500^{\circ} \mathrm{C}$. Annealing a 6061 aluminum plate to a soft state or " 0 " temper requires that the plate be heated to above the solution temperature of $>415^{\circ} \mathrm{C}$ and then cooled at $<30^{\circ} \mathrm{C} / \mathrm{h}$ until the temperature of the plate is $<260^{\circ} \mathrm{C}$ (ref.: Metals Handbook Ninth Edition, Volume 2, "Properties and Selection of Nonferrous Alloys and Pure Metals," p. 29).

Furnaces with handling equipment needed for placing and removing relatively large weights on the control plates for required flattening are very limited both within the Oak Ridge complex and commercially. A movable-hearth electrical-resistance heated furnace with an associated monorail crane, located in Building 9738 at the Y-12 Plant, was qualified and used for this operation during the last campaign. A front view of the furnace with a plate setup with flattening weights and thermocouples on the movable hearth is shown in Fig. 17. The setup of the weight stack for flattening is important and required some development during the last campaign. During cold runs, sticking and scratches on plates were observed when attempts were made to duplicate the stackup used during the previous campaign. These problems were the result of the differential thermal expansion of thin, stainless steel sheets that were used next to the plate. These sheets were replaced with thin aluminum sheets and, as a secondary precaution, a thin coating of talcum powder was applied to the plate before stacking. The stack for flattening consists of the following: 2 -in.-thick aluminum plate, $\sim 0.030$-in. aluminum sheet, control plate, $\sim 0.030$-in. aluminum sheet, 2-in.-thick aluminum plate, 3-in. stainless steel plates, and 3-in.-thick steel plates. Thermocouples are placed directly on the plate in several locations for monitoring and controlling the temperature. An additional stack of 3-in.-thick steel plates was added during the last campaign to increase the flattening load. 


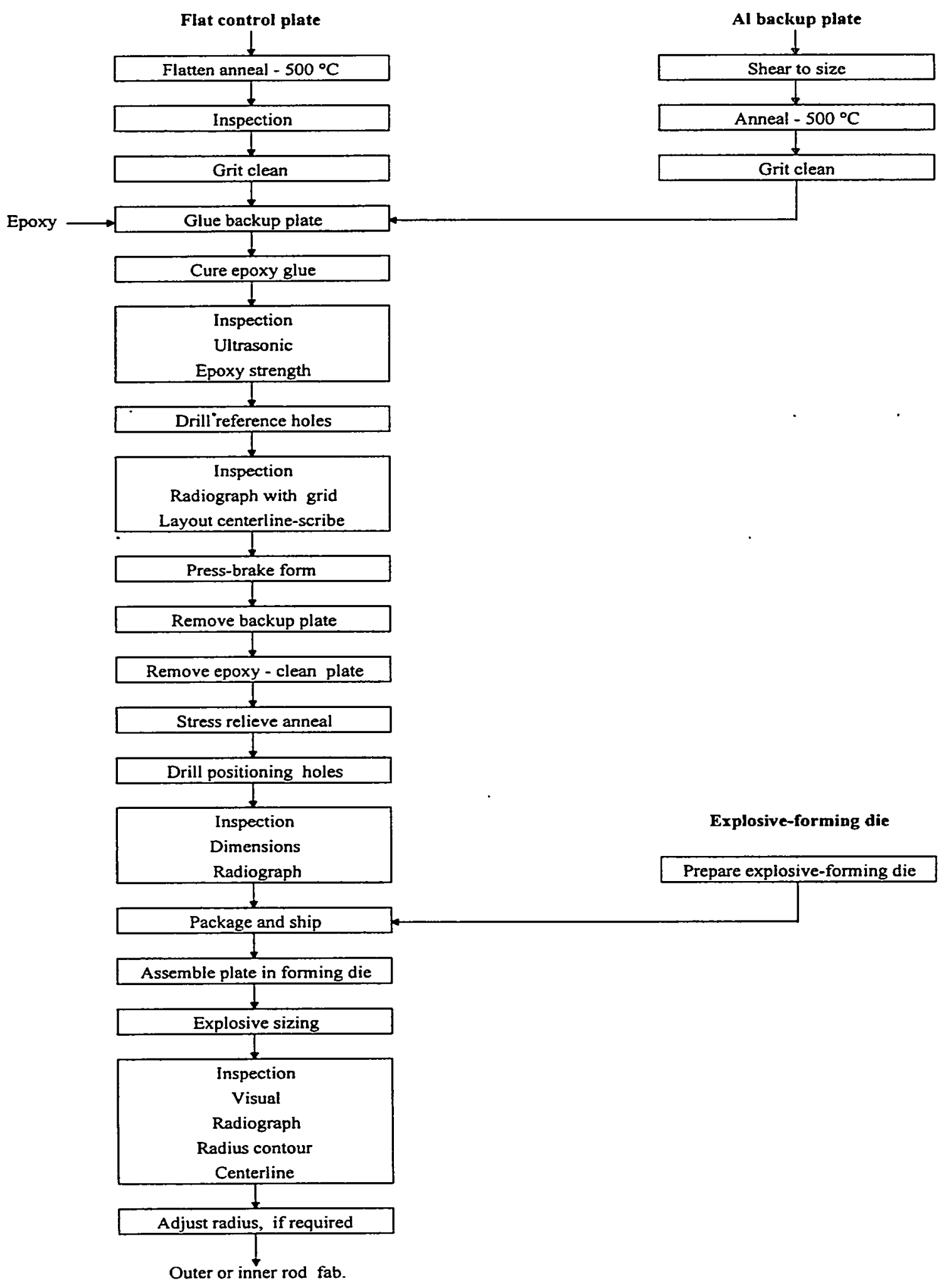

Fig. 16. Flowsheet for formation of curved plates. 


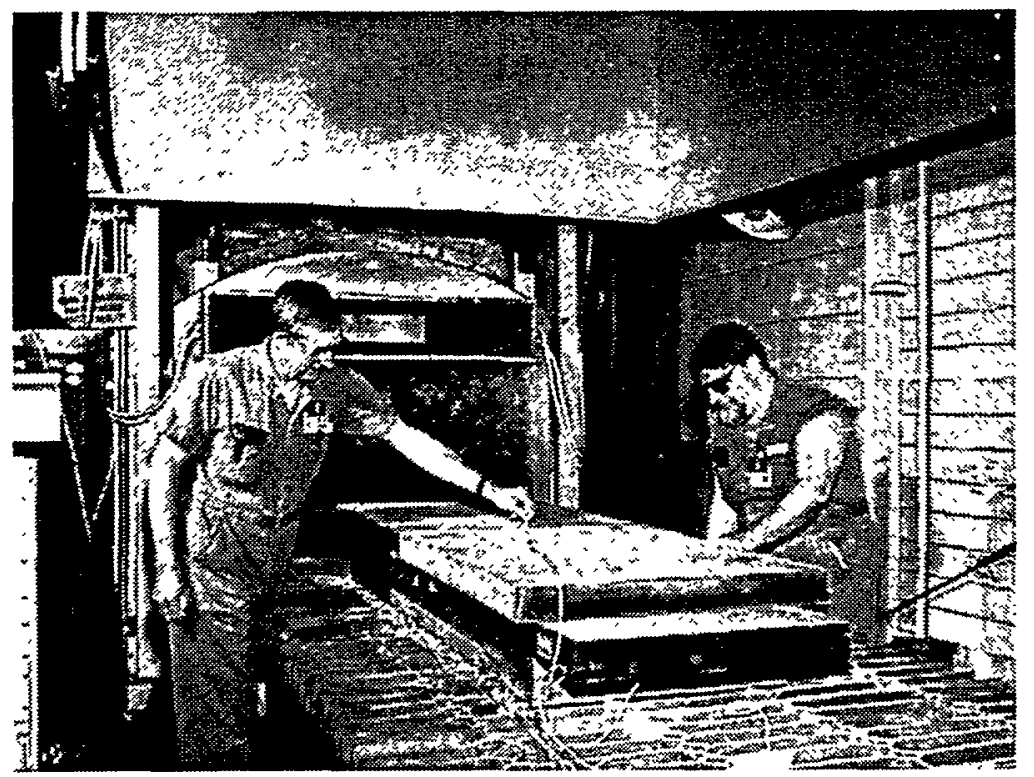

Fig. 17. A movable-hearth electrical-resistance-heated furnace with monorail crane.

The average pressure over the surface area of the plate is relatively small, on the order of $3 \mathrm{psi}$ with the approximately $4500-\mathrm{lb}$ load. One plate is flattened and annealed during a run that achieves a maximum temperature of $500^{\circ} \mathrm{C}$ and is held at that temperature for a minimum of $2 \mathrm{~h}$. The thermal mass of the stack took $\sim 16$ hours to reach that temperature and cooled in the closed furnace without power at $<30^{\circ} \mathrm{C} / \mathrm{h}$. In general, the flattening process produces plates that are flat within $\sim 1 / 16$ in., but plates having areas with a small radius of contour or kinks could not be completely flattened even with multiple runs. These kinks were subsequently removed during the course of contour forming, and no significant problem resulted. In previous campaigns, unsuccessful attempts were made to flatten several plates in a stack during a run. After annealing, each plate is visually inspected for surface defects, and any surface defect $>0.003$ in. deep is noted on the inspection report. The annealing of the backup plate was accomplished in the furnace used for flattening by employing the programmed annealing cycle. A clamp-type flattening fixture should be considered in future campaigns. A clamping fixture was recently used successfully to flatten small plates for an irradiation test.

\subsubsection{Grit Cleaning}

In the previous campaign, the control plates have been acid cleaned between most processing steps. Because of the unavailability of acid-cleaning facilities at the Y-12 Plant and the sticking problems in flattening, the acid-cleaning steps were eliminated and replaced with a single gritcleaning operation just prior to glue bonding a control plate to a backup plate. Other than cleaning the plates for glue bonding, the main purpose of acid cleaning between the processing steps was to increase the visibility of scratches that may have been introduced during processing; there was actually no overriding technical justification for acid cleaning. 
The grit-cleaning operation was developed and qualified by comparing the lap shear bond strength of the samples cleaned to the acid-leaching process used in previous campaigns with grit cleaning. The fixture used to prepare samples for comparison testing and later used as a quality control check on bond strength is shown in Fig. 18. The lap shear tests for $\sim 1$-in. ${ }^{2}$ bonding areas showed lap shear strength of $\sim 1500-2000$ psi and no significant difference in bond strength between samples cleaned by either the acidleaching or the grit-cleaning operation. The test is somewhat dependent upon sample preparation technique, and some of the data differences observed were the result of sample preparation.

The grit cleaning is accomplished using a commercial, portable grit blaster equipped with a hand-operated blasting and grit pickup head. The grit used was -120-mesh aluminum oxide grit blasting media. The aluminum oxide grit was specified to limit the surface to a material similar to that which is naturally present on the aluminum metal plates. The

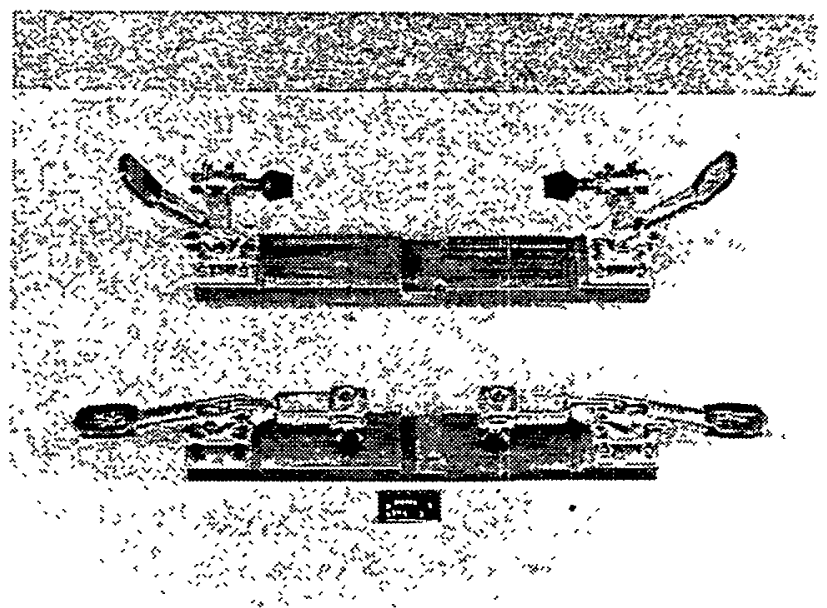

Fig. 18. Fixture used to prepare samples for comparison testing and for performing quality control check on bond strength. blaster cleans an area $\sim 1 / 2$ in: to $3 / 4$ in. wide and requires several hours to clean a plate. The grit cleaning removes a very small thickness of metal from the plates that were measured to $<0.001$ in. The backup plate is also cleaned by grit blasting. Only the sides to be bonded are grit cleaned. After grit cleaning, the plates are wiped with isopropyl alcohol to remove residual dust.

\subsubsection{Glue Bonding of Backup Plate}

The glue used for bonding control plates to the backup plates is a two-part commercial, generalpurpose epoxy adhesive sold as Armstrong A-12 and available through Morton International Specialty Chemical Group. The mix used for bonding is specially formulated to provide a flexible bond and consists of one part of Part A by weight to two parts of Part B by weight. It is important to homogenize each component in its container by thoroughly mixing before dispensing the epoxy parts for a glue batch. An adhesive failure occurred during the preforming operation of one of the plates in the last campaign when the container contents were not homogenized. The adhesive failure did not affect the integrity of the plate being preformed. The components for a glue batch for a single plate are weighed out and thoroughly mixed by hand in a plastic container immediately before using. Care should be exercised to avoid scraping pieces from the mixing container into the epoxy mix. The gluing and curing operations are accomplished in a area that is $>65^{\circ} \mathrm{F}$. 
The 3/8-in.-thick aluminum backup plate is sheared to a size that allows about a 2 -in. margin around the control plate. In the preparation of the backup plates for gluing, the area that will be outside the area of the control plate is masked with tape to identify the area where glue is to be applied. A thin, uniform layer of glue $(-1 / 32$ in. thick) is applied with special Teflon scapulars to both the control plate and the backup plate. A thin glue coating is desirable to avoid excessive run-out of the glue during clamping, but a liberal glue coating is required to obtain good bonding. After application of the glue, the glue surfaces are laid together and clamped using 4-in. by 4-in. wooden pieces and 1/2-in.-diam steel bolts through the ends of the wooden pieces. The wooden clamping pieces are laid adjacent to each other over the entire length of the plate to be bonded. The tightening sequence for clamping is to begin in the middle and work toward the ends sequentially. The $1 / 2$-in. clamp bolts are tightened to a 100 -in.-lb. torque to provide a clamping pressure calculated to be $\sim 25-35$ psi averaged over the surface area of the plate. After clamping, excess glue should be present around all the edges of the control plate. Two bond-strength test strips are prepared with the epoxy mix used for each plate during the gluing operation.

The curing of the epoxy is accomplished over $72 \mathrm{~h}$ with the clamps in place for the first $48 \mathrm{~h}$. Previous campaigns have used ovens for curing at elevated temperatures, but the roomtemperature cure has been used in the last several campaigns and has provided good bonding without the use of additional equipment.

\subsubsection{Inspection}

\subsubsection{Ultrasonic inspection}

After curing, the bond uniformity is evaluated from the backup plate side using a hand-held ultrasonic probe. The probe is coupled to the plate with glycerin and is traversed over the entire bonded area. The area over the core cannot be evaluated with the ultrasonic probe because of interference from the europium and tantalum particles in the core. Indication outside the core of an unbonded area $>1 / 4$ in. ${ }^{2}$ is cause for rejection. Two plates bonded during the last campaign had indications of long, narrow nonbonded areas perpendicular to the long axis of the plate that appeared to correlate with "kinked" areas on the plate that could not be completely flattened. Apparently the kinks caused the glue to be extruded from these areas during clamping. The glue bonds for these two plates were accepted by deviation and were preformed satisfactorily.

\subsubsection{Bond strength}

The lap shear samples are tested on a tensile testing machine, and tensile strength at failure is recorded. During the last campaign, one of the first plates processed debonded during press-brake forming, necessitating implementation of the bond strength test as a routine requirement. In this plate, low strength in the epoxy caused the glue bond to fail in the adhesive layer, rather than at an interface. The low strength in the epoxy was likely the result of not mixing the components before they were dispensed. A minimum bond strength of 1000 psi was established to account for some sample variations. Typically, a shear strength of $\sim 2000 \mathrm{psi}$ should be achieved in this test. 


\subsubsection{Radiography}

During the last campaign, radiography was performed at the ORNL radiography facility using a $300-\mathrm{kV} \mathrm{X}$-ray source instead of the $1-\mathrm{MeV}$ source used in past campaigns and at a 75 -in. sourceto-object distance instead of the 100-in. distance used in the past. The use of the different X-ray facility required some development and a rewrite of the radiography procedures. ${ }^{6}$ The difference in resolution between the original Y-12 Plant procedure and the new procedure was insignificant. At this stage in manufacture, establishment of the centerline of the core section is extremely important, particularly for the outer plates because of the small edge margins (1/8-in. minimum) in the finished machined plates. The longitudinal location of the core and the black/gray interface datum are established using a grid positioned on the plate before $\mathrm{x}$-raying. The grid is a $1 / 4$-in.thick plastic sheet with high-density 0.010 -in.-diam wires glued into accurately located machined slots and with locating pins for positioning in holes drilled in the plate. At this stage in manufacture, the longitudinal location of the core is preformed mainly to verify the previous radiographic analysis and to establish a reference for radiography in other manufacturing stages.

\subsubsection{Drill Reference Holes}

After bonding, a series of holes for radiography references are drilled into the plates in areas that will be removed during final machining operations. A plate setup for drilling the reference holes on a horizontal milling machine is illustrated in Fig. 19. The layout of the required machinedhole pattern is shown in Fig. 20. A different hole pattern is used for inner and outer plates to aid in the differentiation of the two plate types during manufacturing. The small holes along the edges are used to establish the centerline of the core and are used repeatedly during the course of manufacture. The large holes are used to position an X-ray grid on the flat plate, mainly to establish the location of the core and the gray/black interface datum along the length of the plate.

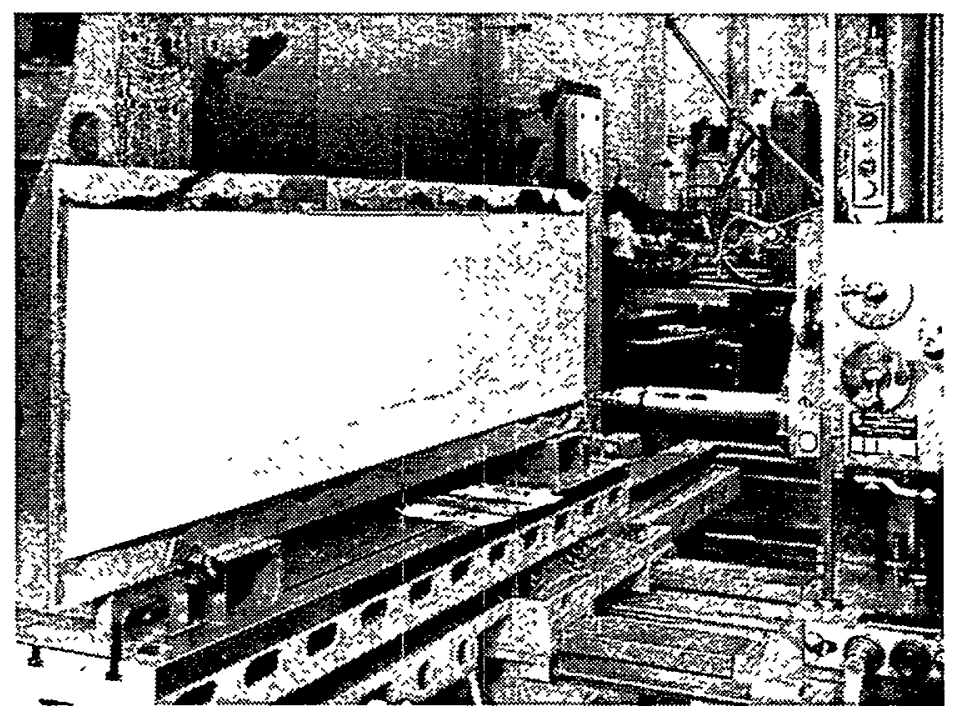

Fig. 19. Plate setup for drilling reference holes on a horizontal milling machine. 


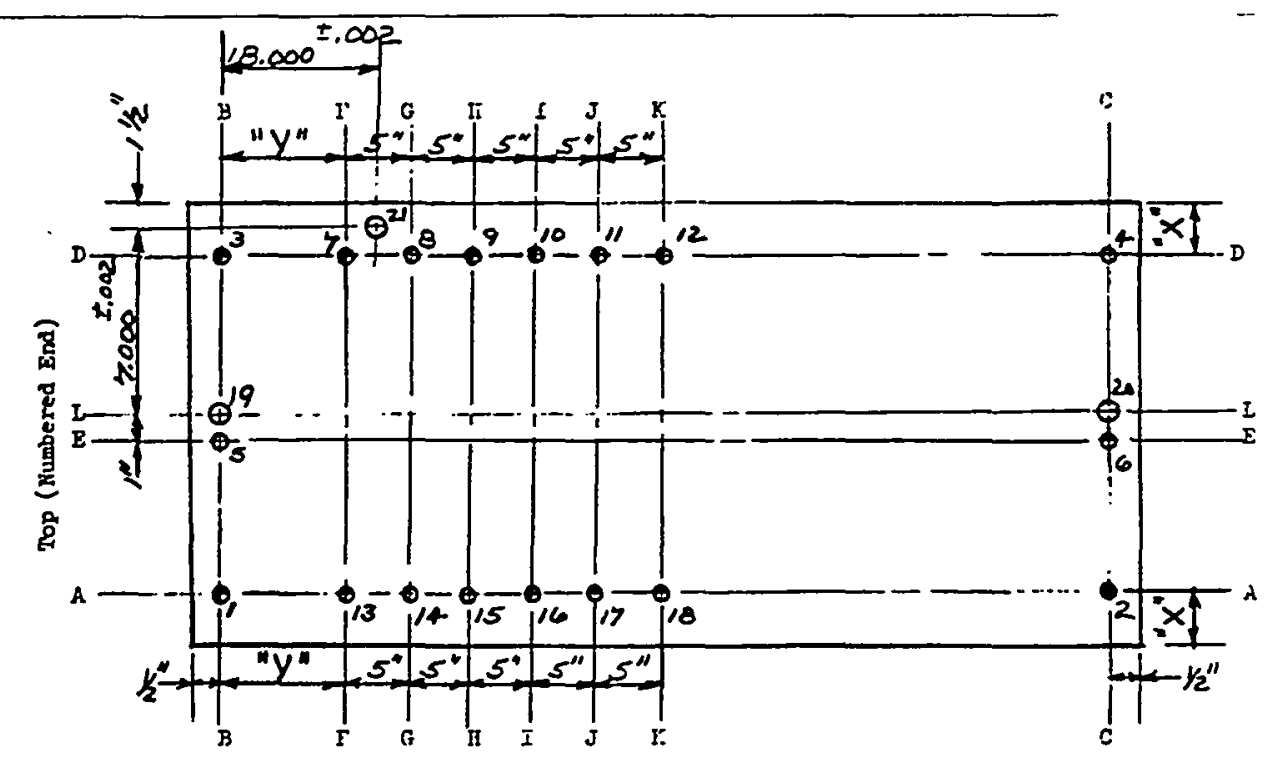

NOTES:

1. Calculate Dimension " $X$ ": Outer, " $X$ " $=\frac{W-17.5}{2}$ in.; Inner, " $X$ " $=\frac{W-15}{2}$ in., where $W$ is the average width of the control plate.

2. Dimension " $Y$ " $=12$ in. for the outer control plates.

3. Dimension "Y" $=17.5$ in. for the inner control plates.

4. Holes $1-18$ are $1 / 16$ in. in diameter and must go through the $1 / 4$-in. plate.

Holes 19-21 are drilled and reamed for a 0.250-in. dowel and must go through both the 1/4-in. plate and the backup plate.

5. Lines $A A, D D$, and $L L$ are parallel to each other. Lines $B B$ and $C C$ are parallel to each other and perpendicular to lines AA, DD, and LL.

Fig. 20. Layout of required machined-hole pattern.

\subsubsection{Lay Out Centerline}

The layout of the centerline is accomplished by the Y-12 Plant inspection department using the reference holes in the plates and the measured distances from the reference holes to core as determined from radiography. The plate is mounted on an inspection table, and gauge pins are used to position the longitudinal centerline of the core parallel to the surface of the table. The setup of a plate for marking the centerline and for scribing the inflection points for the pressbrake operation is illustrated in Fig. 21. One-inch-long lines that serve as positioning guides during the preforming operation are scribed on each end of a plate in 1/2-in. intervals starting from the centerline. 


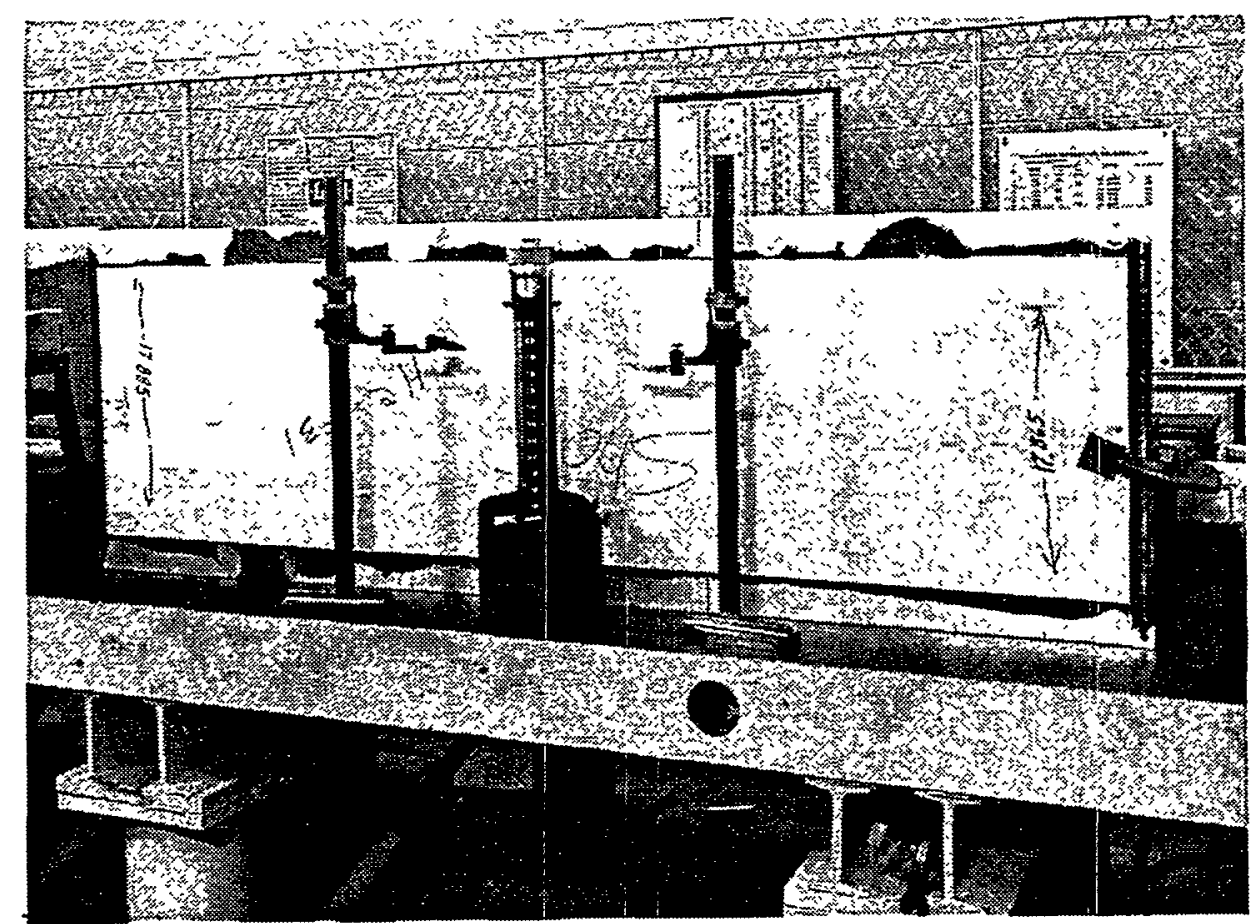

Fig. 21. Plate setup for marking centerline and for scribing inflection points for press-brake operation.

\subsubsection{Press-Brake Forming}

The preforming of the cylindrical shape of the control plates is accomplished in an incremental fashion using a conventional press brake and a rubber pad-type forming process. This process uses a metal punch attached to the ram having an 8-in. radius and a solid rubber striker pad die made from 75-durometer polyurethane rubber. Retractable pointers at each end of the punch are used to align the punch with the inflection points scribed on the control plates. To compensate for end deflection, a 3/16-in.-thick shim, 18 by 12 in., is placed under each end of the rubber pad. Additional shims may be required. The punch and die arrangement used to form control plates is shown in Fig. 22. This type of incremental forming operation was selected over single-step forming during the initial development phase to minimize the chances of breaking the cores during forming. The forming of a control plate is accomplished in 1-in. increments with a plate bent only slightly during each press adjustment $(0.025$-in. adjustment in press stroke). The plate is rotated $180^{\circ}$ between press adjustments, offset $1 / 2$ in., and the operation is then continued in 1 -in. increments. It takes 12 to $16 \mathrm{~h}$ to preform each plate. The appearance of a control plate during preforming is shown in Fig. 23, and a completely formed plate is shown in Fig. 24. 


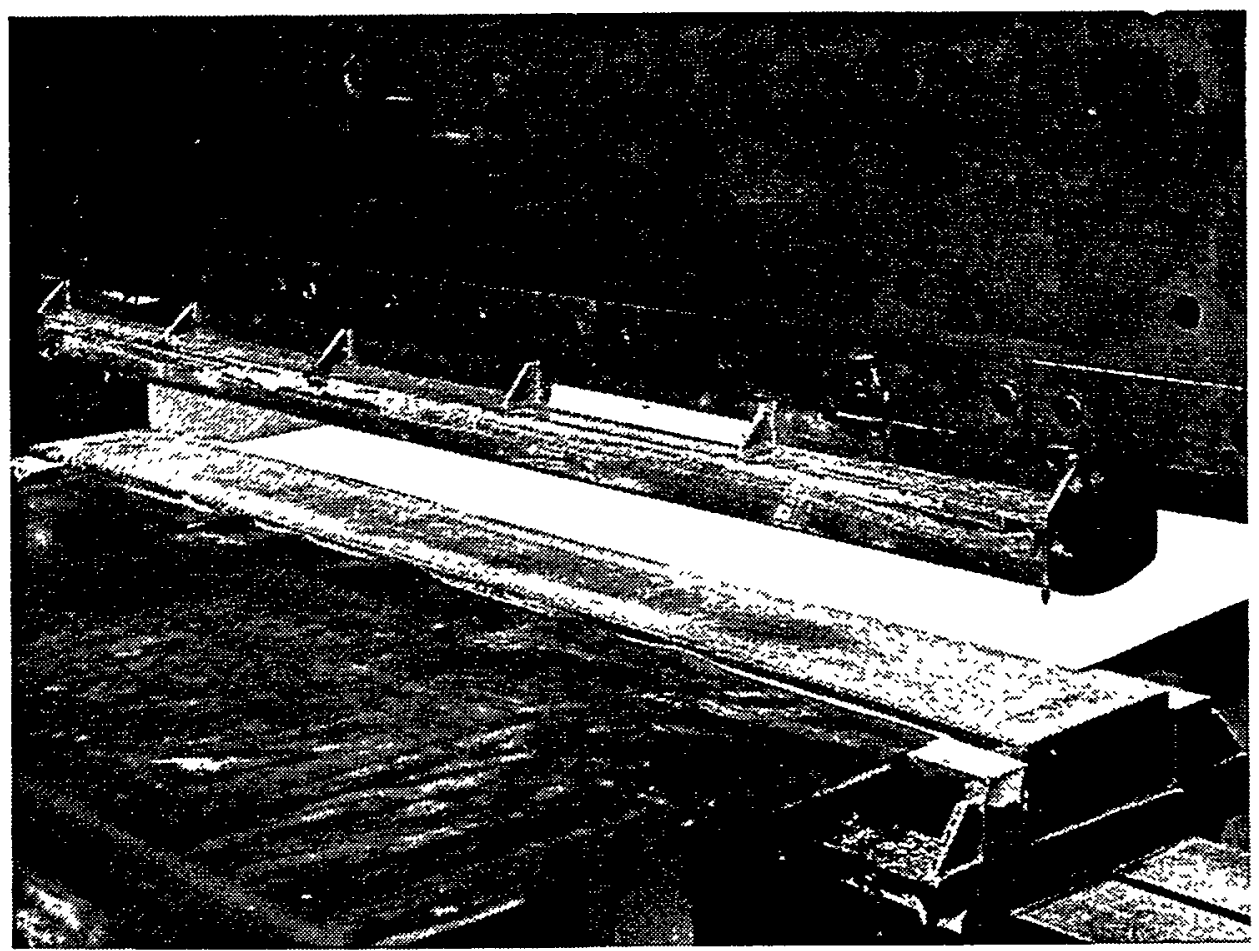

Fig. 22. Punch and die arrangement used to form control plates.

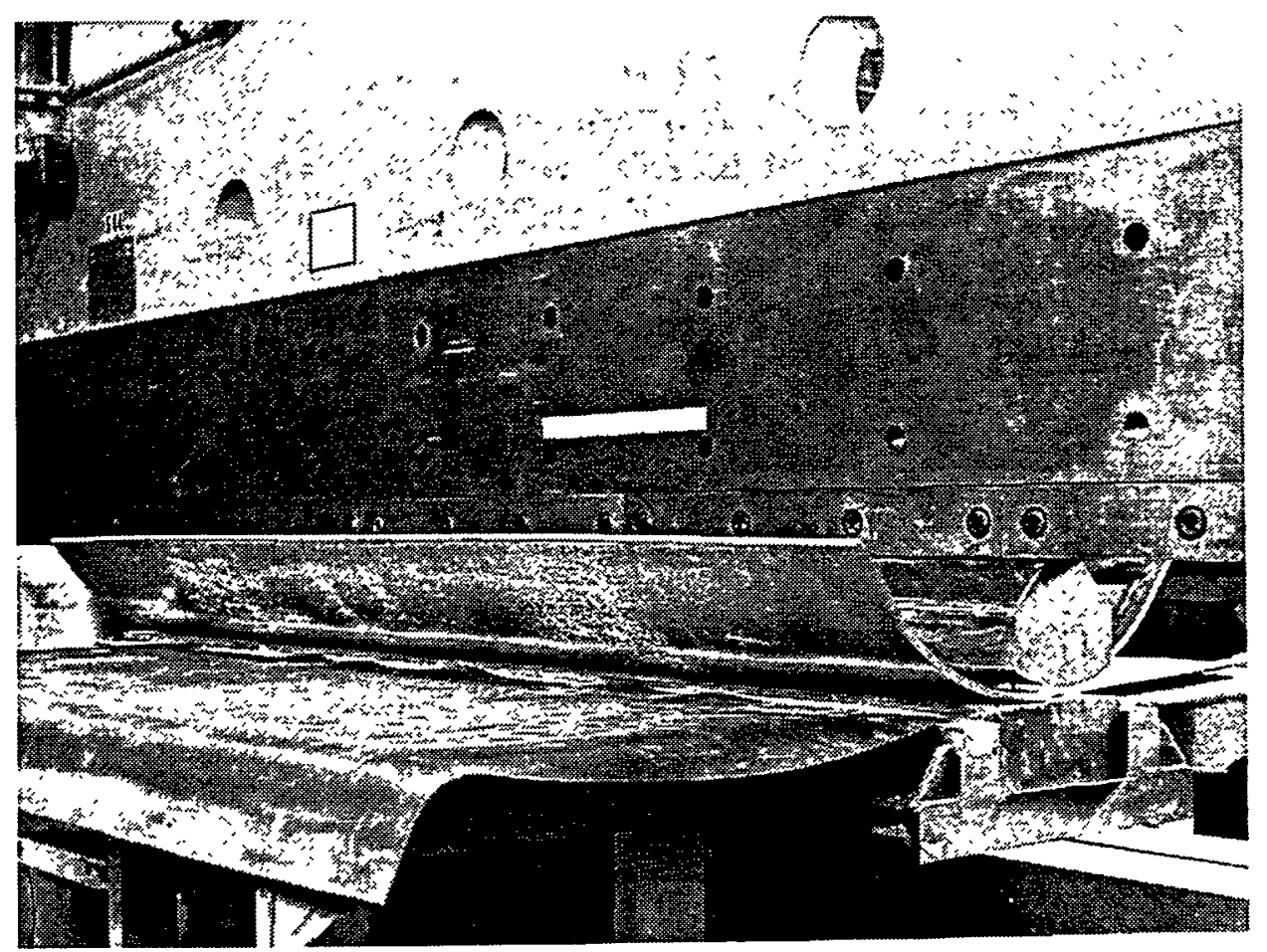

Fig. 23. Control plate during preforming operation. 
The required final preformed inside radius is $91 / 8 \pm 1 / 8 \mathrm{in}$. for the inner and $93 / 8 \pm 1 / 8 \mathrm{in}$. for the outer control plate. Because the control plate is in compression during forming, the radius will be $\sim 1 / 8$ to $1 / 4$ in. smaller after removing the backup plate. To compensate for this spring effect, the plates must be preformed to a greater radius with the backup plate attached. The plates are preformed to a radius needed for explosive sizing, which is $\sim 1 / 4$ to $3 / 8$ in. greater than the finished plate radius. For explosive sizing, the larger radius is important to minimize the "spring in" of the edges during

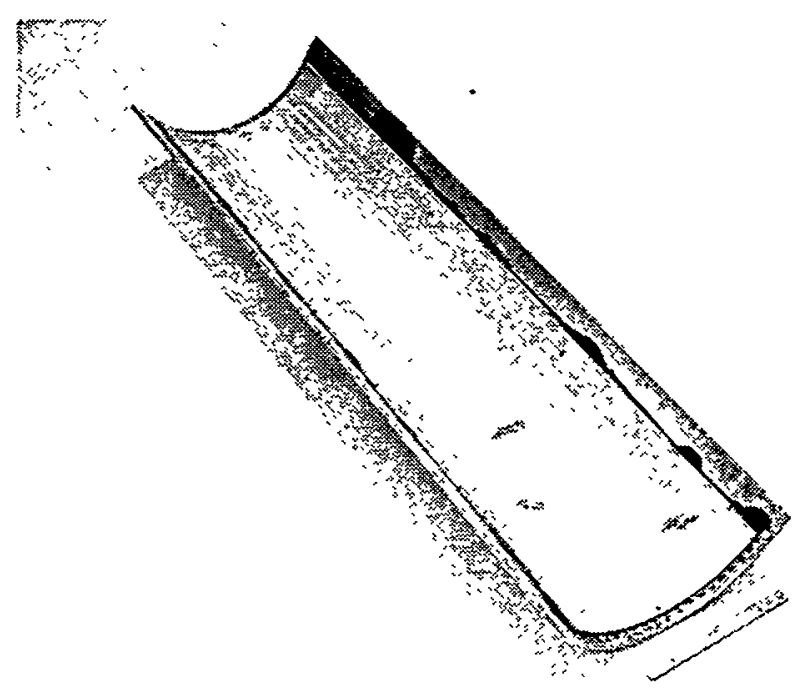

Fig. 24. Completed preformed control plate. explosive sizing. Some considerations have been given during several campaigns to eliminate explosive sizing and directly form the radius on the press brake. Plates with the correct radius have been formed on the press brake, but the ability to consistently achieve the correct radius without some bow along the centerline has not been demonstrated. For inner plates, it might be possible to eliminate the first explosive sizing operation, but for the outer plates, it is highly unlikely that the explosive sizing operation can be avoided.

\subsubsection{Remove Backup Plate}

After the control plate is preformed, the backup plate is removed and discarded. The backup plate is removed by heating the composite control backup plate from the control plate side to allow the epoxy to soften so that the control plate will release and fall away from the backup plate. Exposed calrod-type heaters in a special fixture are used to heat the composite. The heating unit and a control plate with a backup plate positioned on the heating unit for removal are shown in Figs. 25 and 26. A thermal blanket is placed over the plates and the heating unit during heating to reduce the thermal losses. The plate must be heated to $\sim 220^{\circ} \mathrm{C}$ for the epoxy to soften sufficiently for removal. A plate should release within $\sim 30 \mathrm{~min}$ after heat is applied with the fixture. During heating, the release can be hastened by using a screwdriver on the ends as a wedge to loosen the plate. Some difficulties were encountered in controlling the temperature of the heating unit during the last campaign because the epoxy on several plates charred during debonding. For the best results, a small thermocouple was placed in one of the radiography reference holes along the edge of a plate, and the temperature was controlled manually. 


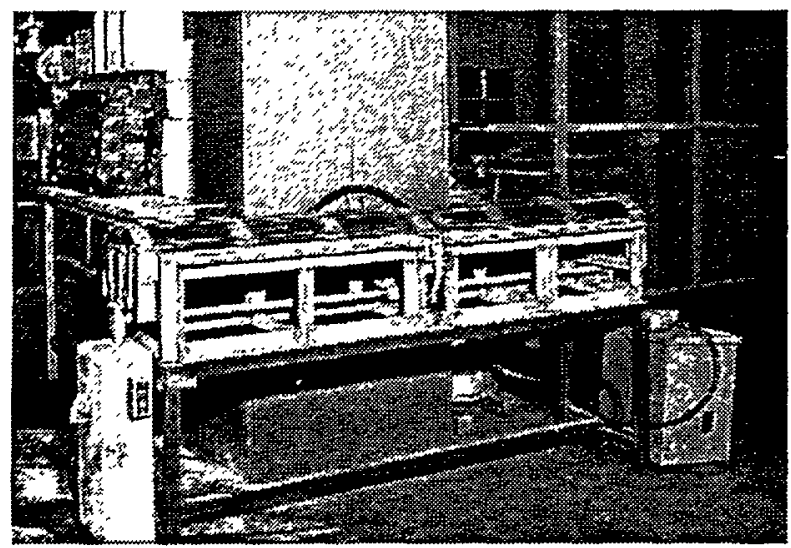

Fig. 25. Heating unit for removal of backup plate from control plate.

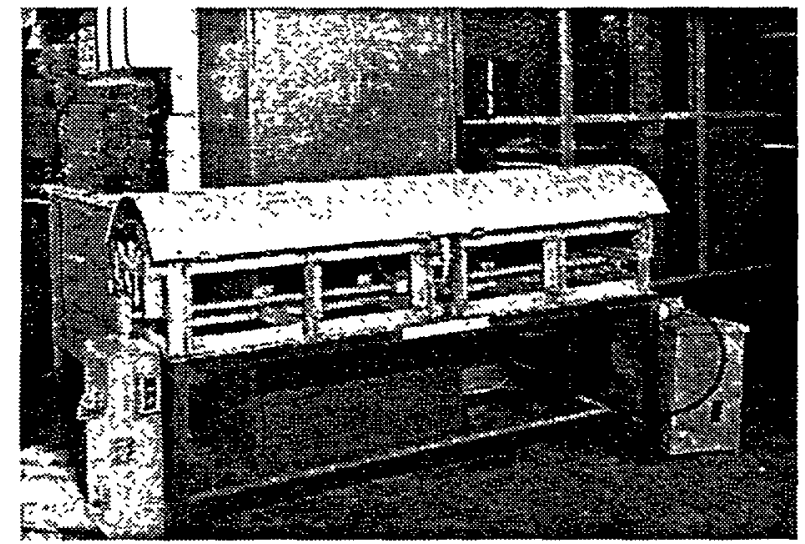

Fig. 26. Plate positioned on heating unit.

\subsubsection{Remove Epoxy and Clean}

After debonding, the control plate will have varying amounts of epoxy remaining after releasing from the backup plate. The methylene chloride solvent used in previous campaigns for epoxy removal could not be used at the Y-12 Plant because of environmental restrictions on its use. During the last campaign, the environmentally acceptable Peel Away-7 adhesive stripper was identified for use. The Peel Away-7 stripper is compatible with aluminum and is a paste-like material that is used in combination with covering paper (Peel Away paper). A relatively thick coating of stripper is applied to a plate, the stripper paper is placed on top, and the stripper is allowed to stand on the plate 15 to $20 \mathrm{~h}$. The softened epoxy is then removed with Teflon scrapers and cheesecloth soaked in alcohol. The stripper works effectively if the epoxy has not been charred. Charred epoxy and other residues not removed by the stripper are removed by light grit blasting after the plates are stress annealed. 


\subsubsection{Stress Anneal}

The plates are stress annealed at $412^{\circ} \mathrm{C}$ for $3 \mathrm{~h}$ to remove stresses introduced during the preforming operation. In this operation, each plate is annealed separately on a special support fixture (Fig. 27) using the same furnace used in the previous flattening and annealing step. Each plate is fitted with two thermocouples to monitor the temperature before it is placed in a preheated furnace. Aluminum foil is used between the fixture and the plate to avoid scratches from the differential expansion of the steel fixture and the aluminum plate. After heating for the prescribed time, the plate on the fixture is removed from the furnace and allowed to cool to room temperature.

During the initial development of the control plate processes, apparently some considerations were given to annealing a control plate after the explosive sizing operation. During forming, most of the stresses in a control plate are introduced during the preforming operation. An additional annealing step after explosive sizing would introduce distortions that would make it difficult to meet the required dimensions. For these reasons, the final stress relieve anneal is performed after the preforming operation.

\subsubsection{Positioning Holes}

Two holes are drilled in the end margins of each plate on

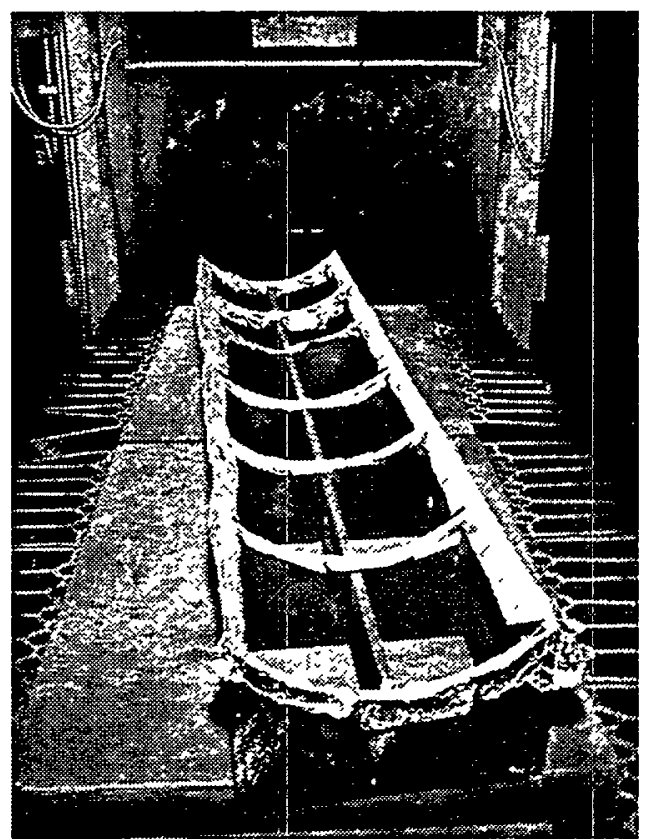

Fig. 27. Fixture used to support preformed control plate for stressrelieve annealing step. the centerline previously determined in the radiography analysis to orient the plate in the explosive-forming die. The hole at the top or cored end is round and 0.469 in. in diameter; the hole in the bottom end is a slot of the same diameter as the round hole but $0.750 \mathrm{in}$. long. These holes are drilled after preforming to avoid the distortions that would have occurred during preforming.

\subsubsection{Inspection}

The dimensional inspection of the plates after preforming consists of a verification of the correct radius for explosive sizing and of the size and location of the explosive-sizing positioning holes. Radius templates are used to verify that the correct radius for explosive sizing of $91 / 8 \mathrm{in}$. for the inner plates and $93 / 8$ in. for the outer plates, both with a tolerance of $\pm 1 / 8$ in., has been met. $A$ courtesy radiograph was made at this stage during the last campaign mainly to ensure that the cores had not cracked during preforming and to verify the centerline before shipping the plates for explosive sizing. 


\subsubsection{Prepare Explosive-Forming Die}

The explosive-forming die with the sealing fixtures is shown in Fig. 28. The holes on the top surface of the die are for the attachment of lifting lugs and for charge-positioning bolts. The numerous holes on the inside surfaces of the die are for the attachment of the rubber sealing bladder, shown in the foreground, along with the sealing bars. Other holes in the die surface and along the side of the die are for the evacuation of the die prior to explosive sizing. The explosiveforming die, which is made from hot-rolled carbon steel, was fabricated in the early 1960 s and must be cleaned and inspected before each campaign. During the last campaign, because of surface scratches and deformations from previous use and from rust pits, it was necessary to remachine the die surface. After machining, the die surface was hand finished to remove the machining marks. Small protrusions on the die surface will be embossed into the plate surface during explosive sizing and must be removed. The threaded holes were also chased and cleaned. The top threads in several of the holes used for tightening the sealing bars were worn to a point where extra-length bolts were required. After cleaning, the die surface was covered with a motor oil film to prevent rusting. The oil film is maintained while the die is being stored and is removed just before use.

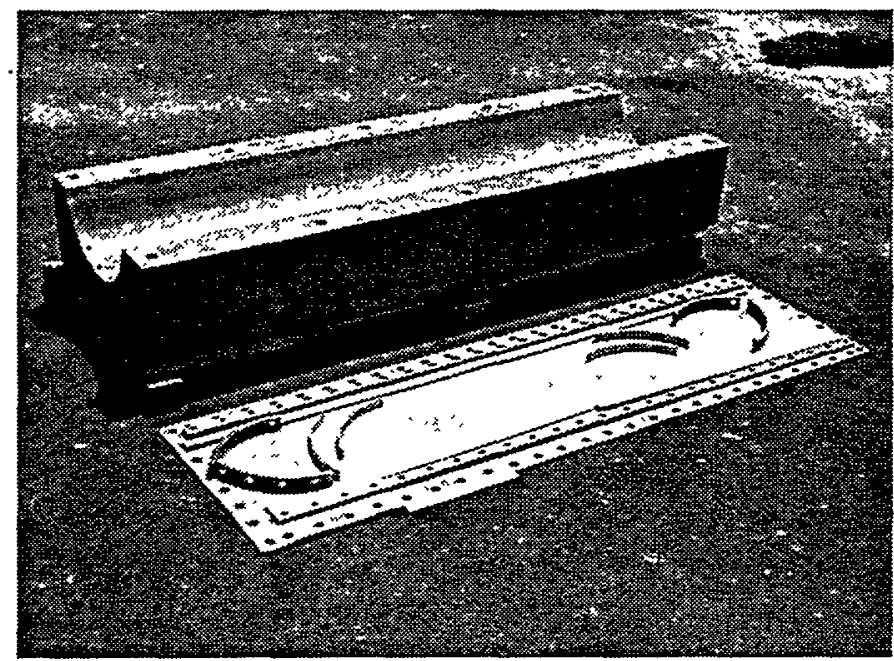

Fig. 28. Explosive-forming die with sealing fixtures.

\subsubsection{Package and Ship}

Because an outside contractor was used, it was necessary to package and ship the die hardware and plates to Sequim, Washington. A special plywood box was made to protect the die during shipment. The plywood boxes for the control plates had padding and wooden braces to protect and minimize plate movement during shipping. The die, accessories, and the first group of plates were shipped on a special-use-dedicated cross-country truck to minimize handling. The second 
group of plates and all plates returning to Oak Ridge were shipped by air freight. Other than weather delays with almost all shipments, no problems were encountered with the plates or the die from shipping.

\subsubsection{Assemble Plate in Forming Die}

The same die is used for forming both the inner and the outer plates. For an outer control plate, the explosive-forming die surface is in direct contact with the control plate. For the inner plates, a formed 0.375 -in.-thick aluminum plate is used to shim the die to the correct radius. The detailed procedures for the assembly of a plate in the forming die and the explosive-sizing operation were extensively rewritten during the last campaign. The setup of the die consists mainly of attaching vacuum lines to the die. The die should be positioned on a work surface that is $\sim 20 \mathrm{in}$. high to allow a comfortable working position for performing the many tasks required for loading and unloading plates from the die. In preparing a die for sizing a plate, the die surface is thoroughly cleaned with lint-free cloth wetted with alcohol and wiped dry with tack cloth just before a plate is placed in the die. It is extremely important to remove all lint, threads, and other similar materials because any materials that are left on the die surface will be embossed in the plate surface from the explosive-forming force. No lubrication is used on die or bladder surfaces.

Before a control plate is placed in the forming die, all sharp corners and burrs are removed by filing the plate edges to allow the plate to be properly seated in the die and to minimize the possibility of the plate cutting the bladder during explosive forming. The locating holes are checked by inserting a spare locating dowel, and any burrs are removed. The plate is first wiped with an alcohol-wetted lint-free cloth and then wiped dry with tack cloth just before positioning in the die. Again, it is very important to remove all lint, threads, and similar materials from the die and plate surfaces. The plate is then positioned in the die cavity by carefully aligning the plate's two locating holes over the die locating pin holes. The locating pins are then screwed through the plate into the die with the pin in the round hole positioned first. Care must be taken not to slide the plate on the die surface to avoid scratching the plate. The surface condition of the locating pins is important because we experienced some difficulties in removing the pins after explosive forming in the first series of plates formed, and several pins were damaged during removal because of galling. During the forming of the last five plates, the pins were lubricated with a thin coating of stearic acid, which essentially eliminated the problem. The stearic acid was applied by dipping the pins in an alcohol slurry containing the lubricant. The preformed plate positioned in the die will likely have some bow that will allow the plate to rock slightly $(\sim 1 / 4$ to $1 / 2$ in.) on the pins. After the plate is positioned in the die, beveled aluminum strips are placed along the long edges and rubber strips are placed along the ends to provide a transition from the plate edges to the rubber bladder. This transition is necessary to decrease the stresses in the rubber along the edges to avoid cutting the rubber bladder during explosive forming. The positioning of the transition strips in the more bowed plates is more tedious. In positioning the rubber bladder over the plate, care must be taken not to dislodge the transition strips, which could result in scratching the plate. 
In previous campaigns, it was found that the 1/4-in.-thick gum rubber bladder needed to be cut to a slightly larger size $(\sim 1 / 2$ in. on each side) than required for a perfect fit to obtain consistent sealing of the evacuation bladder. With the designed clamping arrangement, the vacuum tends to pull a stretched bladder away from the bolt holes and clamping bar, which can result in a leak path. The bolting of the slightly oversized bladder requires that one side be bolted first and then the excess material puckered while the other side is bolted. During clamping, it is important to maintain the position of the transitions strips. The bolting of the sealing strips is first done with an air impact wrench and then hand torqued to a specified level after all bolts have been inserted and seated. The end sealing strips must be individually matched to the hole pattern in the die.

One potential problem that was observed with the bolted clamping arrangement late in the last campaign was the possibility of shredding the rubber bladder around the bolt holes while tightening the full-threaded bolts that were used. Bits of shredded rubber were observed on the convex side (die side) of two plates after explosive sizing that caused embossed impressions into the plate surfaces $\sim 0.003 \mathrm{in}$. deep. The discovery of this problem came too late in the last campaign to correct, but the use of smooth-shank bolts with lubrication should be considered to correct this problem in the future.

The evacuation of the bladder is performed with a mechanical vacuum pump. The initial evacuation should be performed slowly to allow the excess bladder material to move and conform to the cavity and plate surface. After evacuation, the bladder surface should be perfectly smooth with the locating pins obviously protruding into the rubber bladder. The evacuation will seat the plate completely in the die cavity. Apparently in the initial development of the explosiveforming technique, a special clamping arrangement was used to seat the plate into the die cavity before evacuation. According to the Y-12 Plant staff experienced in explosive forming, this technique has not been used in recent memory. The evacuation of a control plate to $<-26 \mathrm{in}$. $\mathrm{Hg}$ should be achieved in 5 to $10 \mathrm{~min}$ if the bladder is not leaking. To achieve the full blank-off vacuum of $-29 \mathrm{in}$. $\mathrm{Hg}$, the mechanical pump requires 30 to $60 \mathrm{~min}$ to out-gas and remove the residual water from the surfaces. The assembly is considered leaktight if the blank-off vacuum pressure does not change after the vacuum pump has been shut off from the assembly for $5 \mathrm{~min}$. Retightening the bolts may be necessary if a leak is observed. During the last campaign, it was not necessary to disassemble the bladder to obtain the required vacuum and leak rate for any shot.

\subsubsection{Explosive Sizing}

After the evacuation of the die cavity, three wooden charge-positioning strips with locating holes for the explosive charge are aligned and positioned above the plate surface. The strips are located to position two strands of Primacord $10 \mathrm{in}$. above the horizontal centerline of the die surface and 5 in. offset from the centerline. Explosive sizing is accomplished under a water head of $>5 \mathrm{ft}$ with two strands of 50 grains/ft Primacord detonated with four detonators (No. 4 or No. 6) that are activated simultaneously. The stringing of the explosive Primacord and the attachment of the detonators are done at the blasting tank because of safety concerns. The Primacord is cut in 96-in. lengths to allow a sufficient length to knot the ends for stringing the Primacord between 
the end positioning strips. The excess explosive is looped and taped on each end. Two detonators are positionied on each Primacord strand 18 in. from the end positioning strips and attached by tape to the cord. The die with the Primacord explosive and detonators in place and ready to fire at the Y-12 Plant is shown in Fig. 29. The wires from the detonators are shown stringing from the die. The evacuation line is shown on the right side of the die.

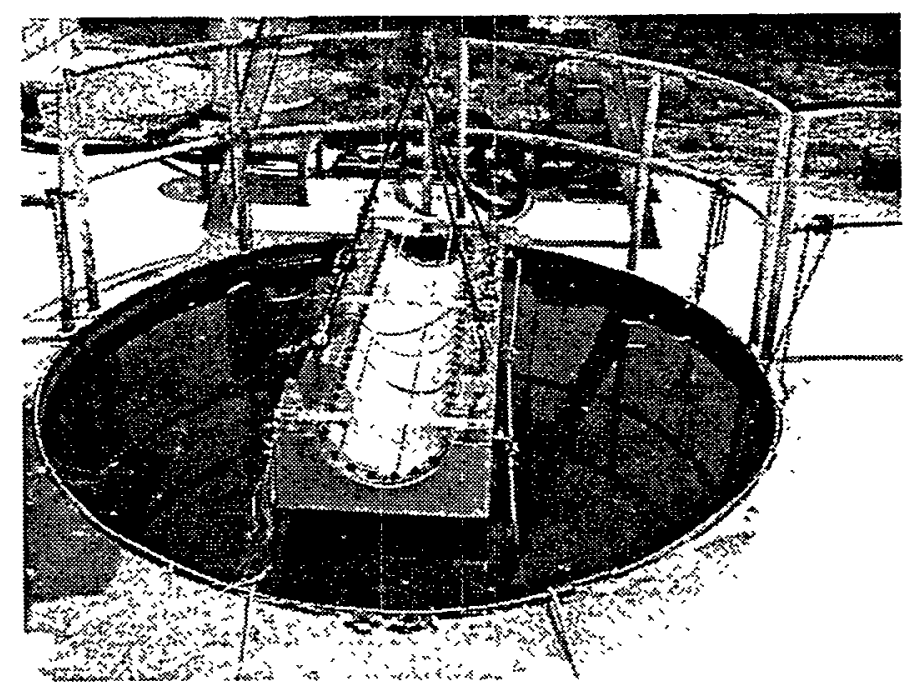

Fig. 29. Die with Primacord explosive and detonators in place ready to fire.

In previous campaigns, the procedure required a continuity check of the detonators before use. The explosives contractor considered this to be an unsafe practice, because of the possibility of a current emanating from the continuity meter, and refused to perform this check. The contractor said that based on their experience, the reliability of detonators has been very high and the risk involved in not checking the detonators' continuity was minimal. During the last campaign, the continuity of the detonators was not checked and no detonators failed.

The detonator wires are connected in parallel to a blasting machine. The vacuum system is turned off before the plates are shot, and the assembly is leak tested before it is lowered into the water tank. After the assembly is lowered into the water, it is shot and immediately removed from the water. Upon removal, the remaining water is blown off the assembly, the broken wooden positioning pieces and used detonator wires are removed, and the rubber bladder is examined for damage. Impacts from the wooden pieces and the detonator caps during the explosion can damage the bladder. During the last campaign, the bladder was damaged slightly from several shots but never to the extent that the damage prevented the subsequent shots in the sequence.

During the last campaign, all plates were shot three times before a plate was removed from the die. The three-shot procedure was based on the judgment of the Y-12 Plant explosives expert who developed the explosive-sizing process and supervised the explosive sizing of all previous 
control plates. He indicated that many plates sized in the past have required multiple shots to achieve the desired contour. Some plates have been shot as many as eight times. With multiple shots, the main concern is that the sides of the plate will spring in slightly. If this occurs, the condition can be corrected with the press brake after the sizing operation. The reshot of the assembly requires a repeat of the sequence starting with positioning new wooden charge positioning pieces. The rubber bladder is retightened between shots. The reshot sequence can be accomplished in less than $30 \mathrm{~min}$.

After completion of an explosive-forming operation, the die assembly is returned to the work area and the plate is removed from the die. In this operation, the remaining water is blown off and the surface is dried with wipes before the clamping screws are removed to minimize water getting on the plate and die surface. After explosive sizing, a plate will be in direct contact with the die cavity with no obvious clearance. When a plate is being removed from the die, the locating pins are first removed and the plate is carefully lifted on one end by prying with a thin blade until the plate can be lifted by hand. As indicated previously, the removal of the locating pins can be difficult and must be done carefully to avoid bending or breaking the threaded stem.

\subsubsection{Inspection}

Inspection, at this point, is to verify that the sized control plate has been properly formed and is acceptable for further processing. For the outer control plates, the contour after this step is in its final form and must meet the final outer radius of $9.30 \mathrm{in} . \pm 0.020 \mathrm{in}$. The inner plates are subsequently welded together to form a cylinder, and their final contour is established by explosively sizing the welded cylinder. Resizing of an outer plate is required if the radius variation is $>0.020 \mathrm{in}$. or if the established centerline does not allow a minimum edge clad after machining of $0.125 \mathrm{in.}$ in the black region. In the last campaign, all plates met the required edge clad thickness and two plates required minor press-brake resizing.

\subsubsection{Visual inspection}

Immediately after explosive forming, the radius of each plate is checked with an inside radius template (8.675 in. for the inner plates; 9.050 in. for the outer plates) along its length in $\sim 1-\mathrm{ft}$ increments to ensure that the radius of the formed plate is within $1 / 8 \mathrm{in}$. of the template size. The bow is evaluated with a metal straight edge placed along the centerline of the plate. The clearance between the plate and the template, or straight edge, is evaluated visually and with paper or plastic feeler gauges. Plates explosively sized during the last campaign were well within the specified radius and bow requirements. All plates had no visible bow and most plates had almost no clearance $(<0.005$ in.) between the template and the plate. Two or three plates exhibited a small amount of spring ( $<1 / 16 \mathrm{in}$.) along the edge. The surfaces of the plates were visually inspected for surface defects. As mentioned previously, two plates had some small embossed areas, apparently from the rubber shards that were imbedded in the plate surface. 


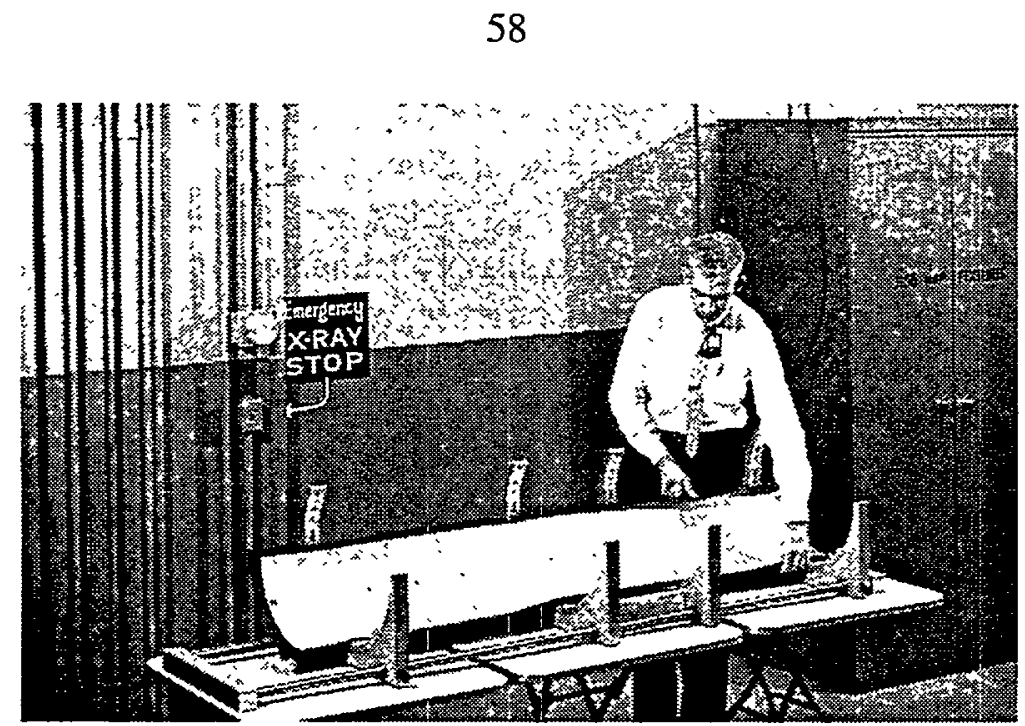

Fig. 30. Fixture for positioning curved control plate for radiography.

\subsubsection{Radiography}

The radiography at this stage is to verify that the cores were not damaged from the explosivesizing operation and to determine the location of the core from the plate edges. The radiography of the curved plate is performed with a special fixture (Fig. 30) that allows the alignment of the plate segment to be $\mathrm{x}$-rayed near to perpendicular with the X-ray source to minimize divergence. Relatively small segments of the plate are radiographed in individual exposures to improve the resolution of the edge dimensions (17 radiograph shots for outer plates and 18 shots for inner plates). The location of the core from the plate edges is determined from the radiographs using the distances measured from the reference holes to the core edge. The measured distances on the curved plates from the longitudinal edges to the core are smaller than like measurements taken on the flat plate because of the deformation of the core edges during forming.

\subsubsection{Contour inspection}

The inspection of the contour of the sized plate is performed on an inspection mandrel mounted on the bed of the mill with the index head and center that will be used to machine the plates. For inspection, the plate is mounted on the inspection mandrel in an unrestrained stress-free state. A master gauge template is mounted on one end of the inspection mandrel. In the last campaign, a new gauge for the outer plates was made by precision electric-discharge machining and then inspected to determine the precise dimensions ( 0.0001 in.) of the reference surfaces. A separate gauge is used for the inner plates. The inspection mandrel with the master gauge attached in shown in Fig. 31. The master gauge is on the right end of the mandrel in the photograph. The attachment of a plate to the mandrel is done with shims in a manner that will not impart any stains, and a dial indicator is used to ensure that the contour has not been disturbed during clamping. In setting a plate on the mandrel, the design radius (8.925 in. for the inner plate; 


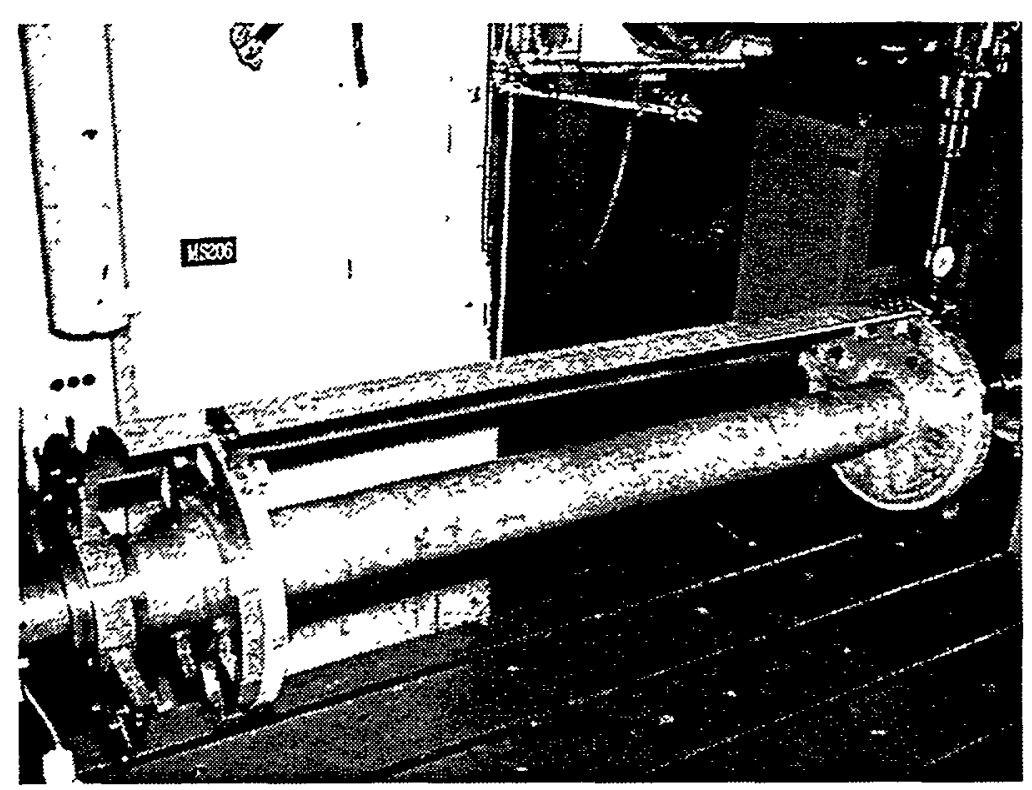

Fig. 31. Inspection mandrel with master gauge attached.

$9.300 \mathrm{in}$. for the outer plate) is set 3 in. from each end of a plate at the "best-fit centerline" by shimming the plate at its edges. The best-fit centerline is defined as the axis from which the contour deviates equally from the segment's outside radius. The best-fit centerline is established by using a dial indicator and by rotating the mandrel with the index head and moving the plate until the deviation of the indicator is equal on both sides when the mandrel is rotated (split tolerance). Typically, a control plate requires several position adjustments to establish the best-fit centerline.

The inspection of the contour consists of determining the radius dimension along the centerline and along the four lines on each side of the centerline $15 / 8 \mathrm{in}$. apart by making axial traverses. A plate is considered satisfactory if the radius varies $< \pm 0.020 \mathrm{in}$. from the design radius. During the last campaign this contour inspection was determined on the machine tool bed using dial indicators. If the deviation exceeds the tolerance, the contour must be corrected by returning the part to press-brake forming and explosive sizing. In the last campaign, the contour of two plates was adjusted with the press brake without significant difficulties. If re-explosive sizing is required, a plate must be returned to the press brake to open the radius to the size required for explosive sizing.

\subsubsection{Centerline Comparison}

The best-fit centerline (CL-2) is compared to the centerline determined before forming (CL-1). A maximum variation of 0.050 in. between the two centerlines is allowed. If these centerlines vary by more than $0.050 \mathrm{in}$., it may be necessary to re-form the plate because the core location may not permit a minimum edge clad thickness of $0.125 \mathrm{in}$. after machining. If it is necessary to 
re-form a plate because of a centerline problem, the plate must be flattened and carried through the entire forming and sizing sequence starting with the flattening anneal. To verify the longitudinal edge clad thickness before machining, punch marks are made in the edges of the plate from CL-2 at equal arc lengths (13.605 in./2 for the outer plates) for use in radiography. In radiography, a 0.010 -in.-diam tungsten wire is stretched between the punch marks and the longitudinal edge clad thicknesses is measured on the radiograph from this wire. The minimum allowed longitudinal edge clad thickness is 0.125 in. 


\subsection{FABRICATION OF OUTER CONTROL ROD}

The majority of the fabrication of the outer plates that make up the outer control rod is accomplished on a large numerically controlled 6-in. horizontal boring milling machine using mandrels mounted between a precision index head and a live center end stock. This same setup was used with the inspection mandrel to determine the best-fit centerline described in the previous section. The inspection mandrel and a Bridgeport milling head are used in the attachment of the end fittings and final machining steps. The machining setup and the procedures used during the last campaign were slightly different from those used previously, mainly because of the improved capabilities of numerically controlled machine tools. These procedures are contained in Y-12 procedure AA6-T-7196-61, Rev. C.

\subsubsection{Lay Out Centerline and Machine Edges}

The mandrel used for layout of the centerline and machining the edges is made of steel with an aluminum shim machined to the nominal inside radius of the outer plate (9.050 in.) attached to the steel cylindrical mandrel. The shim is undercut about 0.015 in. in the areas where the plate will be machined. The arrangement of the mandrel positioned on the machine tool with clamps for machining the longitudinal edges is shown in Fig. 32. The clamping arrangement of the plate to the mandrel shown in the figure is used in the layout of the centerline and machining. The plate is positioned on the mandrel in a manner that will not deform the freestanding contour of the plate and reposition along CL-2 previously determined.

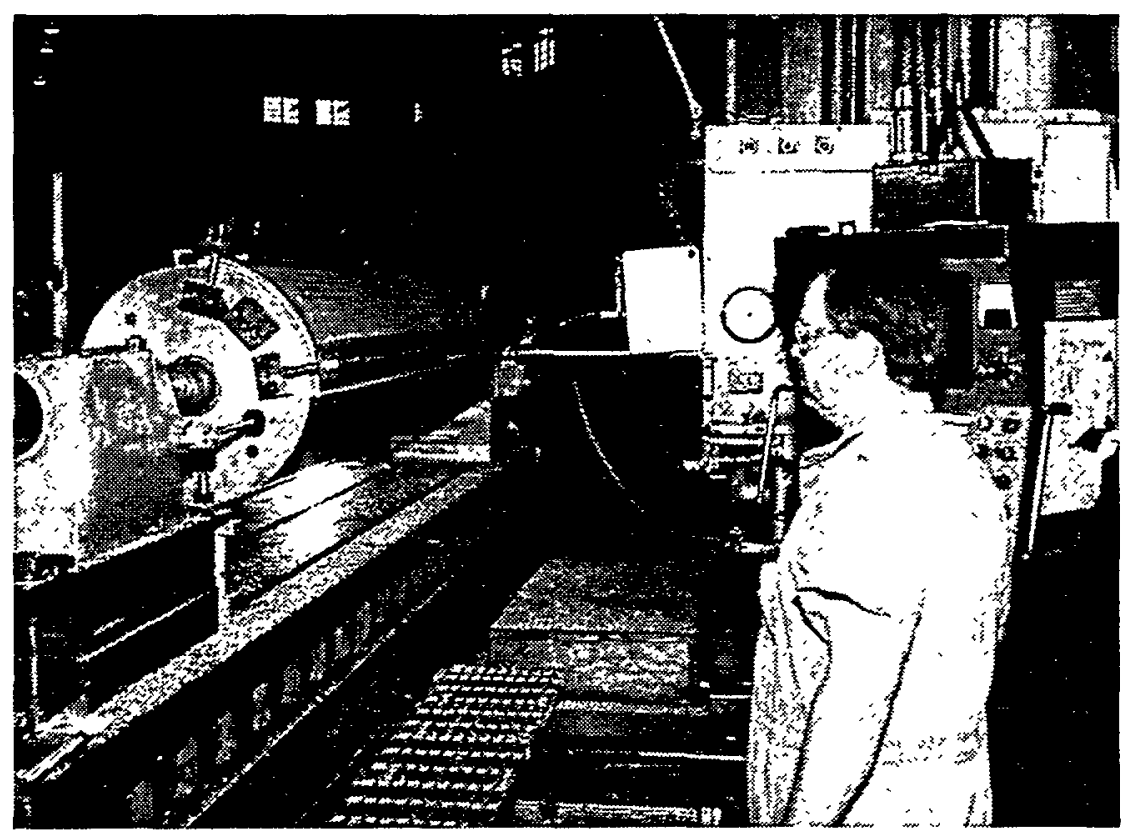

Fig. 32. Clamping arrangement of outer plate for machining longitudinal edges. 
The layout of the correct centerline before machining of the longitudinal edges is extremely important because of the narrow ( 0.125 -in. min) edge clad in the outer control plate design. The nominal longitudinal edge clad for the inner plates is 0.438 in. for comparison. The minimum longitudinal edge clad of $0.125 \mathrm{in}$. in the black section is required to allow the machining of $45^{\circ}$ bevels required for clearance of the track bearing for the inner control plates during installation in the reactor. The bevels are machined in the plate edges near the gray/black interface as one of the final machining steps.

The layout of the final centerline (CL-3) for machining is the centerline determined using distances measured on the last radiographs from the reference holes to the edges of the lines established from the best-fit centerline (CL-2). In establishing trim lines for machining, equal arc angles $\left(41^{\circ} 54^{\prime}\right.$ and $\left.30^{\prime \prime}\right)$ from CL-3 are measured on each end, and marks are scribed on the plate at these locations. CL-3 should not deviate more than $0.050 \mathrm{in}$. from the flat plate centerline (CL-1) or more than 0.030 in. if the two centerlines do not cross. The scribe marks from CL-3 should agree with the marks from the best-fit centerline (CL-2). During the last campaign, CL-3 was almost coincident with CL-2 on all plates fabricated.

After the layout of the side edges for machining, the edge margins are verified by radiography. In this courtesy radiograph, a 0.010 -in.-diam tungsten wire is strung on the convex side of the part between punch marks at the ends of the trim layout lines. The distance from the wire marking the edge of the part to the boundary of the core section is measured on radiographs. The results of these measurements in the $\mathrm{O}-93$ series plates are shown in the following table.

\begin{tabular}{ccccc}
\hline & \multicolumn{2}{c}{ Right side } & \multicolumn{2}{c}{ Left side } \\
Plate number & Max & Min & Max & Min \\
\hline & & & & \\
$0-93-2$ & 0.330 & 0.210 & 0.200 & 0.070 \\
O-93-3 & 0.210 & 0.170 & 0.210 & 0.030 \\
O-93-5 & 0.360 & 0.250 & 0.270 & 0.110 \\
O-93-6 & 0.230 & 0.160 & 0.260 & 0.170 \\
O-93-7 & 0.200 & 0.130 & 0.250 & 0.100 \\
O-93-8 & 0.270 & 0.190 & 0.140 & 0.210 \\
O-93-9 & 0.280 & 0.190 & 0.280 & 0.220 \\
O-93-11 & 0.160 & 0.140 & 0.230 & 0.140 \\
O-93-12 & 0.260 & 0.210 & 0.280 & 0.220 \\
\hline
\end{tabular}

As shown in the table, several of the edge margins are less than the specified minimum of 0.125 in. Based on this information, the trim lines were adjusted to center the europium core section within the plate. 
The longitudinal edges are machined using an end mill cutter as shown in Fig. 32. The machining of an edge requires several passes. After each longitudinal edge has been machined, the cord distance should measure 12.424 in. If the cord distance is $>12.430$ in., equal stock should be removed from each edge.

The machining of the end clad requires a clamping arrangement illustrated in Fig. 33. After machining of the longitudinal edges, this clamping fixture is positioned along the longitudinal edges of the plate. The location of the top or the end containing the core is determined from measurements made on the flat plate radiographs from reference hole 19. A small punch mark is made at this location, and the top end is machined perpendicular to CL-3. The location of the bottom end is determined by measuring $663 / 16 \mathrm{in}$. from the top end down the plate. The bottom end is machined perpendicular to CL-3. The machining of the end was accomplished using the index head to manually rotate the mandrel holding the plate under the end mill cutter. Several passes are required to machine the ends. After machining, the planes of the ends need to be parallel within \pm 0.002 in. for the proper positioning of the end fitting brackets.

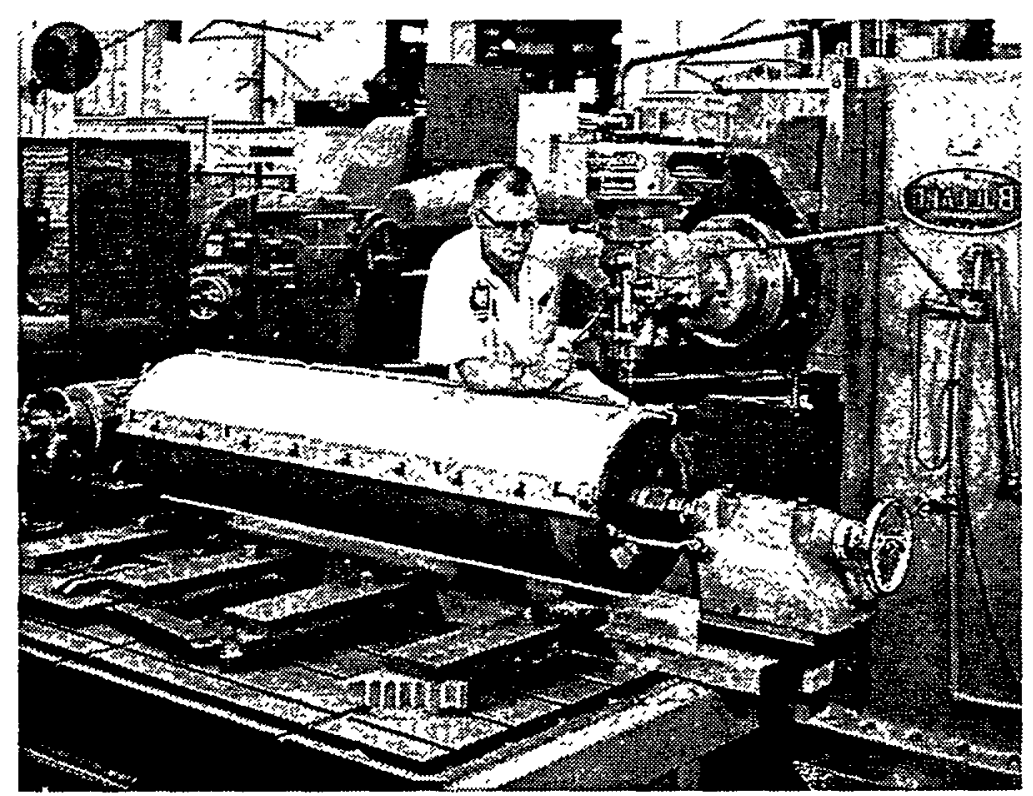

Fig. 33. Clamping arrangement for cutting end clad on outer control plates.

\subsubsection{Drill 1/4-in. Holes}

A large number of 1/4-in.-diam holes are drilled in the white (aluminum) and gray (tantalum) regions of each plate. These holes are pressure-equalization holes required to reduce hydraulic forces on the plate during operation in the reactor. The 30 rows of 13 holes are drilled on a 1-in. grid on the bottom end starting 2 in. below the black/gray interface, and on the top end 5 rows of holes (4 rows with 13 holes and 1 row with 12 holes) are drilled starting 59 9/16 in. from the 
bottom end. During the last campaign, the number of rows of holes on the bottom end was changed from 31 to 30 to provide a larger margin around the europium core section.

The drilling of the 454 quarter-inch holes was accomplished using the same setup that was used to machine the ends. A computer disk was used to load the required hole locations into the numerically controlled mill. Before drilling, the hole pattern is verified using a felt marker in place of the drill bit to mark the hole locations. In drilling, the drill passes through the plate and barely enters the shim plate. Determining the correct bit geometry to drill a hole with the required smooth surface required some development.

\subsubsection{Radiograph}

After a plate is removed from the fixture used for drilling the $1 / 4$-in. holes, the plate is radiographed to verify the dimensions of the finished aluminum edging along the core and longitudinal location of the core. The radiograph technique is identical to the technique used in the previous curved plate radiograph inspections. The results showing the edge cladding variations of the $0-93$ series plates is shown in Table 5.

Table 5. Edge clad margin measured on $0-93$ series outer control plates (side edges minimum is 0.125 in.; top and bottom are 2 in. nominal)

\begin{tabular}{|c|c|c|c|c|c|c|c|c|}
\hline \multirow[b]{2}{*}{ Plate number } & \multicolumn{2}{|c|}{ Right side } & \multicolumn{2}{|c|}{ Left side } & \multicolumn{2}{|c|}{$\begin{array}{c}\text { Top of plate } \\
\text { (to Eu/A1 } \\
\text { interface) } \\
\end{array}$} & \multicolumn{2}{|c|}{$\begin{array}{c}\text { Bottom of plate } \\
\text { (to Eu/Ta } \\
\text { interface) } \\
\end{array}$} \\
\hline & Max & Min & $\operatorname{Max}$ & Min & Max & Min & $\operatorname{Max}$ & Min \\
\hline $0-93-2$ & 0.290 & 0.200 & 0.255 & 0.135 & 2.28 & 2.10 & 1.95 & 1.81 \\
\hline $0-93-3$ & 0.175 & 0.125 & 0.220 & 0.195 & 1.95 & 1.74 & $0.94^{*}$ & $0.76^{*}$ \\
\hline $0-93-5$ & 0.355 & 0.250 & 0.305 & 0.175 & 2.33 & 2.06 & 1.96 & 1.83 \\
\hline $0-93-6$ & 0.215 & 0.205 & 0.270 & 0.210 & 2.63 & 1.83 & 2.14 & 1.45 \\
\hline $0-93-7$ & 0.265 & 0.190 & 0.330 & 0.200 & 1.81 & 2.82 & 2.40 & 1.29 \\
\hline O-93-8 & 0.255 & 0.190 & 0.260 & 0.225 & 2.10 & 1.98 & 2.11 & 2.02 \\
\hline $0-93-9$ & 0.200 & 0.270 & 0.250 & 0.180 & 2.35 & 1.87 & $1.03 *$ & $0.58^{*}$ \\
\hline $0-93-11$ & 0.215 & 0.185 & 0.250 & 0.230 & 2.38 & 2.34 & 2.07 & 2.05 \\
\hline O-93-12 & 0.290 & 0.260 & 0.225 & 0.225 & 2.14 & 2.07 & 1.94 & 1.87 \\
\hline
\end{tabular}

Note: *Additional row of 1/4-in.-diam holes; all previously fabricated plates made in this manner.

As shown in the table, all the plates met the minimum side edge cladding of $0.125 \mathrm{in}$. Two plates were inadvertently drilled with an extra row of 1/4-in.-diam holes as specified in the previous design revision. This is the reason the bottom edge on two plates is outside the nominal 2-in. measurement. 


\subsubsection{Radius 1/4-in. Holes}

The hydraulic demands of the HFIR control systems requires that the drilled holes be radiused on both sides and free of all burrs and tool marks. The specified radius is $1 / 32$ in. and must be blended to avoid sharp edges. Before radiusing, the plate surfaces are sanded and polished to remove surface defects greater than 0.0005 in. The removal of the surface defects before radiusing is required to avoid repeating the radiusing operation because the removal of surface defects will likely alter the hole radii.

A special router-type tool is used to the radius the holes. The radiusing tooling being used on the concave side of a plate is illustrated in Fig. 34. The tool is fitted with a foot that is contoured to match the plate contour and locating dowels to position the tool over a hole to be radiused. The dowels are positioned in adjacent holes to locate the tool precisely over the hole to be radiused. The depth of the cut is established on a dummy plate and locked into place on the tool against a positive stop. The cutting tool is raised and lowered with a hand-operated cam mechanism. The cutter is equipped with a nylon bushing to align the cutter in the hole to be radiused and is continuously lubricated with alcohol during cutting. The hand finishing and radiusing of each plate is a laborious tasks that requires

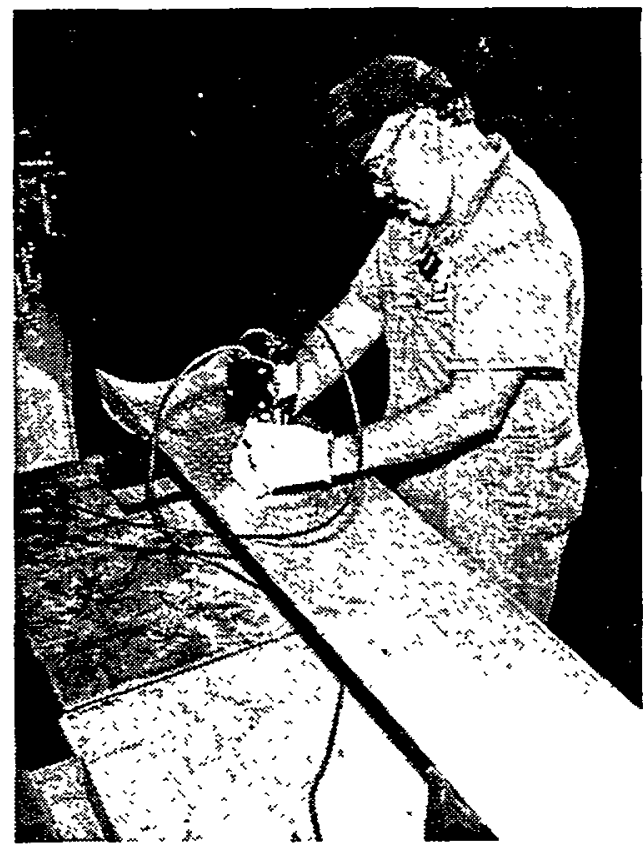

Fig. 34. Tool used for radiusing 1/4-in.-diam holes on outer control plate. from several days to a week or more to complete each plate.

\subsubsection{Dimensional Inspection of Plate}

After completion of the trimming, hole drilling, and radiusing, each plate is inspected to ensure that the plates conform to drawing dimensional tolerances before attachment of the end brackets. In previous campaigns, this inspection was accomplished on the horizontal boring machine tool using the inspection fixture and reference gauge. An outer control plate set up for inspection on the machine tool bed is illustrated in Fig. 35.

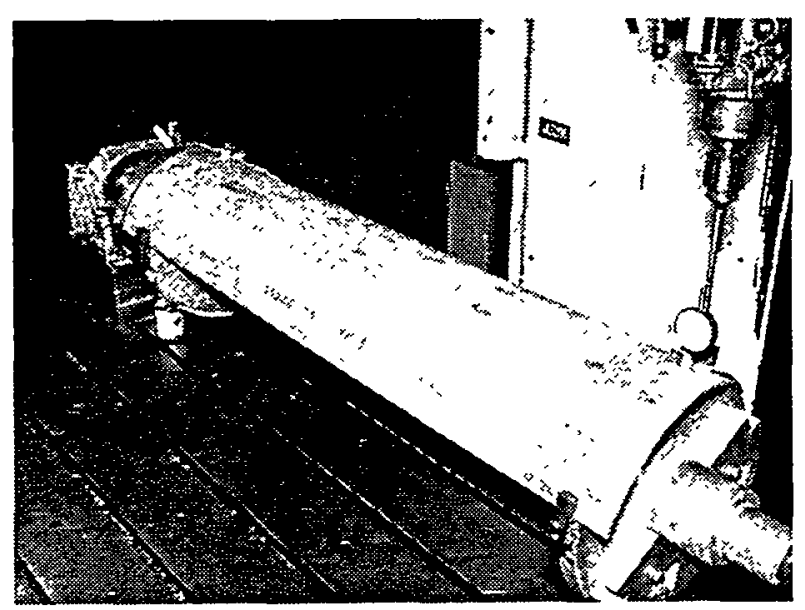

Fig. 35. Outer control plate setup for inspection on machine tool bed. The master gauge is shown on the left side. 
The Y-12 Plant inspection department would not certify the dimensions measured in this manner, and during the last campaign, a precision Mauser CMM inspection device was used to determine the dimensions and contour of the plates. An outer control plate on the Mauser CMM is shown in Fig. 36. Many of the dimensions of the plates determined on the CMM did not conform with the tolerances specified on the engineering drawing. The dimensions of the plates are referenced from the reactor centerline from the bearing lugs while the plate is located in the reactor. Most of the out-of-tolerance conditions will be effectively corrected when the bearing flanges are attached and the bearing lugs are finish machined. To understand the effects of the out-of-tolerance radius condition, a computer-aided design (CAD) layout of the worst out-of-tolerance plate was prepared. The layout showed that the clearance between the outer control plate and inner control rod would not be seriously compromised ( 0.136 in. minimum compared to 0.170 in. nominal) not

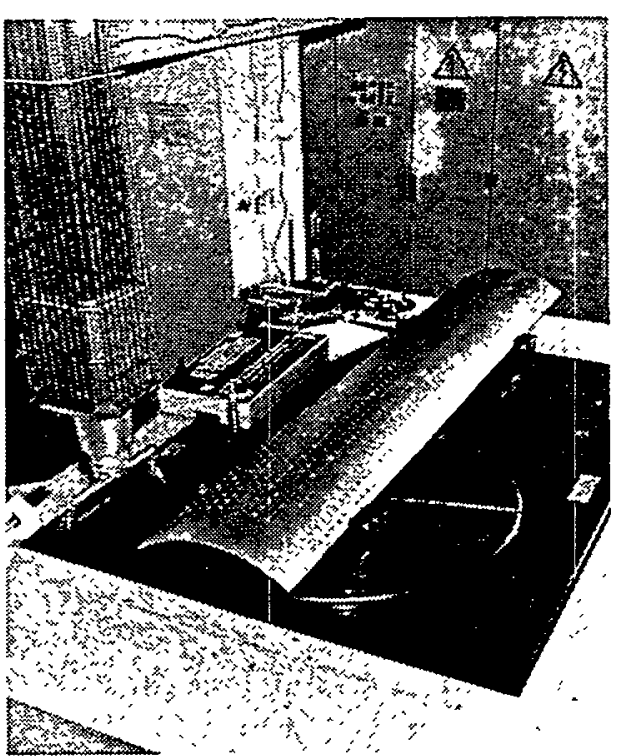

Fig. 36. Outer control plate mounted for dimensional inspection on the Mauser CMM. considering the likely increase in radius when the flanges are attached. Based on this analysis, it was decided to proceed with the attachment of the flanges and final machining of the plates without further rework.

To compare the out-of-tolerance dimensions measured with previously manufactured plates, three randomly selected outer control plates made in the 1976 campaign and previously accepted for reactor use were measured on the CMM. This comparison is shown in the following table.

\begin{tabular}{llll}
\hline Requirements & $\begin{array}{c}\text { Drawing tolerance } \\
\text { (in.) }\end{array}$ & $\begin{array}{l}1993 \text { series } \\
\text { (8 plates; in.) }\end{array}$ & $\begin{array}{l}1976 \text { series } \\
\text { (3 plates; in.) }\end{array}$ \\
\hline $\begin{array}{l}\text { Perpendicular (top) } \\
\begin{array}{l}\text { Perpendicular } \\
\text { (bottom) }\end{array}\end{array}$ & 0.005 & OK & 0.007 \\
Radius contour & \pm 0.0125 & 0.028 & 0.008 \\
profile & & $+0.020 /-0.022$ & $+0.029 /-0.028$ \\
Parallelism (side 1) & 0.005 & & \\
Parallelism (side 2) & & 0.024 & 0.033 \\
Radius (top) & $9.295 / 9.305$ & 0.024 & 0.015 \\
Radius (bottom) & & 9.207 & 9.278 \\
\hline
\end{tabular}

As shown in the table, the 1976 plates had out-of-tolerance dimensions similar to those measured in the current campaign, except the radius of the 1993 series plates was smaller than the 1976 plates. The smaller radius of the 1993 plates may be related to the rework of the explosiveforming die, the radius of the plate before explosive sizing, or the use of three explosive shots in sizing. 


\subsubsection{End Fitting Preparation}

End fittings for both the top and bottom flanges are made from 6061 aluminum plate. The initial plan in the 1993 campaign was to reuse the flanges removed from the 1976 series outer control plates. As the drilling and final machining of the flanges are accomplished on the plates and are custom fitted to each plate, the use of previously used flanges was determined not to be practical in meeting the dimensional tolerance requirements, particularly for the bearing lug locations. In addition, the weld quality on some of the 1976 series flanges was questionable.

Previously, end fittings have been made as a weldment, but during the last campaign the design was changed to make the fittings from a single plate piece, primarily to avoid welding and to reduce fabrication time and costs. The initial weldment design was made in the early $1960 \mathrm{~s}$, but since that time advances in numerically controlled machine tooling have made fabrication of the end fittings from a single piece of aluminum stock practical and cost effective. In addition, the quality assurance documentation requirements of a weldment for a nuclear application is a significant time and cost factor in fabrication. In the fabrication of the end flanges, the rough machining is accomplished on an electric discharge wire cutting machine tool. A rough-cut bottom flange cut from a 5-in.-thick aluminum plate is shown in Fig. 37. The top flanges are cut from a 3-in.-thick aluminum plate. Finish machining is accomplished on a numerically controlled milling machine.

A materials issue in fabrication of the plates from a single piece of stock was the temper of the bearing lugs and the heat-treatment requirements. The thick plate stock is received in the T-6 temper as specified for the bearing lug in the previous design. A partial stress-relieve anneal after rough machining was specified at $350^{\circ} \mathrm{F}$ to maintain the temper of the bearing lugs. The stress-relieve anneal conditions were patterned after conditions used in the manufacture of HFIR fuel elements.

The finished machined end fittings for an outer control plate are shown in Fig. 38. The bottom end fitting, shown in the top of the figure, has a ring for attachment of the reactor drive coupling. Both the bottom and top fittings have two bearing lugs for attachment of track bearings. The bearings attached to these lugs ride in a track that serves to guide the outer plate as it moves between the inner control cylinder and the beryllium reflector. In the attachment of the end fittings, the

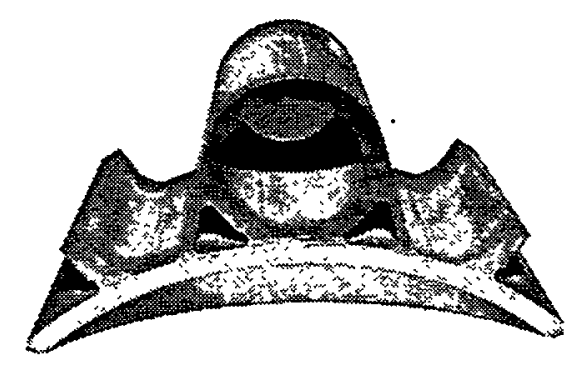

Fig. 37. Rough-cut bottom end flange for outer control plates.
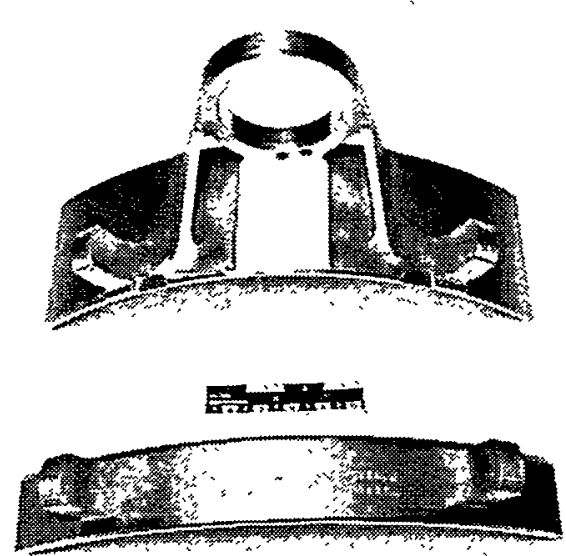

Fig. 38. Finished machined top and bottom flanges before attachment to outer control plate. 
position of these bearing lugs is most important to ensure proper operation of an outer plate in the reactor. The inside radius of the end fittings is machined to a 9.300-in. radius to match the nominal outside radius of a formed plate.

\subsubsection{Attachment of End Fittings}

The attachment of the end fittings and final machining are performed on the same mandrel used for the inspection of the contour after explosive sizing. In the setup for the attachment of the end fittings, a Bridgeport milling head is placed on the boring machine's spindle. A plate positioned on the mandrel for attachment of the end fitting is shown in Fig. 39. The master template is shown on the left. In the attachment of a plate to the mandrel, the plate must be positioned to avoid any deflections in the plate from its freestanding configuration. To ensure that the plate is not deflected during clamping to the mandrel, dial indications are positioned on the centerline and at the edges on each end. After a plate's proper centerline location and edge positions are established on the mandrel, the clamping pads are adjusted to minimize deflection of the plate during clamping. Using screws through two of the 1/4-in.diam coolant holes to hold the plate's centerline significantly reduced the time required for positioning a plate on the mandrel. The maximum allowable deflection is 0.002 in. when the clamps are released and retightened. The purpose of this setup is to have the plate positioned on the mandrel in the exact position used during the previous inspection, except that the centerline axis is offset 0.041 in. The final inspection of a plate is made with respect to the master template gauge, which also has a 0.041 -in. offset. The master template gauge is an important element in the final machining operations, and its functions must be thoroughly understood by the fabricators.

Either fitting may be attached first. In the attachment of an end fitting, "C" clamps are used to hold the fitting in the required position established from the master template. A dowel hole is then drilled on the centerline through the fitting and

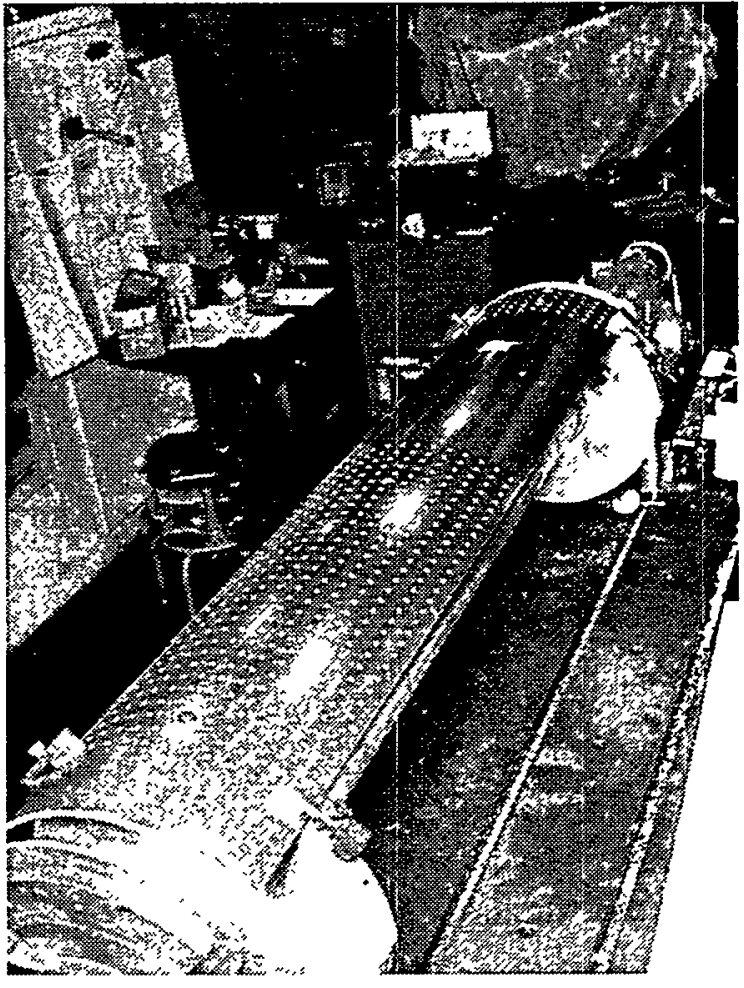

Fig. 39. Plate positioned on the mandrel for attachment of the end fitting. plate, and a $1 / 4$-in. dowel is inserted. The fitting and plate are then drilled, countersunk, and tapped. The fitting is then attached with screws. At this point, the attachment screws and end fittings are removed from the plate, deburred, and cleaned.

The plate is then removed from the mandrel, the mating surfaces are cleaned again, and the fittings are reattached with the screws used previously. Each screw is torqued to $40 \mathrm{in}$.-lb and 
loosened four times to ensure a proper fit-up of the fitting. After torquing, each screw is flared with a hydraulic pressing fixture to prevent the screws from backing out during operation in the reactor. The flaring tool uses a flat bottom punch with a centering stake for positioning the punch in the center of the flat-head screw and a $90^{\circ}$ included angle top punch. A force of $2000 \mathrm{lb}$ is used to flare the specially designed recessed screw, which protrudes $1 / 32 \mathrm{in}$. before flaring. The fixture used for flaring the aluminum screws is shown in Fig. 40.

During the last campaign, the back-off torque of the flaring process was evaluated as a function of flaring pressure. The evaluation showed that a back-off torque of 40 to $50 \mathrm{in}$. $-1 \mathrm{~b}$ could be achieved at a $2000-1 \mathrm{~b}$ force. Multiple torquing of the screws provided more consistent back-off torque values. A force greater than $2000 \mathrm{lb}$ did not increase the back-off torque and tended to excessively deform the plate surface. In earlier outer control plate campaigns, the screw heads were staked rather than flared to prevent them from backing out. A cursory evaluation of the staking technique used showed the flaring process to be comparable or better in back-off torque.

After attachment of the end fittings, the plate is repositioned on the mandrel and the bearing lugs are bored and faced to size using the master template as the

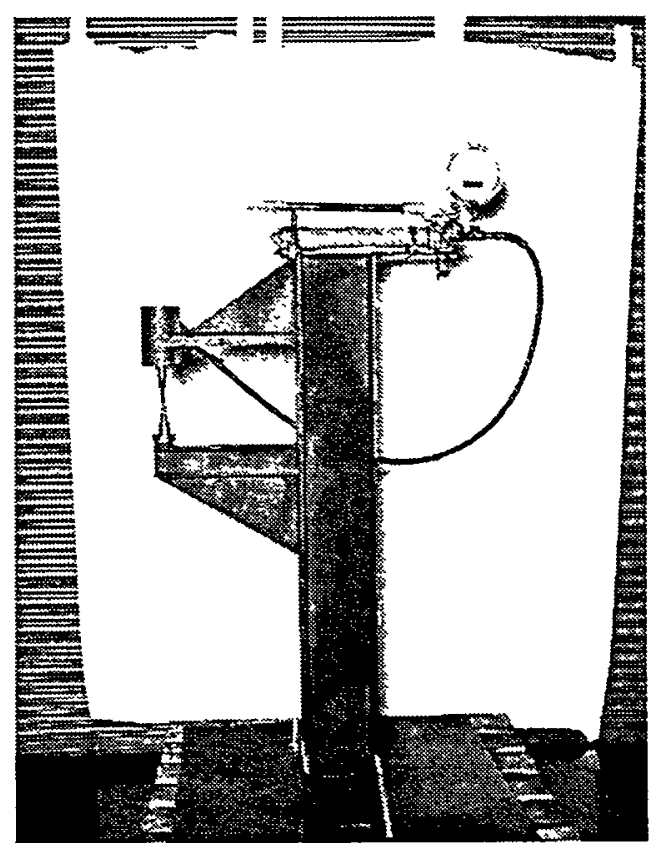

Fig. 40. Fixture used for flaring the aluminum screws. reference. This technique ensures that the bearing surfaces are within the tight tolerances specified on the design drawing. Using this machine setup, the 5/8-in. and 3/4-in. holes are drilled on the centerline and the required bevels machined on the plate and fitting edges. The setup for final machining of the bearing surfaces and holes is shown in Fig. 41. The final machining operation is vibra-etching the serial number and the HFIR outer control rod set and set plate number on the top and bottom ending fittings of each control plate.

\subsubsection{Final Dimensional Inspection}

The finished outer control plate is inspected for compliance with dimensions and surface finish as specified on Eng. Dwg. E-49820 Rev. V, Outer Control Rod Assembly. The milling machine used in the final machining is used in the final dimensional inspection. Before the milling machine can be used for final assembly, the milling machine must be checked for calibration and certified for use. 


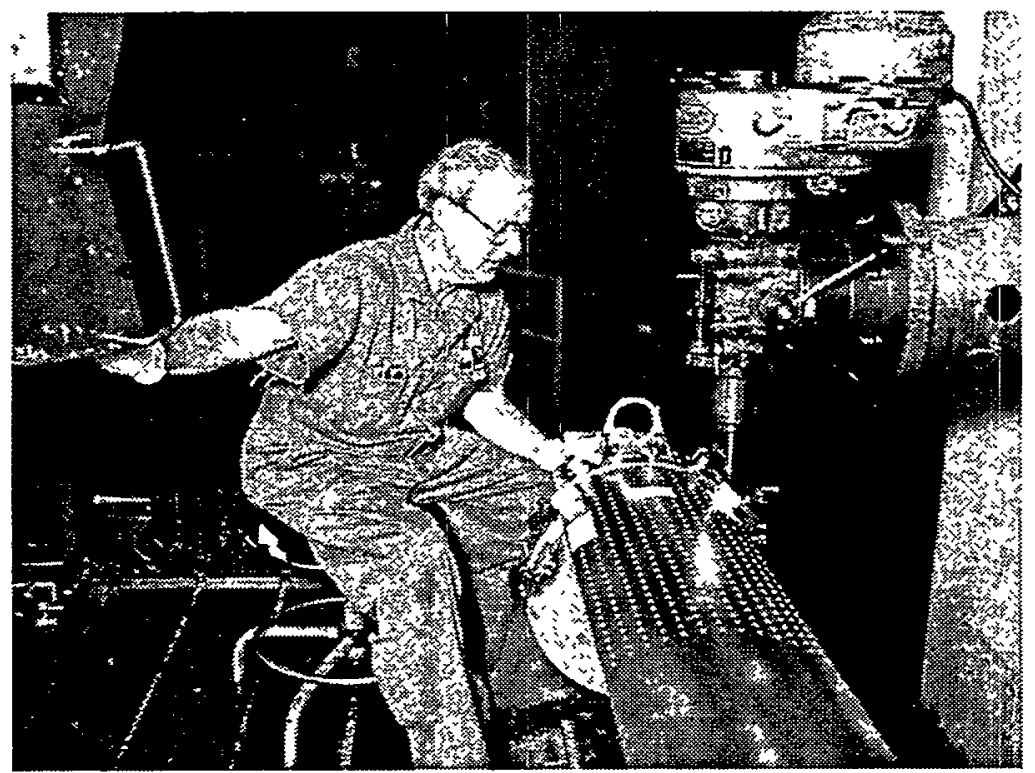

Fig. 41. Setup for final machining of bearing surfaces and holes.

\subsubsection{Final Cleaning of Outer Control Plate}

The final cleaning of the outer plates consists of an alcohol wipe and cleaning all holes with alcohol-wetted nylon bristle test-tube brushes. Care must be taken to clean all surfaces and holes thoroughly to pass a final "white glove" cleanliness inspection. In most instances, recleaning of some of the holes was required to pass the cleanliness inspection. In past campaigns, final cleaning was first done using a mild alkaline detergent solution (1 tablespoon Alconox Master Mix Cleaner per gallon in $160^{\circ} \mathrm{C}$ water) with a hot-water rinse followed by a final alcohol wipe. When this procedure was attempted with the available containers, considerable water spotting was experienced on the polished aluminum surfaces. Because the final machining of the polished plates and brackets is done using only alcohol as the cutting lubricant and final cleaning of aluminum components with alcohol is an accepted practice in HFIR operations, the detergent wash step was eliminated. After cleaning, a plate is allowed to dry in air and then wrapped in plastic sheeting before being placed its individual transport/storage box. The use of compressed air is not allowed for drying to avoid oil or other contaminants that may be present in the compressed air source. 


\subsubsection{Bearing Installation}

The design life of an outer control plate is typically 40 to 50 HFIR cycles, but the bearings must be replaced in the reactor pool after every 7 cycles during their use in HFIR. Replacement bearings are routinely procured and installed by the HFIR operating staff. On new outer control plates, the bearings are installed by crafts personnel at the HFIR just before insertion into the reactor pool for use. The journal-type bearings are currently being manufactured of Haynes 25 with a stainless steel shaft to very tight tolerances. The construction materials of the bearings will likely be changed to Inconel X750 and PH3-8 tool steel with a stainless steel shaft in the near future. In installation, a bearing is pressed onto a shaft, and the 0.440 -in.-diam shaft is pressed into the hole bored in the bearing lug $(0.0001$ to 0.0003 in. interference fit). Finally, the shaft is drilled and secured to the lug with a 1/8-in.-diam pin that is secured by flaring. As a final acceptance, the completed control plate assembly is subjected to a go/no-go check with a female clearance gauge (ORNL- Dwg. E-55098) at HFIR. The plate must pass through this gauge to be accepted for use in HFIR.

During operations in the reactor and replacement of the bearings, the lug bearing holes increased in diameter from this wear. To compensate for this wear, bearing shafts with diameters from 0.440 to $0.446 \mathrm{in}$. are provided. The largest shaft used to date has been 0.445 in. In replacing outer control rod bearings in the reactor pool, the old bearing is removed, the lug bearing hole diameter is measured, and a new bearing assembly with the proper shaft diameter inserted into the lug. 


\subsection{FABRICATION OF INNER CONTROL ROD CYLINDER}

The inner control rod cylinder is composed of four plates, each of which has a black and gray section essentially identical to the poison section in an outer plate; the processing of the inner plates up to the point where the plates are welded into a cylinder is almost identical. The difference in processing of the inner plates is that the hot rolling cropping position is different, the formed curvature is a slightly smaller radius, the overall length is slightly greater, and the longitudinal edges are wider. The poison section is also located in a different place than in the outer plates. The outside diameter of a finished welded cylinder is 17.846 in.

Inner control cylinders were last made in the 1984-87 time frame. The inner control cylinder processes described in this document are primarily a refinement of the information reported in ORNL/TM-9365, which was written in the late 1960s but not issued until 1984. ${ }^{2}$ The information was updated by interviewing personnel who were involved in the last inner control plate campaign.

The flowsheet for fabricating an inner cylinder is shown in Fig. 42. The process consists of welding four formed plates into a cylinder, explosive sizing the welded cylinder, drilling numerous 1/4-in.-diam holes and pressure-equalization holes, final machining, and attaching an end fitting.

\subsubsection{Lay Out Centerline and Machine Edges}

The layout of the centerline and the machining of the edges, except for the mandrel tooling and reference hole locations, are identical to the processes previously described for the outer plates. The reference hole locations are different primarily to differentiate between the two plate types. Because the width of the longitudinal core margins is significantly larger ( 0.435 in. nominal) for the inner plates, the centerline layout is not as critical as it was for the outer plates.

The determination of the correct arc length for the plates to form a 17.846-in.-diam cylinder within $-0.000 /+0.010 \mathrm{in}$. by welding requires an understanding of weld shrinkage and the expansion from the planishing step. The weld shrinkage measured in past campaigns indicated that the average weld shrinkage before planishing is about 0.060 in. with a variation of about \pm 0.010 in. The planishing operation, which results in plastic deformation of the weld region, is necessary to control the arc lengths of the individual plates to fabricate a cylinder within the specification. Each planishing pass increases the arc length about $0.004 \mathrm{in}$. Up to $0.016 \mathrm{in}$. of expansion of a single weld joint was obtained in past campaigns in four planishing passes. The arc length for each segment should be established to allow at least one planishing pass on each weld joint to cold work the cast structure of the weld zone to improve its metallurgical properties. Based on the minimum weld shrinkage of $0.050 \mathrm{in}$. and $0.008 \mathrm{in}$. expansion from two planishing passes, the arc length for each segment should be cut to about 14.058 in. $(14.016+$ $0.050-0.008)$. This arc length value should be verified during cold tests in the next campaign. In the machine shop, the equivalent cord length is normally measured because it can be measured accurately with standard micrometers. 

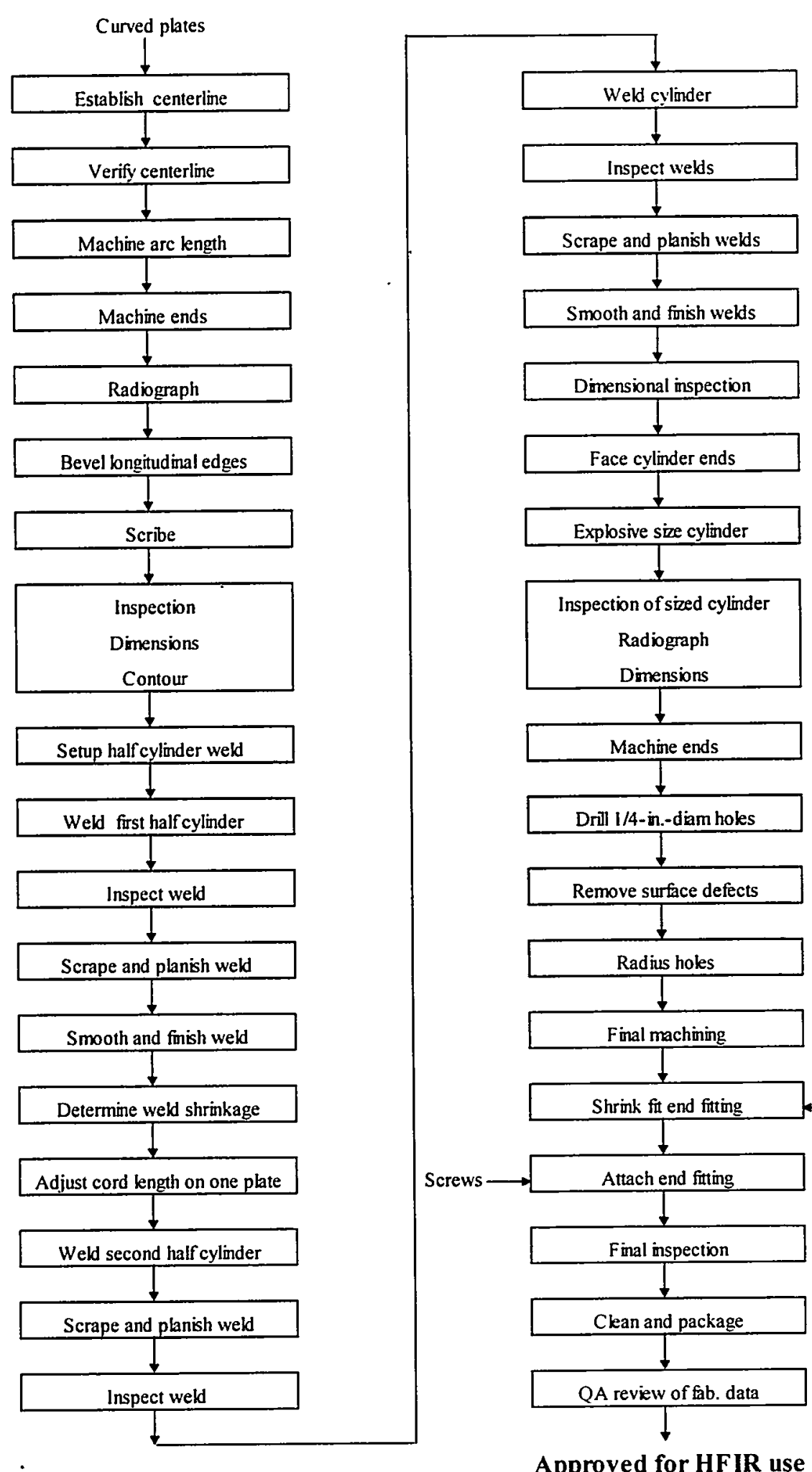

Fabricate end fitting

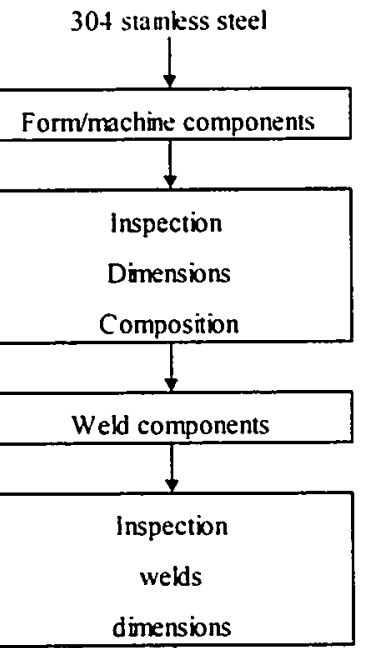

Approved for HFIR use

Fig. 42. Flowsheet for fabrication of inner cylinder. 
To align the plates for welding, each plate is scribed $361 / 2$ in. from the black/gray interface datum on one end. The alignment of these circumferential marks ensures that the black/gray interface is in the same horizontal plane in the control cylinder when operated in the reactor.

The longitudinal edges of each plate are beveled at a $37^{\circ}$ angle with a 1/32-in. land for obtaining a full-penetration weld. The fitup of the two beveled edges forms a groove for welding. After beveling, parallel weld shrinkage marks are scribed on each plate on the inside surface $0.500 \mathrm{in}$. from the land of the bevel edges. The machine setup for scribing the weld shrinkage monitoring line is illustrated in Fig. 43. The markings are not made along the region containing the europium core even though the markings are only about 0.002 in. deep.

\subsubsection{Welding}

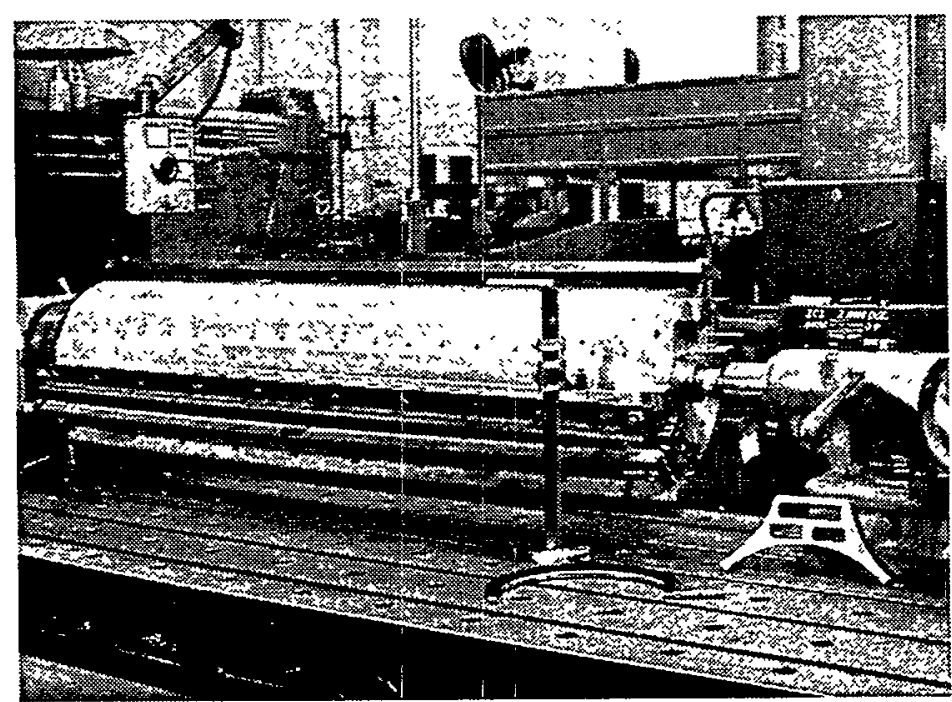

Fig. 43. Machine setup for scribing weld shrinkage monitor on inner control plate.

An external seam welder and a planishing roller are set up in a specially constructed, temporary room to provide a clean environment for performing and finishing the welds. A detailed description of the welding process development is contained in the Welding Journal article of October 1967 by Collins, et al. The components used in welding inner plates in past campaigns are listed below.

- $\quad$ Pandjiris external seamer modified

- $\quad$ Linde side beam carriage

- $\quad$ Linde wire feeder

- $\quad$ Linde HW-13 heliarc torch with No. 10 metal cup

- $\quad$ Miller SR-600 welding machine

- Heliarc automatic head control panel, Model HMC-F

- Planisher manufactured by Airline Welding and Equipment Company 
A specially machined heat sink and chill clamps, made from copper and then plated with nickel to eliminate copper contamination, were designed to fit the Pandjiris external seam welder used in past campaigns. To avoid having to make the relatively expensive heat sink and chill clamps in the future, efforts should be made to use the Pandjiris seamer. The heat sink, which is machined to the contour of the cylinder, serves as the backup bar and has a 1/8-in.-wide by 1/32-in.-deep semicircular groove down the center. This groove is used to position plates for welding. The plates are welded together using the inert gas tungsten arc process (TIG) with filler metal with the weld parameters automatically controlled. The weld is made using direct current with straight polarity, and helium is fed through the torch as the shield gas. The use of the 4043 filler weld wire is absolutely necessary to weld 6061 aluminum without cracks because of the silicon content in the 6061 aluminum.

An overall view of the seam welder being set up to weld two plates into a half cylinder is shown in Fig. 44. Shown in the top of the figure is the longitudinal side beam and carriage with the welding torch and wire feeder mounted on the carriage. The heat sink is mounted on the cylinder shown in the foreground, and the hydraulic actuated chill clamps are in the structure above the cylinder. The loose strap clamps shown in Fig. 44 are tightened after the parts have been clamped in the proper position to be welded with the chill clamps. A top view of the weld setup showing plates being aligned in the chill clamps for welding is shown in Fig. 45.

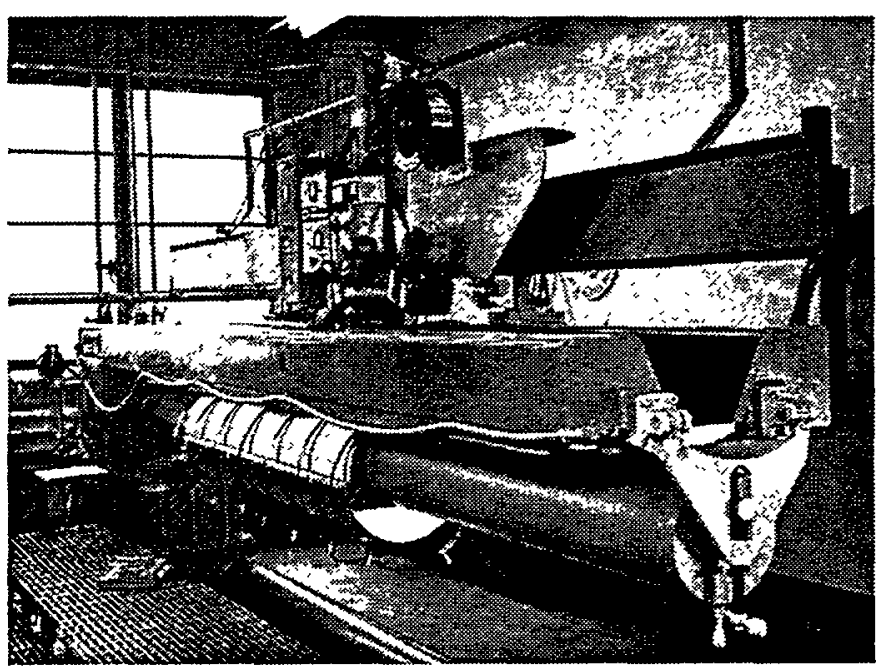

Fig. 44. Overall view of seam welder set up to weld plates in a half cylinder.

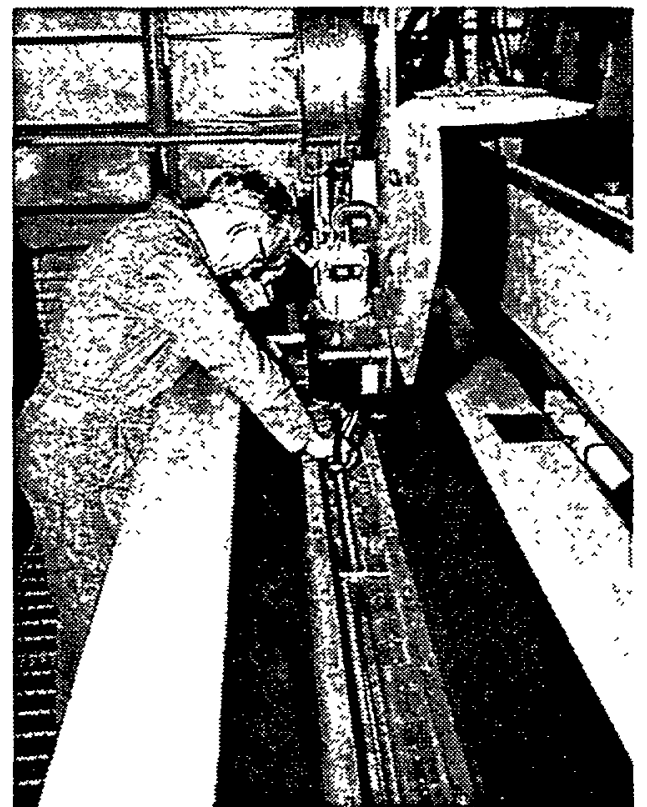

Fig. 45. Top view of weld setup showing plates aligned in chill clamps for welding. 
Before welding, the surfaces of the plates are covered with paper and taped to within 2 in. of the edges to be welded to protect the plates from damage during handling. Run-off tabs, which are 2 in. long by $3 / 4 \mathrm{in}$. wide with the same bevel and land of the weld joint, are then tack welded to each end of each side of the segments to be welded. Immediately before welding, the surfaces and adjacent areas to be welded are scraped to remove any oxide layer. In the setup of two plates or half cylinders for seam welding, the edge of one plate or half cylinder is first aligned in the middle of the groove in the heat sink and clamped into place. The edge of the second segment is butted with the first segment, and the circumferential scribe marks are aligned and clamped. The maximum allowable gap after butting is 0.010 in. at the ends and 0.020 in. in any other section. If the maximum gap is exceeded, the edges must be reshaped by hand until the specified gap tolerance is achieved. The full clamping pressure of the chill clamps is not applied until after the segments have been properly aligned and verified. The strap clamps are not installed until after the plates have been clamped with the chill clamps. After clamping, the distance between the hold-down clamps should provide a uniform 3/8-in.-wide gap. If necessary, the hold-down clamps should be adjusted to achieve this distance because this gap distance will influence the weld width.

In welding, the run-off tabs are first tack welded together. The tracking of the welding torch with the weld groove is then checked to determine what lateral adjustments are necessary during welding. The welding torch is positioned in a $5^{\circ}$ forehand position. The welding electrode used is 3/16-in.-diam, $2 \%$ thoriated tungsten that has been ground to a $16^{\circ}$ included angle with a $1 / 32$-in. flat tip. It extended $5 / 8$ in. from the cover gas cup. The welding wire is $1 / 16$-in.-diam 4043 aluminum welding wire. The welding parameters used to seam weld plates are listed in the following table.

\begin{tabular}{cccccc}
\hline Pass & $\begin{array}{c}\text { Amperage } \\
(\mathrm{A})\end{array}$ & $\begin{array}{c}\text { Voltage } \\
(\mathrm{V})\end{array}$ & $\begin{array}{c}\text { Carriage speed } \\
\text { (in./min) }\end{array}$ & $\begin{array}{c}\text { Wire feed } \\
\text { (in./min) }\end{array}$ & $\begin{array}{c}\text { Shield gas on } \\
\text { torch } \\
\left(\mathrm{ft}^{3} / \mathrm{h}\right)\end{array}$ \\
\hline 1 & $325 \pm 15$ & $13 \pm 1$ & 6 & 19 & 85 \\
2 & $310 \pm 15$ & $13 \pm 1$ & 6 & $36^{*}$ & 85 \\
\hline
\end{tabular}

*Note: The wire feed on second pass is adjusted by welder to obtain correct fill.

In welding, the arc is first struck on the run-off tab and the equipment is set for automatic welding. A weld inspector is present during setup and all welding operations. After the first pass, the face side of the weld is brushed with a stainless steel brush to remove oxide and weld deposits. The weld inspector inspects the weld pass on the face side and, if necessary, the segment is removed from the fixture to inspect the root side. Any visible surface defects are repaired by a hand repair procedure before proceeding to the second pass. After the second pass, the part is removed from the fixture and the welds are visually inspected. Before removal of a welded segment from the fixture, heavy asbestos paper was installed between the mandrel and 
the hold-down clamps to reduce the chances of scratching the part while it was being removed from the fixture. In future campaigns, asbestos paper cannot be used because of environmental considerations and another suitable material will have to be identified. A cross section of a typical two-pass TIG weld in an inner control cylinder is shown in Fig. 46.

After machine welding, visible defects such as cracks and voids are repaired by a hand repair procedure. The hand repair procedure uses the W-607 TIG welding process, which uses a hand-held TIG torch with 3/32-in.-diam 4043 filler wire fed by hand. The visual inspection criteria were not well defined in previous campaigns and need to be changed to reflect current visual inspection criteria like criteria defined in NDE- 21 . Terms such as "no visible defects" are not definitive.

\subsubsection{Scrape and Planish Weld Surface}

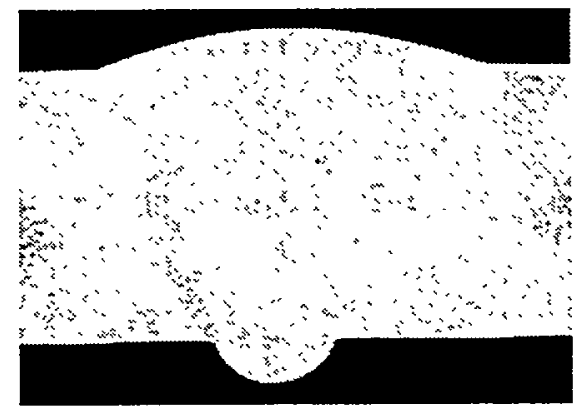

Fig. 46. Cross section of a typical two-pass TIG weld in a HFIR inner control rod cylinder.

After welding and visual inspection, each weld is scraped to remove the excess weld metal close to the contour of the cylinder. The scraping operation is accomplished in a special fixture and a tool similar to a wood plane is used to scrape the weld surface to a flat $\sim 0.010$ in. above the plate surface. No more weld metal should be removed by scraping than is necessary to flatten the weld area required for planishing. The scraping operation for both the inner and outer surfaces is illustrated in Fig. 47.

The planishing operation cold works the weld area and provides a better wear surface for the track bearings that ride in this area during operation in the reactor. The planishing operation is performed on a sheet metal planishing machine. The device has two vertically mounted, crowned (5/16-in. crown) steel rolls that are $51 / 2 \mathrm{in}$. in diameter and $27 / 8 \mathrm{in}$. wide. To provide better tracking and alignment, a 7/8-in.-wide flat area was ground into the circumference of the top roll. The top roll is driven by a constant-speed motor, and the force between the rolls can be adjusted. In planishing, the force between the rolls is adjusted to 15 psi and the weld area is passed longitudinally under the rolls to shape the weld area. Two to four passes are required to planish the weld area. The planishing operation will increase the cord length slightly and can be used to adjust the radius in various areas if necessary. Typically, the circumference grows $\sim 0.009 \mathrm{in}$. after two passes, but after two additional passes, it only grows an

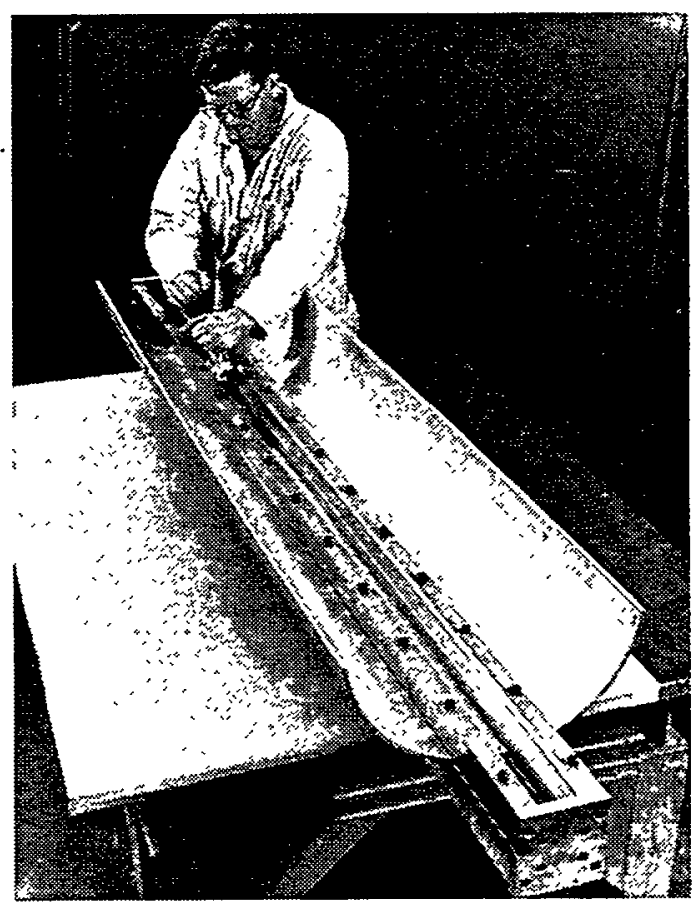

Fig. 47. Scraping operation for inner and outer surfaces. 
additional 0.005 in. During the planishing operation, a pi-tape is used to monitor the diameter change. The measurements are made in specially identified locations at each end to ensure consistent measurements.

After planishing, the weld area is scraped again in the scraping fixtures to remove excess weld metal. The weld areas are then sanded with aluminum grit paper to restore the contour on both the inside and outside surfaces. The thickness and inner and outer contours are repeatedly checked with micrometers and an outside template gauge to ensure that the proper contour is obtained.

\subsubsection{Inspection of Welded Half and Full Cylinder}

The welds and dimensions on the welded half cylinders are inspected before being welded into the full cylinder using essentially the identical procedures that were used for half cylinders. All welds are radiographed with a film wide enough to allow the examination of the weld soundness and to evaluate the alignment of the core sections. The weld radiographs are examined for absence of cracks and voids in the weld areas. The specification requires that the welded joint be sound except for scattered porosity. The definition of acceptable porosity needs to be better defined in future campaigns using the criteria specified in Sect. VIII, Division 1, Appendix 4 of the Pressure Vessel and Boiler Code. The required width of the separation of the cores between plates is $3 / 4 \pm 1 / 32$ in., and the gray/black interface data must be aligned vertically to within $1 / 4$ in. of each other. Weld joint shrinkage is determined in the field by measuring the separation of the scribe lines marked on the plates and with a pi-tape measurement of the arc. These measurements are comparable to within about $0.005 \mathrm{in}$. of each other.

The arc length is inspected using a special inspection fixture shown in Fig. 48. The gauge fixture has precisely determined arc lengths machined into the fixture, which are used as references for measuring the arc length of a plate or half cylinder. An end view of the fixture showing the machined reference lands is shown in Fig. 49. Shown in the fixture is a half cylinder positioned against a stop, which is fastened to the land on the right side of the

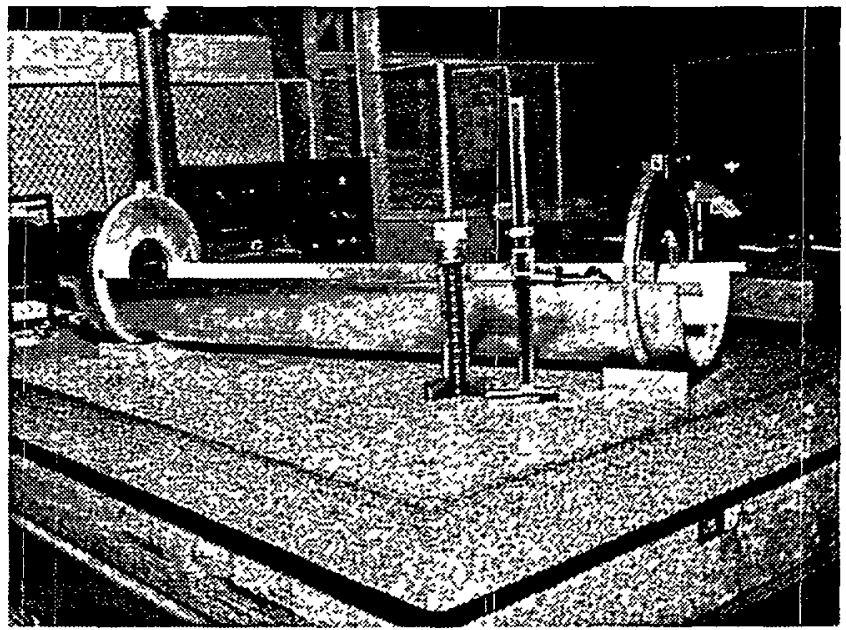

Fig. 48. Special inspection fixture used for measuring arc length of a plate. circular gauge. In measuring the arc length of a segment, one segment edge is clamped against the stop and the arc length is measured relative to the machined land on the left side. The arc length is measured in at least four locations: the ends and 22 in. from each end. If any individual measurement is not within within \pm 0.006 in. of the average, additional measurements are made. 
Two as-welded and planished cylinders from a previous campaign had an average diameter of 17.851 in. and 17.849 in. when the cylinders were measured with a pi-tape in 6-in. intervals. The individual diameters of each increment measured ranges from 17.843 in. to 17.860 in. After explosive forming, the average diameters of the same cylinders were 17.839 in. and 17.838 in., respectively, with a range in diameter from $17.836 \mathrm{in}$. to $17.842 \mathrm{in}$. The variation in the radii of these two cylinders was significantly different. The first cylinder, which was made before the planishing operation had been perfected, had a maximum radius variation of +0.025 in. to -0.022 in.; the latter had a maximum variation of +0.005 in. to -0.007 in. This points out the need to establish a good procedure for the planishing step during cold testing. Both cylinders were within the \pm 0.030 -in. radius variation allowed.

\subsubsection{Face Cylinder Ends}

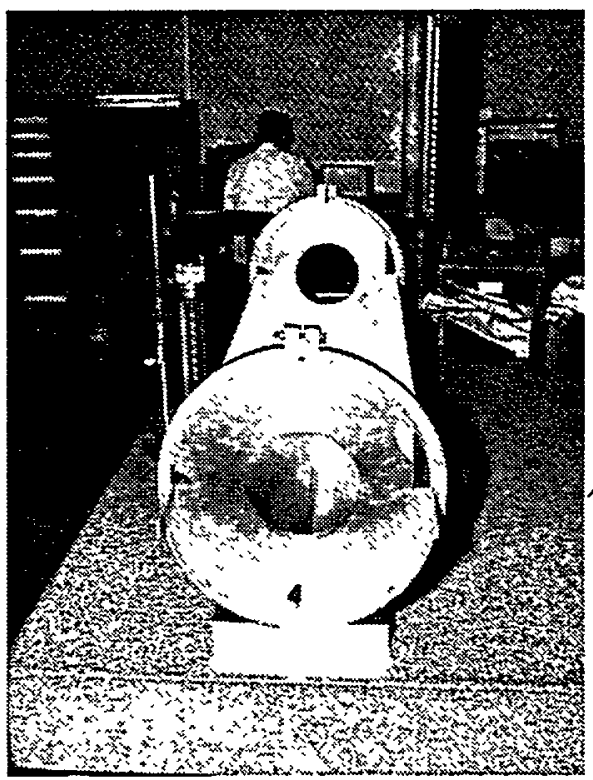

Fig. 49. End view of inspection fixture showing the machined reference lands.

The datum for locating the core section in a control rod is the average gray/black interface. In a welded cylinder, because the distance from the core to the ends of each plate segment varies slightly, the ends of the cylinder will be uneven after welding. The facing of the cylinder ends is necessary to provide smooth ends for the proper fitup of the cylinder in the explosive forming die.

In facing a cylinder, the cylinder is mounted on a special expanding mandrel fixture and mounted on a machining lathe. The locations of the core sections were previously determined for the first explosive forming operation, and dowel-positioning holes were drilled in the plates at that time. The facing removes metal on each end back to the end of these positioning holes. Care is exercised during this operation to ensure that the markings at each end identifying CL-3 are not removed and that the plate identification markings are transferred to the segments of the cylinder. After facing, the average cylinder diameter is obtained from 12 individual pi-tape measurements to ensure that the cylinder is the proper diameter for final explosive sizing. The desired outside diameter of a cylinder for explosive sizing is 17.846 in.

\subsubsection{Explosive Size}

The setup of the die for explosive sizing cylinders is similar to the technique used previously in explosive sizing the quadrant plates. A rubber bladder or boot is used to seal the plate in the die cavity for evacuation. A single strand of 50 grains/ $\mathrm{ft}$ Primacord located along the center axis provides the explosive force, and the die itself forms the water container. Each cylinder is shot three times before disassembling the die. Extreme care should be taken to clean the plate and die 


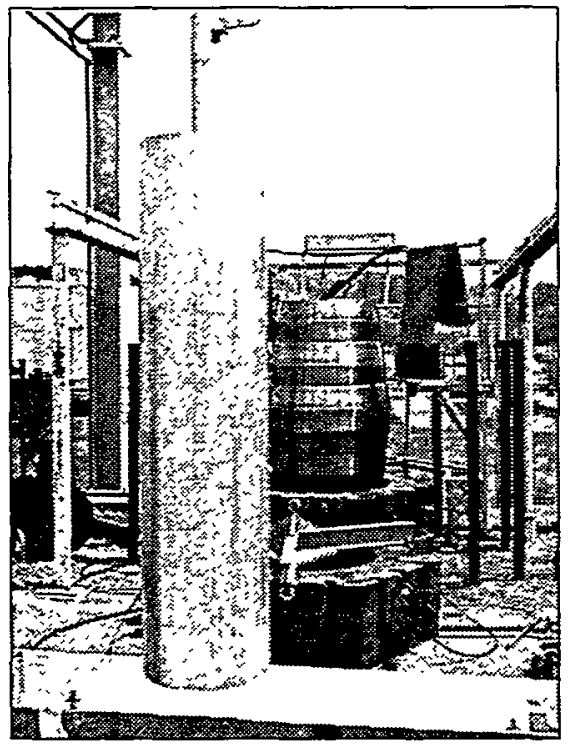

Fig. 50. Inner cylinder

forming die showing outside tapered surfaces and retaining rings. surfaces to prevent forming defects in the cylinder surfaces. A video (Tape No. 0573 "Explosive Sizing of the Inner Control Rod Cylinder") made during the 1984 campaign is an excellent illustration of the explosive sizing operation of the outer cylinder. The outside tapered surfaces of the forming die along with the retaining rings are shown in Fig. 50. The rubber bladder used is shown in the background with a control cylinder in the foreground.

As discussed previously in forming of the plates, the europium oxide-aluminum core section is very brittle. To prevent it from cracking during explosive sizing of the cylinder, the forming die is designed to place the cylinder in compression during the sizing operation. The large cylindrical die is split longitud-inally into two halves to allow insertion of a slightly oversized cylinder into the die. The closure of the die halves places a control cylinder with a nominal outside diameter of 17.846 in. (17.856 in. maximum) in compression against the die surface, which has a 17.832-in. inside diameter. Figure 51 shows the assembled explosive-forming die being closed by

positioning the retaining rings. The outside surfaces of the die are tapered so that forces generated by tightening the tie bolts on the retaining rings act to close the die halves. The die weighs 36,000 $\mathrm{lb}$, and the retaining rings weigh $\sim 750 \mathrm{lb}$ each. The desired finished outside diameter of a cylinder after explosive sizing is 17.842 in.

In preparing the inner die for explosive sizing, the bottom plate is removed and replaced with a slider plate. The top flange and rubber boot are removed, and the die is partially disassembled by removing the three top retaining rings; the three bottom rings are loosened and rested on the bottom flange. The inside surfaces of the die are cleaned with fine-grit paper, if necessary, to remove any rust, and a solvent is used to remove the rust preventive. The surfaces are then wiped with alcohol applied with a clean lint-free cloth and dried with tack cloth. The die halves are then separated by removing the tie bolts that hold the halves together and by using jack screws installed in the die halves to jack the die apart $\sim 1 / 2$ to 1 in. The die halves slide on the slider plate and are doweled in the die to maintain alignment while the halves are separated. To prevent scratching a cylinder

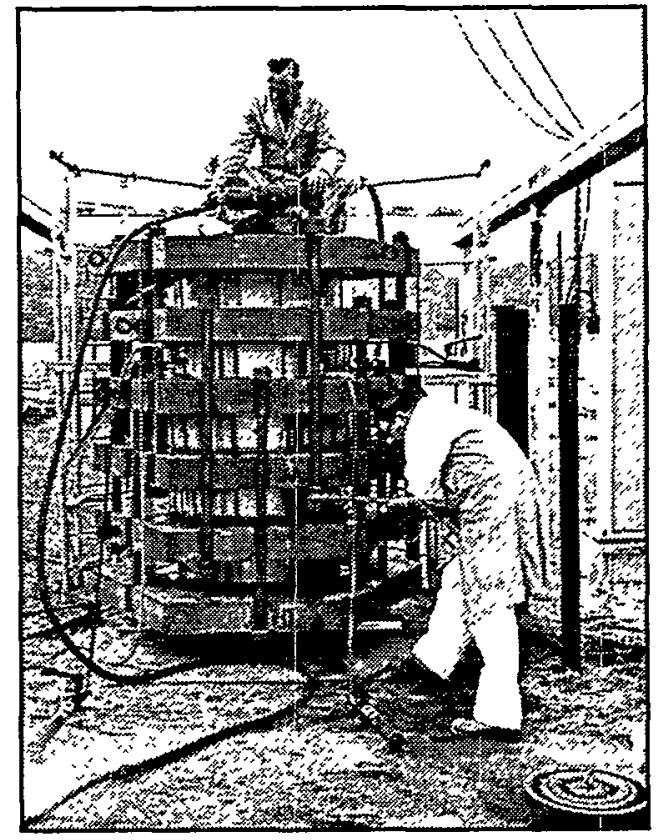

Fig. 51. Closing of the assembled explosive-forming die by positioning the retaining rings. 
during insertion, 0.010-in.-thick aluminum strips, 2 in. wide by $15 \mathrm{in.} \mathrm{long,} \mathrm{are} \mathrm{bent} \mathrm{and} \mathrm{placed}$ over the joint between the die halves. These strips are taped in place and are removed when the die is closed.

After the surfaces of the cylinder are cleaned with alcohol and wiped dry with tack cloth, the cylinder is lowered carefully into the die with an overhead hoist. Care must be taken not to scratch the cylinder on the die while it is being lowered into the die cavity. The cylinder is lifted with a lifting fixture shown in Fig. 52. The lifting fixture has two pneumatic tubes that are expanded and grip the inside diameter of the cylinder. Although the cylinder is only slightly outof-round, it is oriented in the die so that the major axis is $90^{\circ}$ from the split in the die. Care is also exercised to ensure that no weld seam is close to the splits in the die.

In the closure of the die for explosive forming, the jack screws used for opening the die are retracted below the outer surface of the die. The longitudinal O-ring seals along the split halves are inspected to ensure that they are properly sealed in their grooves and they protrude slightly above the top and bottom die faces. The cylinder is inspected to ensure that it is sealed properly on the 1/4-in.-wide land on the inside of the die cavity. The die halves are slowly drawn together using the tie bolts along the sides. A small gap will remain after the tie bolts are snugged because of the larger diameter of the cylinder compared to the die.

In the final closure of the die, the tapered outside surfaces of the die and the retaining clamping rings are cleaned and lubricated. The clamping rings are then installed individually and aligned with the tie bolts. The alignment of the clamping rings is maintained throughout by positioning the tie bolts and tightening the nuts by hand. When all rings and tie bolts have been

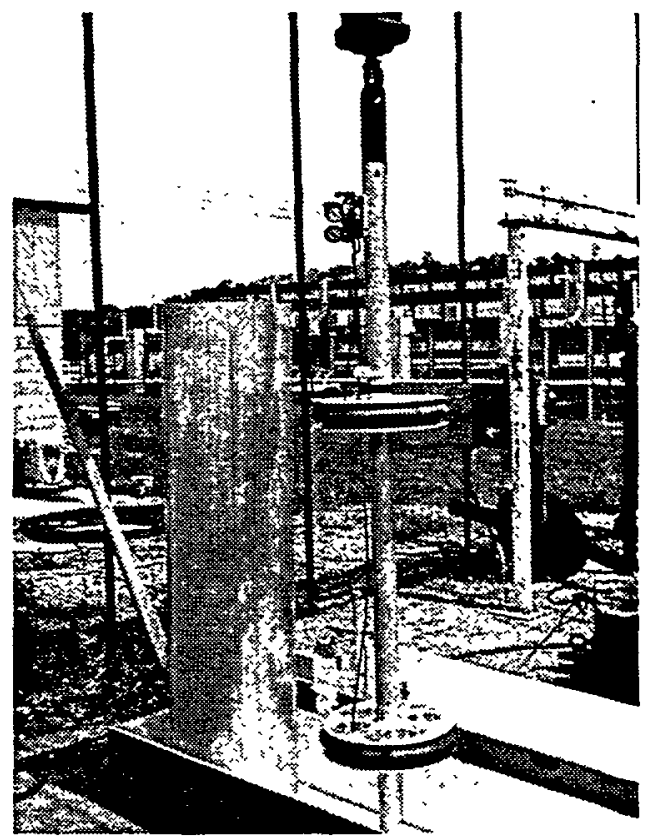

Fig. 52. Lifting fixture used to lift cylinders. installed, they are tightened sequentially and uniformly.

Gradually the diameter of the cylinder compresses and the die halves are closed with the assistance of a pneumatic impact wrench and four 10-ton jacks. The die halves are closed metalto-metal. The die is then jacked up and the slider plate is replaced with a 5-in.-thick steel plate faced with a sheet of rubber. Protectors are placed over the top evacuation holes to prevent the rubber bladder from sealing the holes. The rubber boot is tube shaped with a flange on the top end. After careful cleaning, the bladder is lowered into the die cavity, and the top flange is installed to seal the top surface and to hold the bladder in place. The bottom seal ring is then installed, and the die is evacuated by a mechanical pump to blank-off pressure of $\sim 29 \mathrm{in}$. Hg. No leaks are permitted when the vacuum system is valved off. 


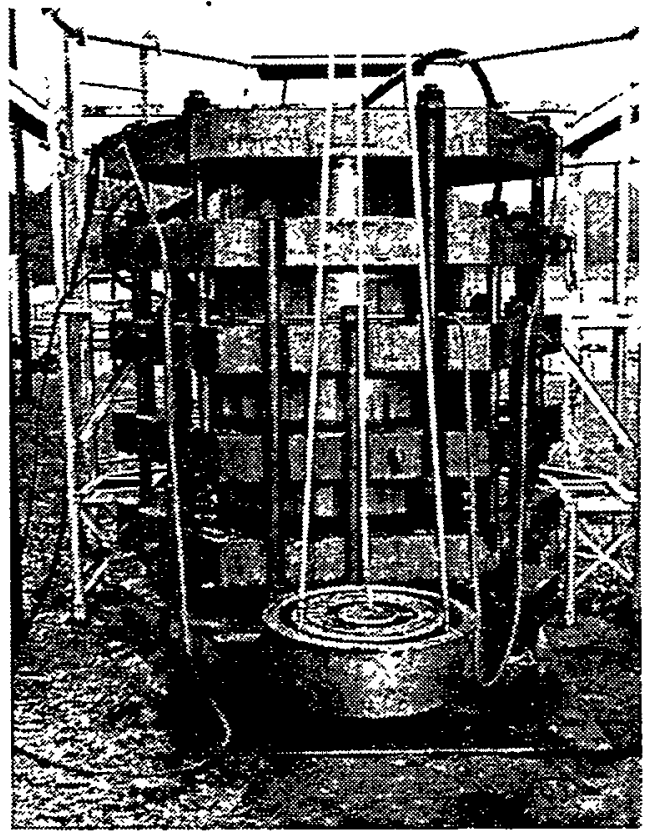

Fig. 53. Inner part of bottompositioning fixture in front of assembled die.

After the bottom fixture is lowered, the lifting rods are removed, and the Primacord is strung through a hole in the center of a wooden piece installed in the top of the die cavity. The Primacord is then pulled tight and knotted to retain one end of the Primacord in the wooden positioning piece's centering hole. The Primacord is now located along the longitudinal centerline of the die cavity and cylinder. The detonator lead wires are run to the top of the die for connection to the shot wire. The die cavity is then filled with water, the detonator leads wire is connected to the shot wire, and the Primacord is detonated. After the shot, the water is pumped from the cavity, the boot is leak checked and examined for damage, and the inner portion of the bottom positioning fixture is removed from the die. If the boot is leaktight and undamaged, the die is prepared for a second shot using the procedure described previously. The third shot is accomplished in an identical manner. A cylinder being shot is shown in Fig. 54.

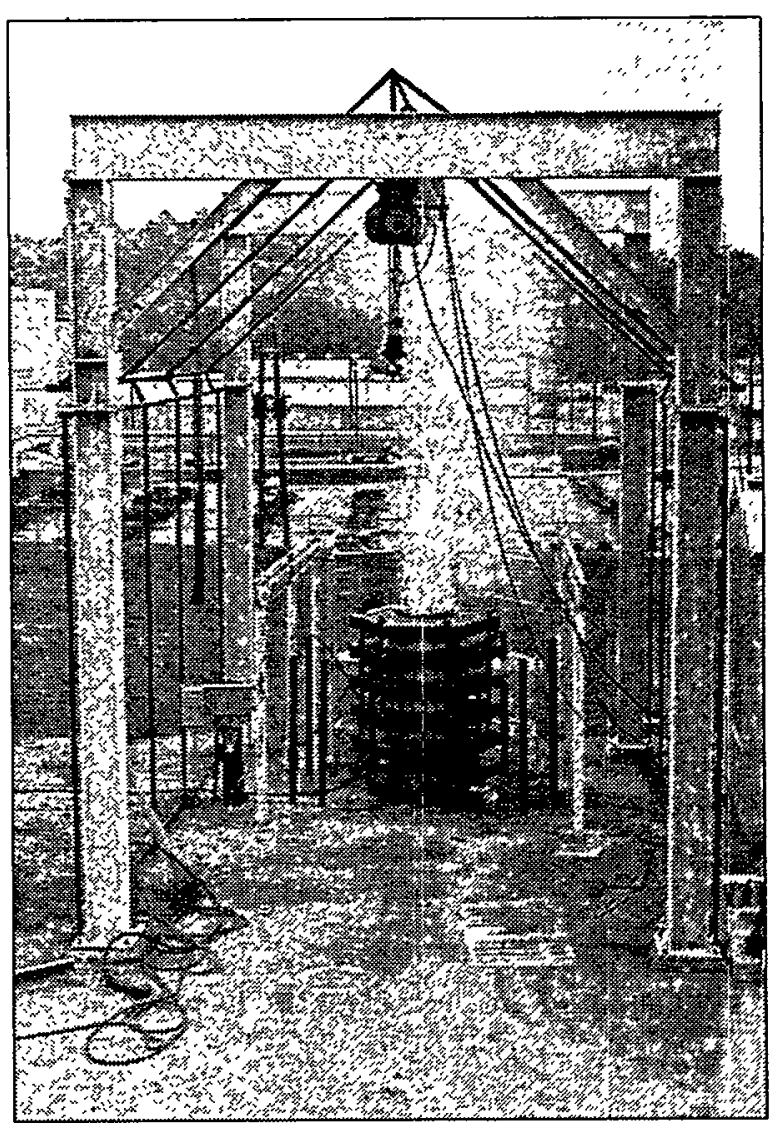

Fig. 54. Inner die assembly during explosive sizing. 
After the third shot, the die is disassembled in the reverse order as previously described and opened with the internal jack screws in the die halves. Aluminum strips are again positioned over the split in the die before removal of the sized cylinder. After removal from the die, the sized cylinder is field inspected for compliance with the dimensional requirements. If the cylinder fails to meet the dimensional requirements after the field inspection, the cylinder is reshot immediately. After satisfactory completion of the explosive-sizing operation, the die is placed back in the standby configuration with the rubber boot installed, and a rust inhibitor is applied to the metal surfaces. A tarpaulin is draped over the outside of the die for weather protection.

The inner cylinder explosive-forming die has been stored outside with a rust-preventive coating under a tarpaulin since last used in about 1987 . The rust-preventive coating is periodically renewed, but some deterioration of the die surfaces is likely. The die will probably require some reworking before use in a future campaign. Because of its weight, the die would be difficult to move to a commercial explosive-forming site. An explosive-forming pool is not required, and other facilities having an explosives-handling license, closer than Washington state, might be considered.

\subsubsection{Inspection of Sized Cylinder and Machine Ends}

After explosive sizing, the cylinder is radiographed to verify that cracks did not develop in either the core sections, the core section interfaces, or the welds as a result of the sizing operation. The cylinder is inspected dimensionally to determine that the contour meets the drawing requirements. If the cylinder does not meet the contour requirements, it may be resized at this stage by repeating the explosive-sizing operation.

The final dimensional inspection of the cylinder is performed on a lathe using the expanding mandrel fixture used for the finished machining of the ends of the cylinder. The mandrel shoes are adjusted to establish the best-fit centerline. The expanding mandrel shoes on the bottom end are adjusted to round out the cylinder as closely as possible, because this end will be held round by the end fitting. The shoes on the top end are adjusted only tight enough to contact the cylinder without distortion. A dial indicator is mounted on the lathe compound and is set at zero at 8.92 in. from the centerline of the mandrel. The surface of the cylinder is probed by rotating the cylinder and traversing the lathe compound. The maximum variation allowed is $\pm 0.030 \mathrm{in}$. from the 8.921-in. radius. If a cylinder does not meet this requirement, it is sent back for resizing. If accepted, the mandrel shoes on the top end are tightened to adapt this end of the cylinder for machining. The references for machining the bottom ends are the scribe marks, which were previously marked on each plate from the average gray/black interface before welding. From this reference, the bottom end is finished, bored, and chamfered to receive the bottom end fitting. The top end is established $683 / 8$ in. from the bottom, and this end is faced with a 1/8-in. radius. Typical measurements of a sized cylinder are listed in the following paragraphs. 


\subsubsection{Drilling and Radiusing of Holes}

Numerous hydraulic pressure equalization holes are required in the inner control cylinder, similar to the 1/4-in.-diam holes that were drilled in the outer control plates. These holes start 2 in. from the average gray/black interface in the tantalum core section and are in most of the white section on both sides of the europium core section except in the weld areas. No holes are drilled in the europium core section. A total of $\sim 2000$ quarter-inch-diameter holes are drilled in an inner control cylinder. In addition, four 5/8-in.-diam holes are drilled for installation alignment.

In drilling the holes, the cylinder remains on the mandrel fixture used for machining the ends and mounted on a numerically controlled horizontal boring milling machine. The mandrel is positioned on the mill using an index head on one end and a live center on the other end identical to the setup used for drilling the outer plates. The longitudinal location of the hole pattern is established with the numerically controlled mill starting 2 in. from the gray/black interface in the tantalum section. The axial location of the hole pattern is established from the centerline of each segment individually. The center row of holes in each segment is drilled first, and then 6 rows of holes on each side of this centerline are drilled for a total of 13 rows of holes per segment. The 5/8-in.-diam holes are located off of the centerline of segment 1 and are spaced equally from this location. The radiusing of the 1/4-in.-diam holes is accomplished using the procedures previously described for the outer plates.

\subsubsection{Final Machining of Cylinder}

The final machining of a control cylinder primarily involves the attachment of a stainless steel control rod drive bracket. This bracket orients the cylinder in the reactor, and its radial alignment with the segment plates is important to ensure that the guide bearings in the reactor track assembly ride on the weld areas and not over the core sections. A closeup view of the end bracket attached to an inner cylinder is shown in Fig. 55. The end of the inner cylinder, which is closest to the black end, is the bottom end of the control cylinder in the reactor. In the Y-12 Plant procedures, this end is referred to as the top end because this end contains the plate identification numbers and all position

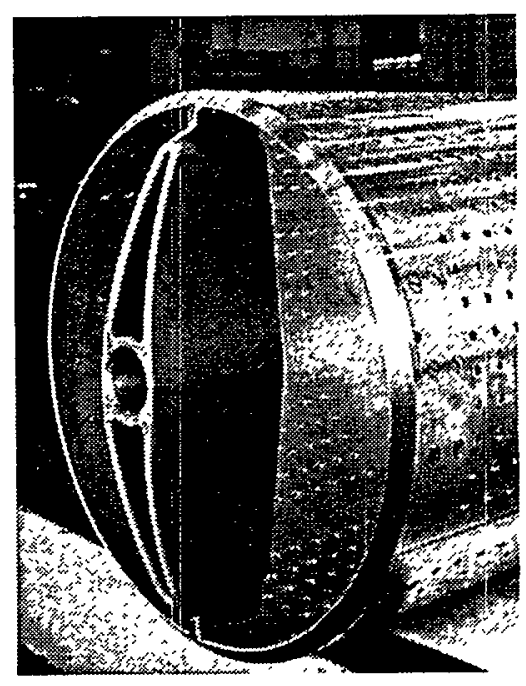

Fig. 55. Closeup view of end bracket attached to an inner cylinder. references.

The drive rod bracket is assembled to the cylinder by shrink fitting the cylinder onto the bracket. The bottom end of the cylinder is heated to $120^{\circ} \mathrm{F}$ with an acetylene torch while being protected by a thermal blanket. The thermal blanket is removed, and the cylinder is slipped over the end bracket with care being taken to ensure that the fitting is properly aligned with positioning scribe marks. After the fitting has been installed on the cylinder, the assembly is set up on a horizontal boring mill, and a cap is inserted on the top end of the cylinder. A long bolt is then positioned 
through the center hole of the bottom bracket and through a hole in the center of the top cap. Nuts on this bolt are tightened to seat the bottom bracket on the cylinder. After the bracket is seated, the assembly is set up on its best vertical centerline; and the cylinder and bracket are drilled, counter bored, tapped, and fastened together with $1 / 4-20 \mathrm{NC}$ stainless flat-head screws. A control cylinder set up for drilling and tapping to the bottom bracket is shown in Fig. 56. The temporary top cap is shown installed on the cylinder in the figure. The ends of screws are tack welded to the stainless steel bracket to prevent the screws from backing out during operation. After welding, the screw heads and ends are blended smooth.

\subsubsection{Final Inspection}

The final inspection of the inner control cylinder is made with the assembly in an unrestrained position so that all

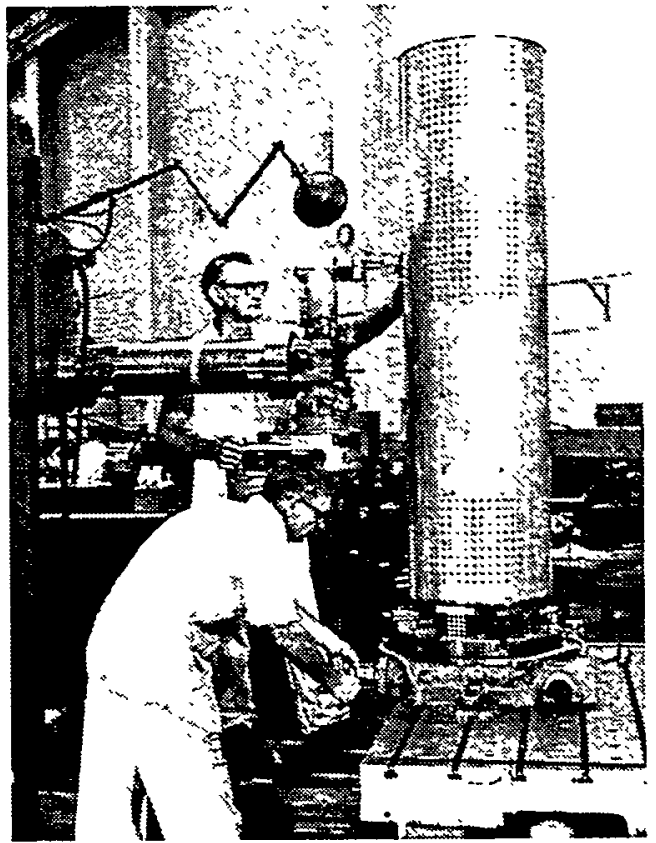

Fig. 56. Setup for final machining of control cylinder. natural radial distortions can be detected. A cylinder with the top end resting on a leveling table attached to the rotary table on an inspection machine is shown in Fig. 57. The radial deviation from the nominal 8.921-in. radius is measured in 12 locations along the length of the cylinder, starting 1 in. below the interface of the end fitting. At each location, the cylinder is rotated, and the radial deviations are recorded. Before any measurements are made, the cylinder is leveled so that the TIR between the top and bottom measuring positions is minimum. For comparison with the best centerline previously determined, measurements are made at the same longitudinal locations used previously. The average diameter at each location is determined by integration of 180 data points. The average diameter of the cylinder is the average of the 12 individual measurements. The final operation before shipping is the cleaning of the cylinder surfaces with alcohol to remove all traces of oil and organic markings. The cylinder is then cleaned with a detergent and wrapped in plastic in the manner previously described for the outer plates. A completed inner control cylinder is shown in Fig. 58.

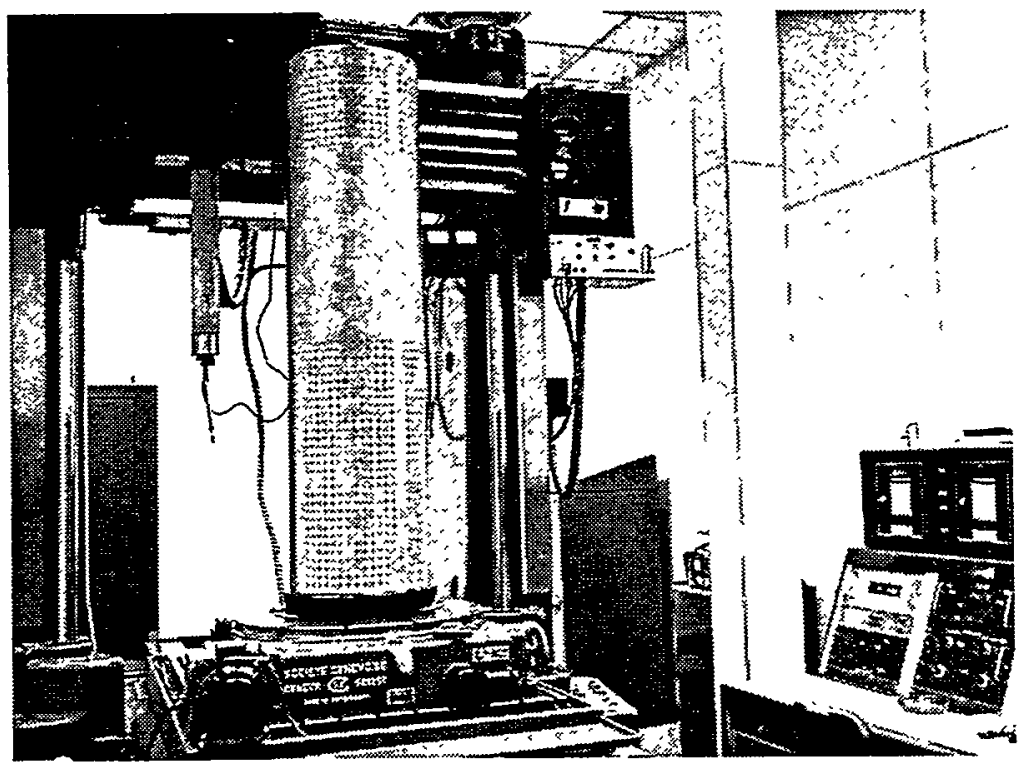

Fig. 57. Position of inner control cylinder for final inspection. 


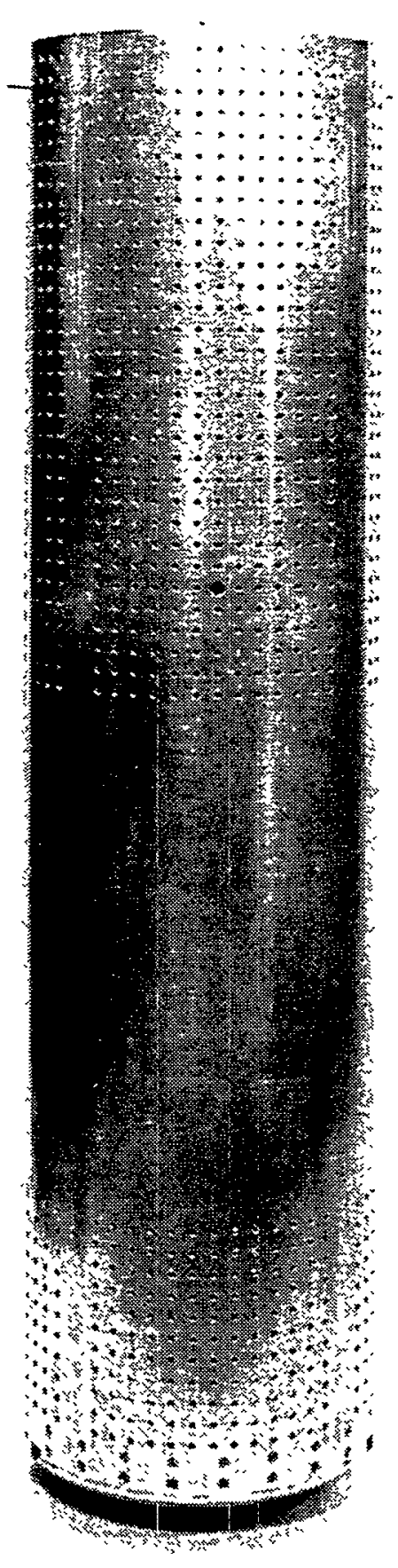

Fig. 58. Completed inner control cylinder. 


\section{SUMMARY OF OBSERVATIONS AND RECOMMENDATIONS}

\subsection{GENERAL}

The fabrication of HFIR control rods is an expensive and time-consuming process that will take at least 2 to 3 years to complete under the best of circumstances using the lessons learned from the current campaign (see Fig. 59). A magnitude estimate of the costs for fabricating control plates in FY 1997 dollars is shown in following table.

Setup and qualifications

$$
400,000
$$

300,000

150,000

300,000

Fabrication of inner cylinder (4 plates)

Total setup and qualification

Incremental cost for an outer plate

Incremental cost for inner cylinder
$1,150,000$

130,000

410,000
Incremental cost

30,000

30,000

70,000

350,000

Because the cost of setup and qualification is such a significant percentage of the overall costs, future plans should be to fabricate additional control plates and cylinders in campaigns as large as can be practically funded.

The cost of fabricating two sets (four each) of outer plates plus one spare (nine plates total) in the last campaign was about $\$ 2.5$ million over the approximately 4 years of the campaign. Some of this cost can be attributed to delays, changes in environmental regulations, and technical problems. 


\begin{tabular}{|c|c|c|c|c|c|c|c|c|c|c|c|c|c|c|}
\hline \multirow[b]{2}{*}{ ID } & \multirow[b]{2}{*}{ Task Name } & \multicolumn{4}{|c|}{ Year 1} & \multicolumn{4}{|c|}{ Year 2} & \multicolumn{4}{|c|}{ Year 3} & \multirow[b]{2}{*}{ Qtr 1} \\
\hline & & Qtr 1 & Qtr 2 & Qtr3 & Qtr 4 & Qtr 1 & Qtr 2 & Qtr 3 & Qtr 4 & Qtr 1 & Qtr 2 & Qtr 3 & Qtr 4 & \\
\hline 1 & Preparation of Flat Plates & & & & & & & & & & & & & \\
\hline 2 & Procure Powders & & & & & & & & & & & & & \\
\hline 3 & Prepare Europium & & & & & & & & & & & & & \\
\hline 4 & Press Compacts & & & & & & & & & & & & & \\
\hline 5 & Hol Roll Plates & & & & & & & & & & & & & \\
\hline 6 & Inspection & & • & & & & & & & & & & & \\
\hline 7 & OA Review & & & & & & & & & & & & & \\
\hline 8 & Formation of Curved Plates & & & & & & & & & & & & & \\
\hline 9 & Flatten Anneal & & & & & & & & & & & & & \\
\hline 10 & Glue Backup Plate & & & & & & & & & & & & & \\
\hline 19 & Brake Press Form & & & & & & & & & & & & & \\
\hline 12 & Remove Backup Plate & & & & & & & & & & & & & \\
\hline 13 & Explosive Size & & & & & & & & & & & & & \\
\hline 14 & Inspection & & & & & & & & & & & & & \\
\hline 15 & Fabrication of Outer Plates & & & & & & & & & & & & & \\
\hline 16 & Establish Centertine & & & & & & & & & & & & & \\
\hline 17 & Machine Plate Edges & & & & & & & & & & & & & \\
\hline 18 & Drill Holes & & & & & & & & & & & & & \\
\hline 19 & Radius Holes & & & & & & & & & & & & & \\
\hline 20 & Inspection & & & & & & & & & & & & & \\
\hline 21 & Machine for End Fittings & & & & & & & & & & & & & \\
\hline 22 & Inspection- QA & & & & & & & & & & & & & \\
\hline 23 & Fabrication of Inner Cylinder & & & & & & & & & & & & & \\
\hline 24 & Establish Centerline & & & & & & & & & & & & & \\
\hline 25 & Machine Plate Edges & & & & & & & & & & & & & \\
\hline 26 & Weld Cylinder & & & & & & & & & & & & & \\
\hline 27 & Explosive Size & & & & & & & & & & & & & \\
\hline 28 & Drill Holes & & & & & & & & & & & & & \\
\hline 29 & Radius Holes & & & & & & & & & & & & & \\
\hline 30 & Machine for End Fitting & & & & & & & & & & & & & \\
\hline 31 & Inspection - QA & & & & & & & & & & & & & \\
\hline
\end{tabular}

Fig. 59. Critical path for fabrication of HFIR control plates. 
This campaign was delayed about $11 / 2$ years by hot-rolling problems in the Metals and Ceramics Division, getting tooling stored at ORNL cleared to ORNL radiation release standards for shipping to the Y-12 Plant, the Y-12 Plant stand-down, priority of weapons programs at the Y-12 Plant, and maintenance associated with old digital hardware on the machining and inspection equipment. During this last campaign, procedures were rewritten and drawings modified to incorporate lessons learned to allow the next campaign to begin with this knowledge base, which should reduce the setup and qualification costs in future campaigns. To avoid having to meet ORNL plutonium radiation release standards for minor uranium contamination that may be present on some of the tooling, efforts will be made to store the tooling at the Y-12 Plant for the next campaign. The storage of this tooling needs to monitored and the tooling maintained, particularly the explosive forming dies, to ensure their serviceability in future campaigns. For future campaigns, the use of outside sources for performing some or all of the work should be also be considered to reduce costs.

The fabrication of control plates involves powder metallurgy, metal forming and heat-treating processes, and precision machining and is a relatively complex operation. Because the metallurgical processes are the keys to successfully fabricating control plates, a person with fabrication experience and a good understanding of powder and other metallurgical processes will be required to supervise future campaigns for $R R D$.

\subsection{PREPARATION OF FLAT PLATES}

In the future, all powders and raw materials should be dedicated by RRD to avoid some of the quality assurance problems experienced in establishing materials certifications. The procurement of a dense arc-melted derived tantalum powder is essential for making the control plates because the use of improperly specified tantalum powder caused rejection of all outer control plates made in the 1977 campaign. In the future, it may be difficult and expensive to procure arc-melted tantalum powder because this is not a standard commercial product. In the last campaign, the vendor had a very difficult time making the powder to the required particle size and did not ship the full ordered quantity. The $40 \mathrm{vol} \%$ loading of tantalum powder specified is very close to the maximum obtainable without having a continuous tantalum phase and should be lowered to $35 \mathrm{vol} \%$ if the nuclear considerations can be met.

During preparation of the raw materials for the compacts, the arc melting of the $\mathrm{Eu}_{2} \mathrm{O}_{3}$ adds significant contamination to the powder and is an expensive and time-consuming process. In the future, some consideration should be given to using a sinter product such as was developed by the M\&C Division for a europium oxide liner used in a materials irradiation test in early 1997.

The sintered europium particles need to be evaluated to ensure that they will not stringer during hot rolling. In the preparation of compacts, the use of a dial indicator to press the compacts to length proved very successful in controlling the compact height. 
Shrink fit of the compacts into the frame as currently specified is not necessary based on HFIR fuel plate experience and should be eliminated to simplify assembly and to avoid additional oxidization of the frame and covers. To eliminate shrink fitting and continue to use the existing powder dies, the dimensions of the billet cavity must be increased slightly. The allowable core width on the outer plates should be narrowed to 13.10 in. maximum to avoid potential problems with the edge margins around the europium core section. With the current design, the margin around the europium core where the plates must be beveled for clearance of the inner control rod track bearings during installation in the reactor is very marginal at the maximum core width of 13.31 in. now allowed. The design of the powder compact and the rolling schedule will need to be modified to meet a narrower core width requirement and to allow for change in the cavity dimensions. Use of electric-discharge machining for forming the cavity in the billet-forming hardware should be considered.

The hot rolling of the plates on the outdated 1908-vintage Mesta rolling mill was difficult even without the problems resulting from using improperly matched rolls. The use of the unmatched rolls probably was a secondary effect on the problems experienced in the last campaign. Matching and resurfacing the mill rolls can be easily accomplished by an outside source within several weeks and should be considered before beginning a campaign on any mill. Before the next campaign, the Mesta mill needs to be updated, or an outside rolling mill should be used. The frame on the Mesta mill is rigid, and it could be modernized by replacing the $120^{\circ}$ babbit bearings with full circumference bearings and adding hydraulic cylinders to support the top roll. The electric drive motor and the feed table also need to be reworked or replaced. The take-off table also needs to be eliminated or modified to avoid scarring the plates during rolling. A Teflon sheet or coating on the rollings might help, but the random way a plate is released from the rolls during hot rolling is likely causing most of the scarring. Hand catching plates without a take-off table as used on HFIR fuel plates may be effective if the safety implications can be resolved. The need for cross rolling requires a mill with at least a 30-in. opening, and it may be difficult to find such a mill available for this type of work. Most available mills have a maximum mill opening of 24 in.

The curving of the billet during hot rolling will likely be a continuing problem in the future because of the sensitivity of the rolling process to the amount of lubrication on the rolls. The wipers used to apply lubrication to the rolls need to be changed to a design similar to the wipers used on the rolls for the HFIR fuel plates to help alleviate this problem. If excess billet curvature is experienced, the billet should be flattened before proceeding because the curvature will likely increase on subsequent passes and result in rupturing of the cladding. Ruptured cladding was experienced on two plates in the last campaign. Some type of press or clamping fixture needs to be developed to replace the diagonal pass procedure for flattening a curved billet during hot rolling. Skewness of the core section resulting from the Mesta mill's changing level during rolling was a significant problem in the last campaign. A hot-rolling rotational sequence was found to minimize skewness and was implemented in the middle of the last campaign. In this sequence, the billet is first rotated on its long axis (flip pass) before leading with the opposite end. This sequence should be used regardless of the mill used in the future. 


\subsection{FORMING OF CURVED PLATES}

In the flattening annealing, the use of aluminum plates eliminated the galling experienced during this operation in the 1987 campaign when stainless steel was used next to the plates. A clamping fixture for flattening to apply more pressure than the dead weights in the current procedure needs to be considered. Talc, which was used as a separation aid, may not be necessary. In the forming of the curved plate, the cleaning of the plates with an abrasive grit was acceptable for bonding and simplified handling of the plates because the work was performed within one work group. A bonding strength test was implemented in the last campaign because of a problem with the epoxy bonding on one plate. This problem was likely caused when the epoxy components were not mixed properly before dispensing the epoxy components for the batch used on that plate. The ultrasonic bond test cannot determine the bond quality in the core area because of interference from the particles in the core but is still valuable in determining the overall bond quality. The ultrasonic test also indicated nonbond in some areas where a plate had slightly raised areas (kinks). These areás did not cause any problems during preforming.

The layout of the centerline from the X-ray results is critical before preforming to ensure that the core is preformed in a manner that allows adequate margins around the core after final machining. The $\mathrm{X}$-ray procedures were rewritten during the last campaign to allow the use of a lower voltage X-ray machine and to clarify the requirements. The preforming was accomplished relatively trouble free. The removal of the backup plate for the preformed plate resulted in some charring of the epoxy until the temperature of the debonding operation was controlled with a thermocouple embedded in the plate edge. A nontoxic cleaner that was environmentally acceptable was identified for the removal of the epoxy remaining on the plates after debonding and worked very effectively. Some of the plates that had charred epoxy remaining after the use of the nontoxic cleaner required abrasive cleaning.

Explosive forming by an outside vendor in Washington state went very smoothly and showed that two plates can be easily explosively sized in a working day after the initial setup. The explosive-forming procedures were completely rewritten and reflect the operations thoroughly. The transportation of the plates by air freight was without incident. After explosive forming, the formed diameter on some plates was smaller than desired. To reduce this "spring-in" problem in the future, the diameter of the preformed plates should be targeted toward the upper tolerance. During explosive forming, shredded rubber from the sealing bladder caused some embossed marks on the finish plates. This problem can be reduced by improving the screws used to clamp the bladder. The use of a stearic acid lubricant eliminated a galling problem on the removal of the positioning pins after explosive sizing.

\subsection{FABRICATION OF OUTER PLATES}

The machining of the curved plates to final size employed, with few modifications, the machining procedures that have been used in the past campaigns. The setup of the correct centerline of a plate on the machining mandrel is a time-consuming, trial-and-error process that 
may take up to several days for one plate. The radius of a plate is inspected on the milling machine before machining, and the radius is adjusted on the brake press if necessary. The radius on two plates was adjusted during the last campaign. The location and verification of the core by $\mathrm{X}$ ray before machining the edges is another critical step because of the small side edge margins around the europium core section in the outer plates. Adjustments of the side margins on some plates were required from the $\mathrm{X}$-ray verification shots. The drilling of the pressure-equalization holes was performed using the numerical positioning features of the milling machine. We found it necessary to verify the machine positioning before drilling because a wrong tape was inadvertently used in programming the milling machine. The drilling of the pressure-equalization holes after developing the proper cutting tool went relatively smoothly.

Radiusing the pressure-equalization holes and hand finishing and polishing to remove all blemishes greater than 0.0005 in. from the plate surfaces was very time consuming. It took on the order of one week per plate to accomplish these operations. The hand finishing of the plates surfaces should be done before the holes are radiused to avoid having to redo the holes. Radiusing both sides of the approximately 500 holes individually with the special tool is a tedious, boring task.

The inspection of the completed curved outer plates at this stage was performed in an unconstrained state on a programmable coordinate measuring machine (CMM). The inspection results showed that a number of dimensions were out of the specified tolerance ranges. Most significant was that the measured radius of the plates was smaller than specified. An outer control plate in the reactor is positioned from the reactor outer control rod tracks and bearings installed on the top and bottom plate brackets. To better understand the effect of the out-oftolerance curvature on the clearances in the reactor, the radius of the most out-of-tolerance plate was used in a detailed CAD layout of the clearances. This layout showed that the clearances were not significantly affected. The clearances will also likely improve when the brackets are bolted in place on the plates. In addition, the other tolerances' conditions were judged not to affect the form fit or function of the plate or will be corrected when the end brackets are attached.

In past campaigns the completed curved plates have been preformed on the milling machine used to machine the plates using a master template gauge. To understand if the current plates were significantly more out of tolerance than previously made plates, three randomly selected plates from the 1977 campaign that had been rejected because of the tantalum powder problem were inspected on the same automated inspection device used in the current campaign. This comparison showed that the out-of-tolerance dimensions in the current campaign were not significantly different from plates that had previously been accepted for use in HFIR. Based on these findings and the curved plate $\mathrm{CAD}$ layout, the tolerances on the plate engineering drawing were revised to reflect more realistic tolerances.

The single-piece construction of the brackets was a significant cost and quality improvement over the welded construction used in the past. The use of programmed electric discharge machining (EDM) for rough cutting was relatively straightforward. The final machining of the 
brackets was done on a numerically controlled milling machine. After the machining programs were established, the machining went relatively smoothly and quickly. Programming for dimensional inspection of the brackets, particularly the lower brackets, is relatively complex because the lower bracket has over 100 inspection point call-outs. Additional design modifications should be considered to further reduce fabrication and inspection costs of the brackets.

The final machining and attachment of the end brackets took several weeks for each plate but went relatively smoothly. It was necessary to develop a procedure for upsetting the aluminum screws used for attachment of the brackets. The screws are upset to prevent them from backing out during operation in the reactor. The current screw design used may not be optimal, but it provides a backoff torque comparable to staking the screw head as was done in earlier campaigns. Torquing and loosening the bracket screws multiple times was found to be very useful in obtaining consistent backoff torque results.

The final inspection of the plates was done on the machine tool used in the final machining of the plates. The assembly drawing was revised to reflect changes in the screw-upsetting procedure and for clarification of dimensional inspection requirements. The final inspection of all plates met the reactor requirements with only minor deviations.

Numerous delays during the entire course of fabricating the outer control plates at the Y-12 Plant resulted from waiting on inspection results. Priority of the weapons and other defense programs was the principal reason for these delays, but the maintenance of the inspection devices was a continuing problem that exacerbated the situation.

The use of two reference centerlines (0.041-in. offset) in the outer control plate assembly created confusion throughout machining and inspection. The continued need for these two centerlines will be examined, and one will either be eliminated or the drawings will be modified to clarify the two centerlines at the conclusion of this campaign.

\subsection{FABRICATION OF INNER CYLINDER}

The section of this report on the inner control rod fabrication is principally a rewrite of the information presented in the previous control plate report. ${ }^{2}$ The references on the welding process report and the explosive-forming video are most useful in understanding the inner control plate processes. Changes made in the text on explosive forming were from personal communications with Jim Turley, the Y-12 Plant explosive-forming expert, and from the video on explosive forming. 


\section{REFERENCES}

1. The High-Flux Isotope Reactor-A Functional Description, ORNL-3572, F. T. Binford, T. E. Cole, and E. N. Cramer, May 1968.

2. Fabrication Procedures for HFIR Control Plates, ORNL/TM-9365, G. A. Bowden, G. R. Hicks, and R. W. Knight, August 1984.

3. Problems with the HFIR Control Rod Drives and their Solutions, ORNL/TM-2505, A. P. Fraas and A. A. Abbatiello, November 1969.

4. "High Flux Isotope Reactor (HFIR) Control Rod Blisters," letter from R. W. Knight to S. S. Hurt, July 9, 1992.

5. ORNL Welding Procedure Specification, WPS-1000-ASME-1, Sect. 3.5.5, Weld Repair of Blisters.

6. HFIR Control Rod Radiography, No. AA6-Q-001, Rev. L. 
. 
Appendix A

PAST FABRICATION CAMPAIGNS' CONTROL DOCUMENTS AND PROCEDURES 
Document Control Tabulation - HFIR-ME-FF-234January 9, 1997

\begin{tabular}{|c|c|c|c|c|c|}
\hline Type document & Drawing No. & Rev. & Date & Status & Title \\
\hline \multirow[t]{11}{*}{ RRD Eng. Dwg. } & E-49443 & $\mathrm{C}$ & $8 / 16 / 93$ & CFC & Inner \& Outer Control Plate - "Billets“ \\
\hline & $E-49820$ & V & $12 / 17 / 96$ & CFC & Outer Control Rod Assembly \\
\hline & E-49821 & $\mathrm{T}$ & $1 / 11 / 97$ & CFC & $\begin{array}{l}\text { Outer Control Rod Lower Flange Finish } \\
\text { Machine }\end{array}$ \\
\hline & E-49823 & $N$ & $9 / 27 / 94$ & CFC & Outer Control Rod Quadrant Details \\
\hline & $E-49825$ & $\mathrm{P}$ & $1 / 11 / 97$ & CFC & $\begin{array}{l}\text { Outer Control Rod Upper Flange Finish } \\
\text { Machine }\end{array}$ \\
\hline & E-50098 & $\mathrm{D}$. & $12 / 17 / 68$ & CFC & $\begin{array}{l}\text { Outer Control Rod Female Clearance } \\
\text { Gauge }\end{array}$ \\
\hline & D-50099 & 0 & $1 / 23 / 68$ & CFC & $\begin{array}{l}\text { Drill Jig for Bearing Shaft Mounting } \\
\text { Lugs }\end{array}$ \\
\hline & $\mathrm{M}-11460-\mathrm{OH}-302-\mathrm{D}$ & 0 & $6 / 21 / 96$ & CFC & $\begin{array}{l}\text { Outer Control Rod Flänge Screw } \\
\text { Details }\end{array}$ \\
\hline & E-49440 & $\mathrm{H}$ & $7 / 3 / 96$ & CFC & Journal Bearing Assembly \\
\hline & $\mathrm{E}-49822$ & $\mathrm{~K}$ & $10 / 12 / 90$ & CFC & Inner Control Rod Assembly \\
\hline & E-29824 & $\mathrm{K}$ & $10 / 12 / 90$ & CFC & Inner Control Rod Details \\
\hline • & $E-42376$ & $T$ & $10 / 12 / 90$ & CFC & Inner Control Rod Drive Bracket \\
\hline
\end{tabular}


Document Control Tabulation - HFIR-ME-FF-234

\begin{tabular}{|c|c|c|c|c|c|}
\hline $\begin{array}{l}\text { Type } \\
\text { Document }\end{array}$ & Specification & Rev. & Date & Status & Title \\
\hline \multirow[t]{10}{*}{$\begin{array}{l}\text { General } \\
\text { Specifications }\end{array}$} & RRD-MS-50 & 1 & $5 / 20 / 91$ & CFC & $\begin{array}{l}\text { Specification for stainless steel materials for } \\
\text { HFIR system and reactor components }\end{array}$ \\
\hline & RRD-MS-52 & 2 & $7 / 2390$ & CFC & Specification for aluminum materials \\
\hline & RRD-JS-24 & 1 & $8 / 09 / 89$ & CFC & Specification for dimensional inspection \\
\hline & RRD-JS-28 & & $3 / 14 / 80$ & CFC & $\begin{array}{l}\text { Specificating for the fabrication of components by } \\
\text { outside suppliers }\end{array}$ \\
\hline & RRD-JS-31 & & $12 / 16 / 81$ & CFC & $\begin{array}{l}\text { Specification for cleaning and cleanliness } \\
\text { requirements }\end{array}$ \\
\hline & WPS-302 & & $8 / 77$ & CFC & $\begin{array}{l}\text { Gas tungsten-arc welding of chromium-nickel } \\
\text { steel }\end{array}$ \\
\hline & WPS-1000-ASME-1 & & $8 / 9 / 89$ & CFC & $\begin{array}{l}\text { Gas tungsten-arc welding of aluminum alloys } \\
6 \mathrm{XXX}\end{array}$ \\
\hline & RRD-MS-101 & 0 & $2 / 5 / 93$ & CFC & $\begin{array}{l}\text { Specification for TA powder for manufacture } \\
\text { HFIR control plates }\end{array}$ \\
\hline & RRD-MS-102 & 0 & $8 / 93$ & CFC & $\begin{array}{l}\text { Specification for } A 1 \text { powder for manufacturer of } \\
\text { HFIR control plates }\end{array}$ \\
\hline & RRD-MS-103 & 0 & $8 / 93$ & CFC & $\begin{array}{l}\text { Specification for europium oxide powder for use } \\
\text { in HFIR control plates }\end{array}$ \\
\hline
\end{tabular}


Document Control Tabulation - HFIR-ME-FF-234

\begin{tabular}{|c|c|c|c|c|c|}
\hline $\begin{array}{l}\text { Type } \\
\text { Document }\end{array}$ & Specification & Rev. & Date & Status & Title \\
\hline \multirow{22}{*}{$\begin{array}{l}\text { Procedures } \\
\text { Rolled Plates }\end{array}$} & MET-MatFQ-D-30 & & $4 / 20 / 93$ & CFC & Fabrication of HFIR control rod plates \\
\hline & MET-MatP-D-49 & 2 & $3 / 14 / 95$ & CFC & $\begin{array}{l}\text { Characterization of as-received europium oxide } \\
\text { powder }\end{array}$ \\
\hline & MET-MatP-D-50 & 2 & $3 / 14 / 95$ & CFC & $\begin{array}{l}\text { Fabrication of arc-melted buttons of europium } \\
\text { oxide }\end{array}$ \\
\hline & MET-MatP-D-51 & 2 & $3 / 14 / 95$ & CFC & Prepare and characterize Eu. O. powder \\
\hline & MET-MatP-D-52 & 2 & $3 / 14 / 95$ & $\mathrm{CFC}$ & Characterization of as-received aluminum powder \\
\hline & MET-MatP-D-53 & 2 & $3 / 14 / 95$ & CFC & Prepare and characterize aluminum powder \\
\hline & MET-MatP-D-54 & 2 & $3 / 14 / 95$ & CFC & Characterization of as-received tantalum powder \\
\hline & MET-MatP-D-55 & 2 & $3 / 14 / 95$ & CFC & Prepare and inspect control rod compacts \\
\hline & MET-MatP-D-56 & 2 & $3 / 14 / 95$ & CFC & Prepare aluminum covers \\
\hline & MET-MatP-D-57 & 3 & $3 / 14 / 95$ & CFC & Prepare aluminum frames \\
\hline & MET-MatP-D-58 & 2 & $3 / 14 / 95$ & CFC & Prepare and assemble evacuated billets \\
\hline & MET-MatP-D-59 & 3 & $3 / 14 / 95$ & CFC & Fabrication control plates \\
\hline & MET-MatP-D-62 & 2 & $3 / 14 / 95$ & CFC & Prepare aluminum evacuation stems \\
\hline & MET-MatP-SOP4 & $\mathbf{0}$ & $2 / 9 / 94$ & CFC & Mesta Rolling Mill Setup and Qualification Plan \\
\hline & MET-MatP-SOP21 & 1 & $10 / 13 / 70$ & $\mathrm{CFC}$ & Pressing of fuel compacts \\
\hline & MET-MatP-SOP31 & 0 & $6 / 09 / 70$ & CFC & Cleaning aluminum cladding for roll bonding \\
\hline & MET-MatP-SOP4I & 0 & $12 / 11 / 70$ & CFC & Cold pressing of powders \\
\hline & MET-MatP-SOP48 & 0 & $12 / 17 / 70$ & CFC & Watson Stillman Press \\
\hline & MET-MatP-SOP49 & 0 & $12 / 17 / 70$ & CFC & Faguhar 500-ton press \\
\hline & MET-MatP-SOP69 & 0 & $3 / 93$ & CFC & Calcining furnace - balcony (MP-28) \\
\hline & MET-MatP-SOP108 & 0 & & & Brew furnace - (MP-2) \\
\hline & GB 5-26-76 & & $5 / 76$ & & Inspection of HFIR Control Plates \\
\hline
\end{tabular}


Document Control Tabulation - HFIR-ME-FF-234

\begin{tabular}{|c|c|c|c|c|c|}
\hline $\begin{array}{l}\text { Type } \\
\text { Document }\end{array}$ & Specification & Rev. & Date & Status & Title \\
\hline \multirow[t]{8}{*}{$\begin{array}{l}\text { Y-12 } \\
\text { Procedures }\end{array}$} & AA6-G-001 & $\mathrm{H}$ & $10 / 16 / 95$ & CFC & HFIR Control Plate Bonding and Unbonding \\
\hline & AA6-GF-7196-61 & A & $10 / 11 / 95$ & $\mathrm{CFC}$ & $\begin{array}{l}\text { HFIR Control Plate Bonding and Unbonding } \\
\text { Data Sheet }\end{array}$ \\
\hline & AA6-Q-001 & $\mathrm{L}$ & $4 / 8 / 96$ & CFC & HFIR control rod radiography \\
\hline & AA6-T-7196-61 & C & $7 / 22 / 96$ & CFC & HFIR outer control rod machining procedures \\
\hline & AA6-T-7091-21 & $\mathrm{F}$ & $2 / 16 / 79$ & CFC & Inner control rod machining procedures \\
\hline & AA6-Y-004 & B & $9 /\lceil 4 / 95$ & CFC & $\begin{array}{l}\text { Flattening of HFIR Inner and Outer Control } \\
\text { Plates }\end{array}$ \\
\hline & AA6-Y-004A & A & $12 / 10 / 96$ & CFC & $\begin{array}{l}\text { Stress Relieve of HFIR Inner and Outer Control } \\
\text { Plates }\end{array}$ \\
\hline & AA6-Y-005 & A & $12 / 10 / 96$ & CFC & $\begin{array}{l}\text { HFIR Control Rod Lower and Upper Machining } \\
\text { Procedure }\end{array}$ \\
\hline
\end{tabular}


Document Control Tabulation - HFIR-ME-FF-234

\begin{tabular}{|c|c|c|c|c|c|c|}
\hline $\begin{array}{l}\text { Type } \\
\text { Document }\end{array}$ & Specification & Rev. & Date & $\begin{array}{c}\text { Cross } \\
\text { Reference }\end{array}$ & Status & Title \\
\hline \multirow{21}{*}{$\begin{array}{l}\text { Y-12 Tooling } \\
\text { Drawing }\end{array}$} & B-T-26829 & & $3 / 13 / 67$ & & CFC & Outer rod. pin expanding tool \\
\hline & D-T-33029 & & $4 / 17 / 63$ & $E-42293$ & CFC & $\begin{array}{l}\text { Explosive forming die platform. } \\
\text { outer rod }\end{array}$ \\
\hline & C-T-33078 & & $12 / 27 / 67$ & E-49820 & $\mathrm{CFC}$ & Drill jig \\
\hline & D-T-33263 & & $6 / 4 / 63$ & & $\mathrm{CFC}$ & Debuffing tool \\
\hline & D-T-33886 & & $4 / 16 / 69$ & & CFC & Pneumatic lifting fixture \\
\hline & D-T-33926 & B & $7 / 24 / 63$ & & CFC & $\begin{array}{l}\text { Explosive sizing die. wooden } \\
\text { charge positioner }\end{array}$ \\
\hline & D-T-33944 & & $8 / 19 / 63$ & & CFC & Gauge adaptor. outer rod \\
\hline & D-T-34945 & & $9 / 01 / 64$ & & CFC & HFIR reactor grade. X-ray grid \\
\hline & D-T-41378 & & $5 / 02 / 67$ & & $\mathrm{CFC}$ & $\begin{array}{l}\text { Molding forming press brake die } \\
\text { mold }\end{array}$ \\
\hline & D-T-41379 & & $5 / 02 / 67$ & & CFC & Mold shipping container \\
\hline & E-T-4854I & & $2 / 07 / 63$ & & CFC & Annealing fixture. outer rod \\
\hline & E-T-46069 & & $3 / 02 / 63$ & E-42293 & CFC & Shipping container. outer rod \\
\hline & E-T-46070 & & $3 / 04 / 63$ & $E-42293$ & CFC & Lifting device. outer rod \\
\hline & E-T-46184 & B & $6 / 17 / 65$ & $E-42293$ & CFC & Explosive forming body. outer rod \\
\hline & E-T-46185 & & $3 / 02 / 63$ & $E-42293$ & CFC & Lifting device. carrier. outer rod \\
\hline & E-T-46853 & A & $6 / 17 / 64$ & E-42293 & CFC & $\begin{array}{l}\text { Explosive forming. body detail. } \\
\text { outer rod }\end{array}$ \\
\hline & E-T-46859 & & $4 / 25 / 63$ & E-42293 & CFC & Flat plate shipping container \\
\hline & E-T-52715 & & $3 / 16 / 64$ & E-49901 & CFC & $\begin{array}{l}\text { Machining mandrel. detail. outer } \\
\text { control rod }\end{array}$ \\
\hline & E-T-52716 & & $3 / 16 / 64$ & E-49901 & CFC & $\begin{array}{l}\text { Machining mandrel. detail. outer } \\
\text { control rod }\end{array}$ \\
\hline & E-T-52717 & & $3 / 16 / 64$ & E-49901 & CFC & $\begin{array}{l}\text { Machining mandrel. assembly. } \\
\text { outer control rod }\end{array}$ \\
\hline & E-T-52727 & & $3 / 19 / 64$ & E-49901 & CFC & $\begin{array}{l}\text { Machining mandrel. detail. outer } \\
\text { control rod }\end{array}$ \\
\hline
\end{tabular}




\begin{tabular}{|c|c|c|c|c|c|c|}
\hline $\begin{array}{l}\text { Type } \\
\text { Document }\end{array}$ & Specification & Rev. & Date & $\begin{array}{c}\text { Cross } \\
\text { Reference }\end{array}$ & Status & Title \\
\hline \multirow[t]{20}{*}{$\begin{array}{l}\text { Y-12 Tooling } \\
\text { Drawing }\end{array}$} & E-T-52731 & & $3 / 16 / 64$ & E-49901 & CFC & $\begin{array}{l}\text { Machining mandrel. detail. outer } \\
\text { control rod }\end{array}$ \\
\hline & E-T-53501 & A & $5 / 05 / 64$ & E-49902 & CFC & $\begin{array}{l}\text { Riveting mandrel. assembly: inner } \\
\text { and outer control rod }\end{array}$ \\
\hline & E-T-53502 & & $4 / 15 / 64$ & E-49902 & CFC & $\begin{array}{l}\text { Riveting mandrel. assembly. inner } \\
\text { and outer control rod }\end{array}$ \\
\hline & E-T-53503 & A & $5 / 05 / 64$ & E-49902 & $\mathrm{CFC}$ & $\begin{array}{l}\text { Riveting mandrel. assembly. inner } \\
\text { and outer control rod }\end{array}$ \\
\hline & E-T-53504 & & $4 / 27 / 64$ & E-49902 & CFC & $\begin{array}{l}\text { Riveting mandrel. assembly. inner } \\
\text { and outer control rod }\end{array}$ \\
\hline & E-T-53505 & A & $5 / 06 / 64$ & E-49902 & $\mathrm{CFC}$ & $\begin{array}{l}\text { Riveting mandrel. assembly. inner } \\
\text { and outer control rod }\end{array}$ \\
\hline & E-T-53506 & & $4 / 29 / 64$ & E-49902 & CFC & $\begin{array}{l}\text { Riveting mandrel. assembly, inner } \\
\text { and outer control rod }\end{array}$ \\
\hline & E-T-53694 & A & $9 / 22 / 64$ & E-42293 & CFC & $\begin{array}{l}\text { Outer rod. mech. research. outer } \\
\text { control rod }\end{array}$ \\
\hline & E-T-54617 & & $6 / 16 / 65$ & & CFC & Curved rod fixture (radiography) \\
\hline & E-M-55623 & $\mathrm{F}$ & $8 / 22 / 77$ & E-49823 & CFC & $\begin{array}{l}\text { HFIR control rod segment@glayout } \\
\text { of holes }\end{array}$ \\
\hline & E-M-55625 & D & $8 / 22 / 77$ & E-49823 & CFC & $\begin{array}{l}\text { HFIR outer control rod segment } \\
\text { procedure for layout and } \\
\text { machining }\end{array}$ \\
\hline & E-T-55922 & & $2 / 16 / 65$ & & CFC & $\begin{array}{l}\text { Small I.D. sweep gauge. sheff. } \\
\text { head detail }\end{array}$ \\
\hline & E-T-55923 & & $2 / 16 / 75^{-}$ & & CFC & $\begin{array}{l}\text { Small I.D. sweep gauge. sheff. } \\
\text { head detail }\end{array}$ \\
\hline & E-T-55930 & & $2 / 16 / 75$ & & CFC & $\begin{array}{l}\text { Small I.D. sweep gauge. sheff. } \\
\text { head detail }\end{array}$ \\
\hline & E-T-55964 & A & $12 / 25 / 65$ & E-49825 & CFC & Aligning fixture for machining \\
\hline & E-T-55977 & & $1 / 22 / 65$ & & CFC & Flaring pressure assembly \\
\hline & E-T-55978 & & $1 / 22 / 65$ & & CFC & Flaring pressure assembly \\
\hline & E-T-55979 & & $1 / 22 / 65$ & & CFC & Flaring pressure assembly \\
\hline & E-T-55992 & & $3 / 05 / 65$ & & $\mathrm{CFC}$ & Set up gauge assembly. outer rod \\
\hline & E-T-55997 & & $3 / 22 / 65$ & & CFC & $\begin{array}{l}\text { Fixture machining mandrel } \\
\text { accessories detail }\end{array}$ \\
\hline
\end{tabular}




\section{5}

Document Control Tabulation - HFIR-ME-FF-234

\begin{tabular}{|c|c|c|c|c|c|c|}
\hline $\begin{array}{l}\text { Type } \\
\text { Document }\end{array}$ & Specification & Rev. & Date & $\begin{array}{c}\text { Cross } \\
\text { Reference }\end{array}$ & Status & Title \\
\hline \multirow{6}{*}{$\begin{array}{l}\text { Y-12 Tooling } \\
\text { Drawing }\end{array}$} & E-T-55998 & & $3 / 29 / 65$ & & CFC & Hole chambering tool assembl! \\
\hline & E-T-66750 & & $12 / 21 / 67$ & E-49825 & $\mathrm{CFC}$ & Machining fixture. outer rod flange \\
\hline & E-T-66756 & & $12 / 21 / 67$ & E-49825 & $\mathrm{CFC}$ & Inspection fixture. outer rod flange \\
\hline & E-T-66767 & & $2 / 14 / 68$ & $E-49821$ & $\mathrm{CFC}$ & $\begin{array}{l}\text { Machining and welding fixture. } \\
\text { outer rod flange }\end{array}$ \\
\hline & E-T-66773 & & $2 / 14 / 68$ & $E-49821$ & $\mathrm{CFC}$ & Header for lower flange. outer rod \\
\hline & E-T-66774 & & $2 / 14 / 68$ & E-49825 & $\mathrm{CFC}$ & Header for upper flange. outer rod \\
\hline
\end{tabular}


ORNL/TM-9365/R1

INTERNAL DISTRIBUTION

1. R. L. Beatty

2. W. K. Brown

3. S. E. Burnette

4. G. F. Flanagan

5. H. A. Glovier

6. P. C. Hambaugh

7. G. N. Helton

8. T. J. Huxford

9. R. W. Knight

10. R. J. Lauf
11. J. E. Lee

12. C. H. Linginfelter

13. J. P. Moore

14. A. E. Pasto

15. J. D. Sease

16. D. L. Shuter

17. V. K. Sikka

18. Central Research Library

19. Laboratory Records-RC

20-21. Laboratory Records

\section{EXTERNAL DISTRIBUTION}

22. R. E. Daniels, Facility Representative Team Leader, LM-113, ORO, Bldg. 7964-D, MS 6390

23. H. R. Fair, Operations Support Team Leader, LM-113, ORO, Bldg. 7964-B, MS 6390

24. B. S. Willis, Deputy Site Manager for Operations, LM-113, ORO, Bldg. 4500-N, MS 6269 